\begin{abstract}
UNIVERSIDADE DE SÃO PAULO
FACULDADE DE MEDICINA DE RIBEIRÃO PRETO

DEPARTAMENTO DE NEUROCIÊNCIAS E CIÊNCIAS DO COMPORTAMENTO

PROGRAMA DE PÓS-GRADUAÇÃO EM SAÚDE MENTAL
\end{abstract}

TATIANA DE ABREU BRAGA SOARES

Cigarro e outras formas de tabaco: investigação de conhecimento, atitudes e percepção de risco em estudantes de Medicina 
TATIANA DE ABREU BRAGA SOARES

Cigarro e outras formas de tabaco: investigação de conhecimento, atitudes e percepção de risco em estudantes de Medicina

Dissertação apresentado ao Programa de Pós-Graduação em Saúde Mental da Faculdade de Medicina de Ribeirão Preto, Universidade de São Paulo, para obtenção do título Mestre.

Área de concentração: Saúde Mental

Orientadora: Prof ${ }^{a}$ Dr $^{a}$ Flávia de Lima Osório

Ribeirão Preto 
AUTORIZO A REPRODUÇÃO E DIVULGAÇÃO TOTAL OU PARCIAL DESTE TRABALHO, POR QUALQUER MEIO CONVENCIONAL OU ELETRÔNICO, PARA FINS DE ESTUDO E PESQUISA, DESDE QUE CITADA A FONTE.

FICHA CATALOGRÁFICA

Soares, Tatiana De Abreu Braga

Cigarro e outras formas de tabaco: investigação de conhecimento, atitudes e percepção de risco em estudantes de medicina- Ribeirão Preto 2018 123 fls.il.

Dissertação de Mestrado, apresentada à Faculdade de Medicina de Ribeirão Preto da Universidade de São Paulo.

Orientador: Flávia de Lima Osório.

1. Tabagismo. 2. Estudantes de Medicina. 3. Conhecimento Médico. 4. Percepção de Risco. 


\section{FOLHA DE APROVAÇÃO}

Tatiana de Abreu Braga Soares

Cigarro e outras formas de tabaco: investigação de conhecimento, atitudes e percepção de risco em estudantes de Medicina

Dissertação apresentada à Faculdade de Medicina de Ribeirão Preto da Universidade de São Paulo para a obtenção do título de Mestre em Saúde Mental.

Aprovado em

Banca Examinadora

Prof. Dr.

Instituição: Julgamento:

Assinatura:

Prof. Dr.

Instituição: Julgamento:

Assinatura:

Prof. Dr.

Instituição: Julgamento:

Assinatura: 
DEDICO esse trabalho à minha família, em especial à minha filha Ana Luiza, à minha mãe Ana Lucia, pelo amor incondicional, gratidão imensa pelo apoio, carinho e cuidado por toda minha vida e ao longo do período de elaboração deste trabalho. À minha irmã Luciana, por estar sempre ao meu lado. Ao meu pai Cesar, por todo apoio e carinho. À todos aqueles que de alguma forma colaboraram para que essa etapa fosse concluída. 


\section{AGRADECIMENTOS}

À minha orientadora Profa. Dra. Flávia de Lima Osório, por me acolher no meio do caminho, pela disponibilidade, ensinamentos e por me ajudar a ser mais resiliente.

Aos funcionários do Programa de Pós-Graduação em Saúde Mental da Faculdade de Medicina de Ribeirão Preto, em especial à Ivana, pela prontidão, disponibilidade e carinho sempre.

Às faculdades de Medicina de Ribeirão Preto, FMRP-USP, UNAERP, BARÃO DE MAUÁ E UNISEB, que permitiram a realização da coleta de dados

À toda rede de apoio que se formou durante esses anos.

Ao Cássio, por todo o auxílio quanto à análise estatística.

À minha família e aos meus amigos que me incentivaram, apoiaram, compreenderam e acreditaram em todos os momentos.

Por fim, agradeço a todos os participantes do estudo que se disponibilizaram a colaborar com a pesquisa. 


\section{RESUMO}

SOARES, T. A. B. Cigarro e outras formas de tabaco: investigação de conhecimento, atitudes e percepção de risco em estudantes de Medicina. 2018. Dissertação (Mestrado) Faculdade de Medicina de Ribeirão Preto, Universidade de São Paulo, Ribeirão Preto, 2018.

O tabagismo mata um a cada 10 fumantes no mundo e é a principal causa evitável de morbimortalidade. O Brasil possui cerca de 25 milhões de tabagistas. Os profissionais de Saúde têm um importante papel no controle da pandemia do tabagismo, seja como educadores, formadores de opinião ou como promotores de prevenção e tratamento. A epidemia de tabagismo nas últimas décadas caracteriza-se pela redução do número de usuários de cigarro e crescente uso de formas alternativas de tabaco. Este estudo teve como objetivo caracterizar o perfil de consumo, crenças, percepção de risco, atitudes e conhecimentos a respeito de tabagismo em estudantes de Medicina do $1^{\circ}$ e $6^{\circ}$ anos. Trata-se de um estudo observacional transversal, com componente descritivo e com componente analítico. Foram entrevistados alunos do curso de Medicina de uma faculdade pública (FMRP-USP) e de três faculdades privadas (UniSEB, UNAERP e Centro Universitário Barão de Mauá) da cidade de Ribeirão Preto-SP. O questionário incluiu dados sócio demográficos, de exposição ao tabaco e outras substâncias psicoativas, motivação para cessação, avaliação de conhecimento médico sobre tabagismo, atitudes perante o tabaco e percepção de risco. A coleta de dados aconteceu nos anos de 2016 e 2017. A análise de dados foi realizada com o auxílio do programa estatístico Statistical Package for the Social Sciences (SPSS). Adotou-se como nível de significância para todas as análises $\mathrm{p} \leq 0,05.859$ alunos foram convidados a participar da pesquisa e 420 responderam o questionário, 63,3\% era do sexo feminino. Os achados do presente estudo vão ao encontro com o que vem sendo descrito na literatura. A prevalência de tabagismo encontrada foi semelhante à prevalência de tabagismo no Brasil, porém uma prevalência menor em alunos do $1^{\circ}$ ano. A idade média de experimentação foi de 17,5 anos. A maioria dos estudantes não se via como dependente de tabaco, fazia uso ocasional e utilizava principalmente o Narguilé $(15,2 \%)$, produto considerado mais prejudicial quando comparado ao cigarro comum ( $\mathrm{p}>0,001)$. O consumo de álcool foi elevado e descrito como um facilitador para o uso de tabaco. A nicotina foi considerada viciante $(\mathrm{p}>0,001)$. O fumo ocasional foi considerado prejudicial $(88,3 \%)$, assim como o uso dos diferentes produtos de tabaco na gestação. No que diz respeito ao papel dos profissionais de saúde, 93,1\% acredita que deveria aconselhar seus pacientes a parar de fumar; $63,7 \%$ que profissionais fumantes seriam menos propensos a aconselhar seus pacientes; $81,3 \%$ acredita que deveria aconselhar seus pacientes a evitar outras formas de tabaco e 78,2\% considera esses profissionais modelo para pacientes e público em geral. Verificou-se a falta de conhecimento e percepção de risco distorcida (crenças) quanto ao potencial de dependência dos produtos alternativos de tabaco e riscos do tabagismo. Sextanistas relataram ter recebido treinamento formal para abordagem do fumante e cessação do tabagismo e sentir-se seguros para orientar seus pacientes. Formação e treinamento adequados são essenciais e demandam maior responsabilidade social e acadêmica pelos estudantes de Medicina. Investir em ações que trabalhem especialmente as crenças, percepções de risco e atitudes a respeito dos diferentes tipos de tabaco, são necessárias para uma maior conscientização quanto ao uso e prejuízos à saúde causados pelo tabagismo.

Palavras chaves: Tabagismo, estudantes de medicina, conhecimento médico, percepção de risco. 


\begin{abstract}
SOARES, T. A. B. "Cigarette and other forms of tobacco: investigation of knowledge, attitudes and risk perception in medical students". 2018. $84 \mathrm{f}$. Dissertation (Master Degree). Faculdade de Medicina de Ribeirão Preto, Universidade de São Paulo, Ribeirão Preto, 2018.

Smoking kills one out of every 10 smokers in the world and is the leading preventable cause of morbidity and mortality. Brazil has about 25 million smokers. Health professionals play an important role in the control of the tobacco pandemic, whether as educators, opinion makers, or as promoters of prevention and treatment. The smoking epidemic in recent decades is characterized by reduction in the number of cigarette users and increasing use of alternative forms of tobacco. This study aimed to characterize the profile of consumption, beliefs, perception of risk, attitudes, and knowledge about smoking in medical students of $1^{\text {st }}$ and $6^{\text {th }}$ years. This is an observational cross-sectional study, with descriptive and analytical component. Medical students of a public college (FMRP-USP) and of three private colleges (UniSEB, UNAERP and Centro Universitário Barão de Mauá) of the city of Ribeirão Preto-SP were interviewed. The questionnaire included socio-demographic data, exposure to tobacco and other psychoactive substances, motivation for cessation, assessment of medical knowledge about tobacco use, attitudes, and perception of risk. Data collection occurred in 2016 and 2017. Data analysis was performed with the aid of the statistical program Statistical Package for the Social Sciences (SPSS). The significance level adopted for all analyses was $p \leq 0.05$. Among 859 students invited, 420 answered the questionnaire, $63.3 \%$ female. The findings of this study respond to what has been described in the literature. The smoking prevalence found was similar to Brazil's average, but lowest in first-year students. The average age of experimentation was 17.5 years. Most students did not identify themselves as tobacco addicts, were occasional users and used mainly hookahs (83\%), product considered more harmful when compared to cigarettes ( $\mathrm{p}>0.001$ ). Alcohol consumption was high, described as a facilitator for the use of tobacco; nicotine is regarded as addictive ( $\mathrm{p}>0.001)$; casual smoke as harmful $(88.3 \%)$, as well as the use of different tobacco products in pregnancy. With regard to the role of health professionals, 93.1\% believe they should advise their patients to quit smoking; $63.7 \%$ believe that professionals who are smokers would be less likely to advise their patients; $81.3 \%$ believe they should advise their patients to avoid other forms of tobacco, and $78.2 \%$ consider these professionals an example for patients and the general public. A lack of knowledge and distorted perception of risk (beliefs) was noted about the addictiveness of alternative products of tobacco and risks of smoking. Sixth-year students reported having received formal training to approach the smoker and cessation of smoking and feel safe to guide their patients. Appropriate education and training are essential and require greater academic and social responsibility by medical students. Investing in actions that work especially on beliefs, perception of risk and attitudes regarding the different types of tobacco are necessary for a greater awareness regarding the use and damage to health caused by smoking.
\end{abstract}

Key words: Smoking, medical students, medical knowledge, perception of risk. 


\section{LISTA DE FIGURAS}

Figura 1- Fluxograma de inclusão e exclusão de sujeitos na amostra ............. $\quad 30$

Figura 2- Caracterização dos motivos para não fumar cigarro comum pelos estudantes do $1^{\circ}(\mathrm{N}=120)$ e $6^{\circ}$ ano $(\mathrm{N}=47)$ de Medicina .

Figura 3- Caracterização dos motivos para fumar cigarro comum pelos estudantes do $1^{\circ}(\mathrm{N}=120)$ e $6^{\circ}$ ano $(\mathrm{N}=47)$ de Medicina

Figura 4- Caracterização dos estudantes do $1^{\circ}(\mathrm{N}=73)$ e $6^{\circ}$ ano $(\mathrm{N}=44)$ de Medicina quanto aos motivos para fumar atualmente 


\section{LISTA DE TABELAS}

Tabela 1- Características sócio demográficas da amostra de estudantes do $1^{\circ}$ $(\mathrm{N}=337)$ e do $6^{\circ}$ ano $(\mathrm{N}=83)$ de Medicina

Tabela 2- Caracterização do uso de cigarro comum pelos estudantes do $1^{\circ}$ ano $(\mathrm{N}=120)$ e $6^{\circ}$ ano $(\mathrm{N}=47)$ de Medicina

Tabela 3- Frequência de uso de substâncias psicoativas nos últimos doze meses pela amostra estudantes do $1^{\circ}(\mathrm{N}=337)$ e $6^{\circ}(\mathrm{N}=83)$ ano de Medicina

Tabela 4- Frequência de uso atual de produtos de tabaco pelos estudantes do $1^{\circ}$ $(\mathrm{N}=337)$ e $6^{\circ}(\mathrm{N}=83)$ ano de Medicina

Tabela 5- Frequência de uso prévio de produtos de tabaco pelos estudantes do $1^{\circ}$ $(\mathrm{N}=337)$ e $6^{\circ}(\mathrm{N}=83)$ ano de Medicina

Tabela 6- Perfil de consumo atual semanal dos produtos de tabaco pelos estudantes do $1^{\circ}(\mathrm{N}=337)$ e $6^{\circ}(\mathrm{N}=83)$ ano de Medicina

Tabela 7- Uso de produtos de tabaco em relação ao ingresso no curso de Medicina por alunos do $1^{\circ}(\mathrm{N}=337)$ e $6^{\circ}(\mathrm{N}=83)$ ano

Tabela 8- Caracterização da exposição ao tabaco no contexto ambiental por estudantes do $1^{\circ}(\mathrm{N}=337)$ e $6^{\circ}(\mathrm{N}=83)$ ano de Medicina

Tabela 9- Percepção quanto ao uso do tabaco em situações sociais por estudantes do $1^{\circ}(\mathrm{N}=337)$ e $6^{\circ}(\mathrm{N}=83)$ ano de Medicina

Tabela 10- Percepção de risco à saúde relacionada ao consumo de tabaco por estudantes do $1^{\circ}(\mathrm{N}=337)$ e $6^{\circ}(\mathrm{N}=83)$ ano de Medicina

Tabela 11- Indicadores comparativos de potencial de prejuízos à saúde dos diferentes produtos de tabaco tendo-se por referência o cigarro comum pelo estudantes do $1^{\circ}(\mathrm{N}=337)$ e $6^{\circ}(\mathrm{N}=83)$ ano de Medicina

Tabela 12- Conhecimento médico em relação à dependência de nicotina em estudantes do $1^{\circ}(\mathrm{N}=337)$ e $6^{\circ}(\mathrm{N}=83)$ ano de Medicina

Tabela 13- Efetividade de métodos para cessação do tabagismo na avaliação dos estudantes do $1^{\circ}(\mathrm{N}=337)$ e $6^{\circ}(\mathrm{N}=83)$ ano de Medicina

Tabela 14- Conhecimento quanto aos malefícios dos produtos de tabaco em relação ao uso na gestação pelos estudantes do $1^{\circ}(\mathrm{N}=337)$ e $6^{\circ}(\mathrm{N}=83)$ ano de Medicina 
Tabela 15- Conhecimento quanto aos malefícios dos produtos de tabaco em relação a aumentar o risco de alguns tipos de câncer pelos estudantes do $1^{\circ}(\mathrm{N}=$ $337)$ e $6^{\circ}(\mathrm{N}=83)$ ano de Medicina .

Tabela 16- Conhecimento quanto aos malefícios dos produtos de tabaco em relação ao aumento do risco de doenças cardiovasculares pelos estudantes do $1^{\circ}$ $(\mathrm{N}=337)$ e $6^{\circ}(\mathrm{N}=83)$ ano de Medicina

Tabela 17- Conhecimento quanto aos produtos de tabaco que contém nicotina por estudantes do $1^{\circ}(\mathrm{N}=337)$ e $6^{\circ}(\mathrm{N}=83)$ ano de Medicina

Tabela 18- Conhecimento quanto ao potencial de dependência dos produtos de tabaco pelos estudantes do $1^{\circ}(\mathrm{N}=337)$ e $6^{\circ}(\mathrm{N}=83)$ ano de Medicina

Tabela 19- Treinamento recebido e conduta de atendimentos realizados pelos estudantes do $6^{\circ}(\mathrm{N}=83)$ ano de Medicina 


\section{LISTA DE ABREVIATURAS E SIGLAS}

ANVISA Agência Nacional de Vigilância Sanitária

ASSIST Alcohol, Smoking and Substance Involvment Screening Test

CDC U.S.Centers for Disease Control and Prevention

CUMB Centro Universitário Barão de Mauá

DP Desvio Padrão

DPOC Doença pulmonar obstrutiva crônica

ERICA Estudo de Riscos Cardiovasculares em Adolescentes

FMRP Faculdade de Medicina de Ribeirão Preto

GHPSS Global Health Professional Students Survey

GTSS Tobacco Surveillance System

INCA Instituto Nacional do Câncer José de Alencar Gomes da Silva

INPAD Instituto Nacional de Ciências e Tecnologia para Políticas Públicas do Álcool e Outras Drogas

LENAD Levantamento Nacional de Álcool e Drogas

OMS Organização Mundial de Saúde

PETab Pesquisa Especial de Tabagismo

PETuni Perfil do tabagismo entre estudantes universitários do Brasil

SNC Sistema nervoso central

SPSS Statistical Package for the Social Sciences - Pacote estatístico para as ciências sociais

TCLE Termo de consentimento livre e esclarecido

TRN Terapia de reposição de nicotina

UNAERP Universidade de Ribeirão Preto

UniSeb Universidade Estácio de Sá

USP Universidade de São Paulo

VIGITEL Vigilância de fatores de risco e proteção para doenças crônicas por inquérito telefônico

WHO World Health Organization 


\section{SUMÁRIO}

1. INTRODUÇÃ

1.1 Tabagismo - Epidemiologia e relevância ……………………………………... 15

1.1.1 Epidemiologia do Tabagismo no Brasil ....................................................... $\quad \mathbf{1 6}$

1.1.2 Tabagismo, jovens e as formas alternativas de tabaco ................................... $\quad \mathbf{1 7}$

1.1.3 Tabagismo e estudantes universitários ......................................................... $\quad \mathbf{2 0}$

1.1.4 Tabagismo e estudantes de Medicina ……………………………………. $\quad 20$

1.2 Justificativa ......................................................................................... 25

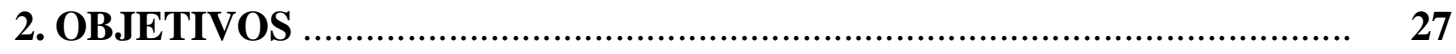

2.1 Hipóteses ...................................................................................... 28

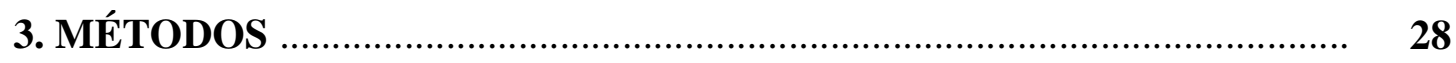

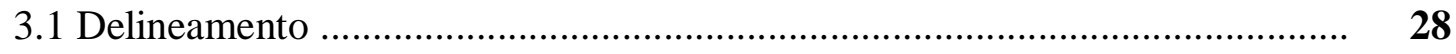

3.2 Sujeitos do estudo ................................................................................. $\quad 29$

3.3 Critérios de inclusão e exclusão ……………………………………………... 29

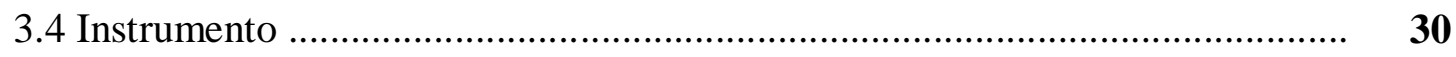

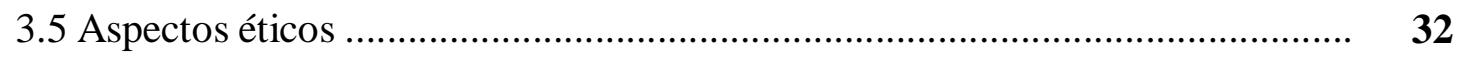

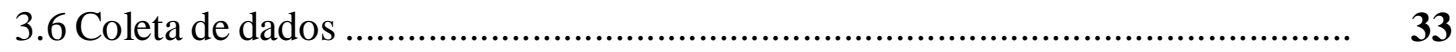

3.7 Análise de dados ..................................................................................... 33

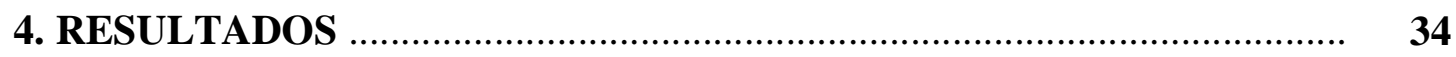

4.1 Caracterização dos dados sociodemográficos da amostra .................................. $\quad 34$

4.2 Uso de tabaco - geral (substâncias psicoativas) ................................................. 35

4.3 Uso específico de produtos de tabaco .......................................................... 42

4.4 Uso de tabaco no curso de Medicina ............................................................... 45

4.5 Exposição ambiental .................................................................................. 47

4.6 Atitudes e percepção ................................................................................. 47

4.7 Conhecimento médico ............................................................................. 51

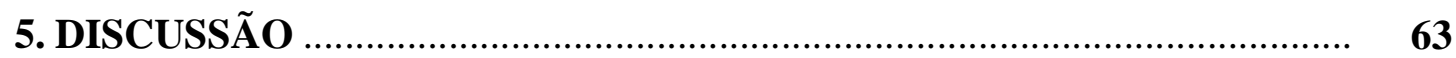

5.1 Caracterização sociodemográfica da amostra ……………………………….... $\quad \mathbf{6 3}$

5.2 Uso de tabaco - geral (substâncias psicoativas) ................................................. $\quad 64$ 
5.3 Uso específico de produtos de tabaco 67

5.4 Uso de tabaco no curso de Medicina 68

5.5 Exposição ambiental ............................................................................. $\mathbf{6 8}$

5.6 Atitudes e percepção .............................................................................

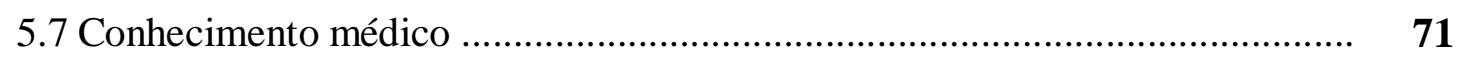

5.8 Limitações do estudo ............................................................................ 75

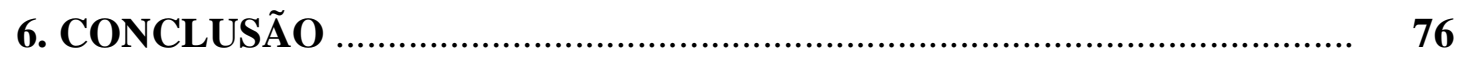

7. REFERÊNCIAS …............................................................................ 77

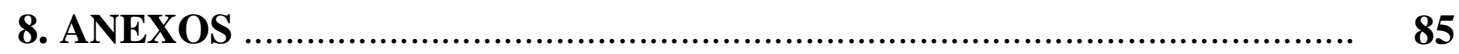

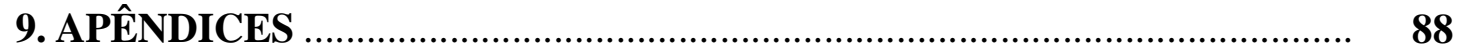




\section{INTRODUÇÃO}

\subsection{Tabagismo - Epidemiologia e relevância}

Atualmente cerca de $21 \%$ da população mundial é usuária de tabaco (1,1 bilhão de pessoas), o que o torna uma das substâncias aditivas mais utilizada no mundo, além disso, uma em cada 10 mortes são causadas pelo tabaco (WORLD HEALTH ORGANIZATION, 2017).

A nicotina, um alcaloide tóxico presente na folha do tabaco, é a substância psicoativa responsável pela adição ao tabaco. Exerce efeitos estimulantes no Sistema Nervoso Central (SNC) e vasoconstritor nos vasos sanguíneos de pequeno calibre (SILVA, SESTELO, 2007).

Além da dependência à nicotina, a exposição às diversas substâncias que constituem o tabaco relaciona-se a cerca de 50 doenças, em especial a doenças cardiovasculares (em $21 \%$ dos fumantes) e respiratórias, doença pulmonar obstrutiva crônica (DPOC) (em 20\% dos fumantes) e, de maneira relevante, a diversos tipos de câncer, em 30\% dos fumantes (VIEGAS, 2007).

O tabagismo é a principal causa global evitável de morbidade e mortalidade, e tem relevante impacto econômico, respondendo por prejuízos de US\$ 500 bilhões ao ano devido à perda de produtividade, adoecimento e mortes prematuras (ERIKSEN, MACKAY e HOSS, 2012).

De acordo com a Organização Mundial de Saúde (OMS), o tabagismo já vem sendo há tempos uma das principais causas de morte prematura, sendo responsável por cerca de $11 \%$ dos óbitos no mundo, causando a morte de cerca de sete milhões de pessoas a cada ano (WORLD HEALTH ORGANIZATION, 2017), incluindo nesse total 600.00 óbitos causados por fumo passivo, sendo que até 2030, estes números terão crescimento de $48 \%$, chegando a oito milhões de óbitos, dos quais $80 \%$ ocorrerão em países em desenvolvimento (WORLD HEALTH ORGANIZATION, 2015).

Em 2003, em resposta à pandemia do tabaco, a OMS finalizou a elaboração de um tratado internacional com medidas visando a sua redução, o chamado WHO Framework Convention on Tobacco Control conhecido no Brasil (que é signatário desde 2005) como Convenção-Quadro para o Controle do Tabaco. Esse tratado contém as obrigações legais que devem ser seguidas pelos signatários e inclui medidas para redução da demanda e da produção de tabaco e provê direções detalhadas para que sejam implantadas políticas de controle de tabaco em todos os níveis governamentais. Entre essas medidas estão incluídas aquelas 
relacionadas à disseminação de conhecimento para educadores e profissionais de saúde e aquelas relacionadas à provisão de tratamento para o tabagismo (WORLD HEALTH ORGANIZATION, 2003).

\subsubsection{Epidemiologia do Tabagismo no Brasil}

No Brasil, a adesão às propostas da Convenção-Quadro para o Controle do Tabaco vem tendo efeito bastante positivo nos últimos anos; no entanto, apesar da redução considerável do número de fumantes nas últimas décadas, a prevalência de fumantes ainda é relevante.

Levantamentos multicêntricos recentes estimaram que, entre a população maior de 15 anos, o Brasil possui 25 milhões de tabagistas atuais, sendo que 21 milhões e 600 mil pessoas são fumantes diários (GIOVINO et al., 2012).

Segundo resultados do II LENAD (Levantamento Nacional de Álcool e Drogas), entre 2006 e 2012 o número de adultos fumantes caiu de 20,8\% para 16,9\% (queda de 19\%) e o número de menores de 18 anos fumantes caiu de 6,2\% para 3,4\% (queda de 45\%) sendo que a idade média de início é de 16 anos (INPAD - Instituto Nacional de Ciência e Tecnologia para Políticas Públicas do Álcool e Outras Drogas, 2014).

É importante notar que a queda descrita acima é menor nas mulheres e que, embora a taxa de fumantes seja maior nas classes sociais mais baixas, houve um aumento de $110 \%$ na taxa de fumantes entre os indivíduos da classe social mais alta (classe A). Além disso, apesar da queda na porcentagem de fumantes, o número médio de cigarros usados ao dia aumentou (de 12,9 para 14,1) e 96,5\% dos fumantes relatam fumar diariamente. É digno de nota também, que apesar da proibição legal da venda de quaisquer produtos de tabaco a indivíduos com menos de 18 anos no Brasil, 62\% dos menores de idade relatam que a idade nunca os impediu de comprar cigarros (segundo o mesmo levantamento).

De acordo com o VIGITEL (vigilância de fatores de risco e proteção para doenças crônicas por inquérito telefônico) a frequência de adultos fumantes no ano de 2016 foi de 10,2\% e diminuiu em média 0,62 percentual ao ano (desde 2009), observa-se maior frequência nos homens $(12,7 \%)$ do que nas mulheres $(8,0 \%)$. A frequência de fumantes passivos também diminuiu em média 0,66 ponto percentual ao ano, foi de 7,3\% não havendo diferença significativa entre os sexos (MINISTÉRIO DA SAÚDE BRASIL, 2016). 
Em relação à frequência de uso e tipo de tabaco utilizado no Brasil, um estudo revelou que, entre os fumantes com idade superior a 15 anos, 87\% fumam tabaco diariamente; em relação ao tipo de tabaco utilizado, 90\% fumam cigarros (incluindo cigarros manufaturados, kretets ou cigarros-de-cravo ou cigarros enrolados à mão) e $80 \%$ fumam apenas cigarros manufaturados (GIOVINO et al., 2012). Neste mesmo estudo, a prevalência de uso regular de outras formas de tabaco (por exemplo: cachimbos, charutos, narguilé, tabaco mascado ou inalado) foi de apenas $1,3 \%$ nos indivíduos do sexo masculino e em $0,9 \%$ no sexo feminino.

Observa-se então, diante do exposto, que apesar da queda recente do número de fumantes, esses números ainda são elevadíssimos, e uma vez que o tabagismo é caracterizado como uma doença crônica, espera-se que nas próximas décadas o impacto das doenças associadas ao fumo sobre o Sistema de Saúde ainda seja extremamente relevante. No Brasil, 12,9\% dos óbitos podem ser atribuídos ao tabagismo (PINTO et.al., 2017), 81\% das mortes por câncer de pulmão ocorrem em tabagistas, e o tabaco está associado a 78\% dos óbitos por doença pulmonar obstrutiva crônica, $21 \%$ das mortes por doenças cardíacas e $18 \%$ por acidente vascular cerebral (PINTO, PICHON-RIVIERE E BARDACH, 2015).

O tabagismo gera em média $\mathrm{R} \$ 39,4$ bilhões de custos médicos por ano, o que equivale a $8 \%$ de todo gasto com a saúde, além disso, há um alto custo indireto, cerca de R \$17,5 bilhões resultantes da perda de produtividade devida à incapacidade e morte precoce (PINTO et.al., 2017).

\subsubsection{Tabagismo, jovens e as formas alternativas de tabaco}

Cerca de $80 \%$ dos tabagistas começam a usar tabaco antes dos 18 anos de idade, o que faz com que o tabagismo seja considerado uma verdadeira epidemia pediátrica. A maioria dos jovens que começa a fazer uso diário de tabaco torna-se adulto dependente de nicotina: de cada três jovens que fumam, apenas um conseguirá abandonar o uso, e um dos que permanecer fumando irá morrer por causa de doenças relacionadas ao tabaco (US DEPARTMENT OF HEALTH AND HUMAN SERVICES, 2012).

Um estudo de revisão no Brasil mostrou uma prevalência média de $9 \%$ de fumantes entre adolescentes de 10 a 19 anos (BARBOSA FILHO, CAMPOS e LOPES, 2012) entretanto, esse cenário vem mudando nos últimos cinco anos, o ERICA (Estudo de Riscos Cardiovasculares em Adolescentes) realizada entre os anos de 2013 e 2014 divulgou que a 
prevalência média de adolescentes com idade entre 12 e 17 anos foi de 5,7\% (FIGUEIREDO et al., 2015).

Um estudo com jovens com idade média de 16 anos na cidade de Ribeirão Preto, mostrou que jovens experimentadores de tabaco têm maior risco de se tornar tabagista na presença consumo de álcool, uso de drogas ilícitas e amigos fumantes (BONILHA et.al.,2014).

O LENAD revelou que, enquanto menos de $2 \%$ dos adolescentes relataram uso de maconha no ano anterior, $7 \%$ eram fumantes atuais e cerca de um terço destes fumavam 20 ou mais cigarros por dia; sendo a média de idade de início do fumo de 14,7 anos (MADRUGA et al., 2012).

Apesar do conhecimento crescente acerca dos riscos à saúde associados ao fumo, a queda no consumo em jovens e adultos que vinha ocorrendo nos últimos anos, vem estagnando. Esse fator vem gerando preocupação e necessidade de tomada de medidas de prevenção de uso pelos jovens, ou seja, com a regulação de produtos de tabaco para impedir seu uso por menores de idade e investimento em intervenções de prevenção e tratamento baseado em evidências. Enquanto o uso de cigarros vem diminuindo mais lentamente, o uso de formas não combustíveis de tabaco (formas que não produzem fumaça, conhecida como "smokeless tobacco") mantémse estável, e observa-se atualmente o uso concomitante de mais de uma forma de tabaco entre os jovens.

A tendência que se observa é a de popularização e uso crescente, em vários países, dos chamados produtos de tabaco alternativos ou formas alternativas de tabaco.

As diferentes formas de tabaco variam de acordo com o modo de preparo e aditivos de sabor e cheiro, mas todas contêm nicotina, que é de alguma maneira liberada para o SNC. As formas de uso de tabaco que requerem combustão do mesmo, incluem, além do cigarro (manufaturado ou enrolado à mão, com ou sem aditivos de sabor, com ou sem filtro), o cachimbo, o charuto, as cigarrillas e o narguilé. O tabaco pode ser utilizado sem queima ou produção de fumaça (os chamados "smokeless tobacco") quando mascados ou em preparações em que é absorvido pela mucosa oral (snuff ou snuss) ou aspirado pelo nariz (como o rapé) (VIEGAS, 2008).

Uma forma recente de uso de nicotina é o chamado "e-cigarro" ou "cigarro eletrônico", dispositivo eletrônico de liberação de nicotina, proibido no Brasil pela Agência Nacional de Vigilância Sanitária (ANVISA) desde 2009. Tem sido utilizado de forma ilícita pelos jovens e, assim como o cigarro tradicional polui o ambiente e emite um vapor d'água prejudicial à 
saúde, vem sendo considerado como possível "porta de entrada" para a dependência de nicotina e uso diário de cigarros (ANVISA, 2014).

Enquanto o uso de cigarros convencionais vem apresentando queda ou estabilização nos diversos centros, o uso das formas alternativas de tabaco e os e-cigarettes vem crescendo, particularmente entre os jovens (BIENER et al., 2011; REGAN, DUBE e ARRAZOLA, 2012; MCMILLEN, MADUKA e WINICKOFF, 2012), inclusive no Brasil (SZKLO et al., 2011).

Uma vez que as campanhas antitabaco focam nos perigos do cigarro, pessoas predispostas ao uso ou aquelas que estão tentando cessar o uso de cigarros, têm se voltado para o uso destas formas alternativas. Acredita-se que o aumento global do uso destas formas atípicas de tabaco tem ocorrido por sua aceitabilidade, globalização da indústria do tabaco e pela falsa impressão de risco associado ao seu uso. Aparentemente, os usuários acreditam que essas formas são menos danosas do que o cigarro convencional (AKL et al., 2013; VIEGAS, 2008).

Em especial, vem se disseminando entre os jovens brasileiros o uso do tabaco através do narguilé (também conhecido como cachimbo d'água, waterpipe, hookah, shisha, etc.). $\mathrm{O}$ narguilé está se difundindo globalmente entre os jovens, sendo considerado como o tabaco da moda do século XXI, assim como o cigarro foi no século XX. Fora isto, há o apelo de sua apresentação, marcado por essências e diversos sabores, o que o torna particularmente atraente para os jovens (VIEGAS, 2008). Além disso, essa forma de tabaco parece ser particularmente bem aceita entre as garotas (AKL et al., 2013). Embora não haja um padrão na composição de tabaco nesta forma de uso, sabe-se que o conteúdo de nicotina é ainda mais elevado do que o encontrado no tabaco do cigarro comum. Também é maior o nível de monóxido de carbono em sua fumaça e o uso de narguilé novamente está associado a várias doenças, como o câncer de pulmão e doenças respiratórias (AKL et al., 2010).

Em levantamento recente conduzido com 82.155 universitários (18-24 anos) de 148 instituições de ensino nos Estados Unidos, os resultados mostraram que 23\% da amostra já havia feito uso de narguilé na vida e 9\% havia feito uso no último mês (JARRETT et al., 2012).

Apesar da falsa noção de segurança relacionada ao uso das formas alternativas de tabaco e à noção de que formas que não emitem fumaça não causam mal às pessoas ao redor, deve-se lembrar que todas as formas orais de tabaco contêm substâncias cancerígenas. O mais relevante é o fato de que muitos acreditam que essas formas não levariam à dependência, o que também é um engano, uma vez que todas elas contêm nicotina e, portanto, podem levar à dependência (VIEGAS, 2008). 


\subsubsection{Tabagismo e estudantes universitários}

Um estudo americano com universitários, revelou que 15\% dos estudantes universitários eram usuários de mais de um produto do tabaco, faziam uso de três ou mais produtos de tabaco e eram mais propensos a consumir produtos de tabaco emergentes como cachimbos e cigarros eletrônicos do que usuários de cigarros apenas. Entre os usuários "simples" que faziam uso de apenas um produto de tabaco o produto mais usado era o cigarro convencional (BUTLER et al, 2016).

Universitários demonstraram usar cigarros mais frequentemente, entretanto, formas alternativas de tabaco, como narguilé vem sendo cada vez mais utilizadas, e o número de usuários de diversas formas de tabaco é maior do que o número de usuários de cigarro comum. Além disso, estudantes que não eram usuários de tabaco apresentaram uma percepção de risco maior do que estudantes tabagistas. Sendo o narguilé o produto percebido como o menos prejudicial pelos usuários de tabaco. (LATIMER, BATANOVA E LOUKAS, 2014).

Universitários fumantes brasileiros não acreditam que o consumo do tabaco afete sua vida diária ou consuma muito tempo nas rotinas relacionados aos comportamentos de fumar. O ambiente da faculdade foi apontado como provocador da vontade de fumar. (LOPES, CUNHA E BIZARRO, 2014).

Recentemente, um estudo com estudantes da área da saúde, fumantes e não fumantes, indicou que universitários fumantes acreditam menos que os profissionais de saúde devam receber treinamento para o tratamento do tabagismo ou devam aconselhar rotineiramente seus pacientes quanto a cessação e tem uma percepção reduzida quanto a serem modelo de comportamento para pacientes e para o público em geral (DA SILVA et al., 2017).

\subsubsection{Tabagismo e estudantes de Medicina}

É sabido que os profissionais de saúde têm um papel fundamental na redução do uso de tabaco e que mesmo intervenções breves podem aumentar a chance de cessação dos fumantes (STEAD et al., 2013). 
Uma vez que o tabagismo é uma pandemia, relacionada a altas taxas de morbimortalidade, um dos focos de ação para sua abordagem consiste obviamente no treinamento de profissionais de saúde em relação à prevenção e ao tratamento, com o objetivo de prevenção e cessação do uso de tabaco. Para tal objetivo, é necessário um bom treinamento dos futuros profissionais de saúde.

Dentre os profissionais de saúde, os médicos têm um papel claramente relevante, tanto por sua participação direta na abordagem dos fumantes quando por exercer um papel de modelo de saúde para a população.

Deve-se ter em mente, também, que os próprios médicos estão sujeitos ao uso de tabaco e, apesar da tendência de queda de prevalência entre eles nos países desenvolvidos, o uso de tabaco entre os médicos cresce nos países em desenvolvimento (SMITH, LEGGAT, 2007), o que pode ter um impacto negativo no objetivo de redução de tabagismo nesses centros.

O fato do profissional de saúde ser ou não fumante tem impacto sobre sua atuação no tratamento dos tabagistas, bem como no modo como os tabagistas recebem sua orientação (KAWAKAMI et al., 1997).

Estudos que avaliam a prevalência de uso, as atitudes e comportamentos relacionados ao tabaco em estudantes e profissionais da área da Saúde são conduzidos com o propósito de caracterizar a exposição nestes profissionais e quais os fatores de risco para essa exposição. Além disso, podem investigar as crenças que esses profissionais (ou futuros profissionais) têm a respeito do tabaco e podem aferir se os mesmos estão recebendo a formação técnica adequada e se estão conseguindo colocar em prática as condutas aprendidas.

Uma vez que o início do uso do tabaco se dá geralmente na adolescência, e que a indústria do tabaco tem essa população como alvo de vendas, deve-se lembrar da importância de se avaliar os futuros profissionais de saúde ainda enquanto estudantes, na faixa de maior risco para transição de uso para dependência. Além disso, é durante o curso de formação que os profissionais vão adquirir treinamento adequado para abordagem do tabagismo.

Já em 1999, um estudo do Rio Grande do Sul, com estudantes de Medicina abordou a importância de promover uma educação voltada para a cessação do tabagismo, com programas educativos sobre a dependência da nicotina, a fim de desenvolver habilidades nos futuros médicos para que pudessem intervir adequadamente com seus pacientes tabagistas atuais e futuros. Neste estudo observou-se que, embora muitos estudantes reconhecessem os efeitos adversos do cigarro para a saúde e o importante papel que tem o profissional da saúde na 
cessação do tabagismo, poucos forneciam a seus pacientes fumantes sequer intervenções mínimas (DAUDT et al., 1999). Por outro lado, um estudo na Faculdade de Ciências Médicas da Santa Casa de São Paulo identificou que os alunos de Medicina possuíam conhecimento regular acerca de tabagismo e que incorporaram o tema do tabagismo em sua prática clínica, questionando os pacientes e fornecendo orientação para cessação, inclusive mais do que os professores médicos (talvez refletindo um aumento gradual da relevância do tabagismo no currículo médico), embora o autor aponte que a abordagem do tema e o aprendizado ainda sejam problemáticos em vários centros (MATTOS, SILVA e FRANKEN, 2009).

Em 2011, um estudo com universitários da área da saúde revelou que a maioria dos estudantes de Medicina sabia que a nicotina é substância responsável pela dependência, entretanto, 12,5\% não consideraram a dependência nicotínica uma doença (BOTELHO, DA SILVA E MELO, 2011). Recentemente, um estudo da Universidade de São Paulo, apontou que os estudantes de Medicina acreditam que os médicos deveriam rotineiramente aconselhar seus pacientes para a cessação do tabagismo, mostraram ter maior conhecimento quanto a terapias de reposição de nicotina que outros tipos de tratamento e consideraram os profissionais de saúde modelos de comportamento para seus pacientes (MARTINS et al., 2017).

Particularmente em relação aos estudantes de Medicina, poucos estudos investigaram a prevalência de uso, exposição passiva e aspectos do treinamento em tabagismo. A maioria dos estudos foi conduzida em países desenvolvidos, e com métodos diversos (SMITH, LEGGAT, 2007).

Um estudo que revisou a literatura publicada internacionalmente sobre o uso de substâncias legais e ilegais por estudantes de Medicina de 1988 a 2013 concluiu que existem muitas variações regionais, a maioria dos estudos e a maioria dos estudos foram feitos na América e na Europa. Além disso, relatou que as principais substâncias utilizadas eram principalmente álcool (24\%), tabaco (17,2\%) e cannabis (11,8\%) (RONCERO et al.,2015).

Os estudantes de Medicina no Brasil iniciam a faculdade na fase de transição da adolescência para a vida adulta, este período é considerado de maior risco de uso e progressão do tabaco.

De 2005 a 2008, a Organização Mundial de Saúde, os U.S. Centers for Disease Control and Prevention (CDC) e a Canadian Public Health Association, conduziram o estudo chamado Global Health Professional Students Survey (GHPSS), como parte do Tobacco Surveillance System (GTSS), o Sistema Internacional de Vigilância do Tabagismo da OMS. O GHPSS é um 
estudo que avaliou alunos de terceiro ano de graduação de cursos da área da Saúde (Medicina, Enfermagem, Odontologia e Farmácia) em 47 países (mais a Faixa de Gaza), todos considerados como low ou middle-income countries.

No Brasil, o GHPSS recebeu o nome de "Tobacco Profile among University Students of Brazil: Tobacco Smoking Surveillance Project among Healthcare University Students" ou "Perfil do tabagismo entre estudantes universitários no Brasil (PETuni)" e foi conduzido em Campo Grande (2006), João Pessoa (2006), Rio de Janeiro (2006/2007), Florianópolis (2007) e Juiz de Fora (2007) (Ministério da Saúde, 2009). A prevalência de fumantes de cigarro no curso de Medicina variou de 7,6\% em João Pessoa a 24,4\% em Juiz de Fora (maior entre os homens em todos os centros e a maioria sendo fumante ocasional), enquanto a prevalência de uso de outras formas de tabaco variou de 0,8\% em João Pessoa a 8,2\% em Florianópolis (também com maior prevalência entre os rapazes).

Um resultado interessante desse estudo é que, apesar da maioria dos alunos reconhecerem que os profissionais de saúde devem receber treinamento em cessação de tabagismo e que eles devem rotineiramente aconselhar seus pacientes a parar de fumar, 22 a $50 \%$ deles não acreditam que profissionais de saúde têm papel como modelo de comportamento. Em relação ao conhecimento adquirido no curso, quase todos relataram já terem ouvido falar dos efeitos do fumo no curso, mas muitos não haviam recebido treinamento formal. Deve-se ressaltar como limitação importante deste estudo, o fato de ter avaliado apenas alunos do terceiro ano de graduação (MINISTÉRIO DA SAÚDE, 2009). É sabido que, no curso de Medicina, o contato com o paciente e o treinamento clínico ocorre principalmente durante o internato (dois últimos anos). Portanto, a avaliação de alunos do terceiro ano não é a forma ideal de se avaliar a aquisição de conhecimento e de treinamento em tabagismo.

O mesmo protocolo do GHPSS foi conduzido em 12 faculdades de Medicina de quatro países da Europa (Alemanha, Itália, Polônia e Espanha) em 2009 (LA TORRE et al., 2012), a prevalência de usuários foi de 30\% (variando de 28\% na Alemanha a 31\% na Itália), considerada maior do que a prevalência da população geral naqueles países, e nitidamente maior do que a encontrada no Brasil. Formas alternativas (tabaco mascado, cachimbos e charutos) já haviam sido experimentadas por $34 \%$ dos alunos, no geral. Novamente, apenas a minoria relatou ter recebido treinamento formal de cessação de tabagismo (16,5\% em média). Os autores ressaltam a importância da inserção do tabagismo no currículo médico e de treinamento formal adequado, bem como enfatizam que as instituições de saúde onde eles estudam (no caso, as faculdades de Medicina), têm o dever moral de ajudá-los a cessar o uso, seja via 
aconselhamento ou informação, seja ajudando diretamente aqueles que estão motivados a cessar.

Apesar da relevância, o GHPSS, por sua característica de estudo do tipo levantamento multicêntrico, não permite a identificação detalhada sobre padrão de uso, níveis de dependência ou a percepção de risco por parte dos estudantes em relação ao tabaco, nem busca identificar fatores de risco ou de proteção para uso e dependência de tabaco.

Estudos não epidemiológicos podem fornecem informações relevantes sobre esses aspectos. Um estudo recente conduzido na Faculdade de Medicina da Universidade de São Paulo (USP), estimou a prevalência de fumo em suas diversas formas, com ênfase na percepção de risco acerca do narguilé, bem como as atitudes, crenças e conhecimento dos estudantes acerca do tabagismo em alunos no terceiro ano e novamente no sexto ano de graduação em Medicina (MARTINS et al., 2014).

Os resultados corroboraram a tendência de uso de formas alternativas de tabaco, uma vez que o número de usuários de charuto, cachimbo e, principalmente o uso de narguilé, foi mais frequente que o uso de cigarro comum. O uso deste foi considerado baixo, e mais frequente no sexo masculino. Interessante foi o fato de que, no sexo masculino, a prevalência de usuários de cigarro cai de 9,8 para 5,3\% do terceiro para o sexto ano, enquanto no sexo feminino, ela aumenta de 1,4 para 2,7\% (embora essa diferença longitudinal não seja estatisticamente significativa). Por outro lado, deve-se observar que a prevalência de uso de narguilé foi muito alta e não se reduziu com o avançar do curso (cerca de $40 \%$ das mulheres e cerca de $50 \%$ dos homens relatam uso tanto no terceiro quanto no sexto ano de graduação), apesar de praticamente todos reconhecerem que a presença de água no narguilé não filtra as substâncias tóxicas do tabaco. No entanto, uma parcela dos alunos (que variou de 8 a 19\% e não decresceu ao longo do curso) manifestou noções distorcidas sobre os riscos do tabaco, pois afirmaram que tabaco, na forma de cachimbo e charuto, seria menos danoso por conter menos aditivos do que o cigarro usual. Além disso, os estudantes de Medicina acreditam que profissionais da saúde fumantes são menos propensos a orientar a cessação do tabagismo aos seus pacientes.

Os achados enfatizam a necessidade de melhores programas de educação preventiva nas faculdades de Medicina para proteger a saúde dos futuros médicos e para ajudá-los a enfrentar esse novo desafio epidêmico.

Outro aspecto interessante a ser levado em conta quando se avalia a questão da percepção de risco, é o fato de que, além do aumento do uso das formas alternativas de tabaco, 
o senso comum pode sugerir que apenas fumantes diários são usuários problemáticos e terão consequências danosas para a saúde. Desta forma, fumantes ocasionais podem ter a falsa sensação de segurança ou minimizar o risco de se tornar dependente no futuro.

Atualmente, enquanto as taxas de fumantes diários nos países ocidentais vêm caindo, a taxa de fumantes ocasionais continua estável (ou aumentando) e nos Estados Unidos, entre os fumantes, $30 \%$ são fumantes ocasionais (TONG et al., 2006). Embora as estratégias de cessação tenham sido desenvolvidas para os fumantes diários, o uso ocasional de tabaco está associado a um aumento de morbimortalidade e riscos para os fumantes passivos. Além disso, essa população está em risco para evoluir para uso diário, uma vez que a nicotina é a substância com maior potencial para levar à transição de uso ocasional para níveis de dependência, conforme já discutido acima. Um estudo recente estimou as taxas de transição de uso para dependência de várias drogas e encontrou valores de 67,5\% para usuários de nicotina, 22,7\% para usuários de álcool, 20,9\% para usuários de cocaína e 8,9\% para usuários de maconha (LOPEZQUINTERO et al., 2011), confirmando o alto potencial da nicotina para causar dependência, o que já vinha sendo observado em neurobiológicos em modelos animais de adição.

Muitos estudos que avaliam taxas de fumantes em universidades usam apenas a medida da OMS, que define como fumante atual aquele que fez uso de cigarro em pelo menos um dia nos últimos 30 dias. Já o termo fumante regular, segundo os CDCs americanos, diz respeito ao indivíduo que fuma pelo menos um cigarro por dia durante 30 dias. Existe uma carência de estudos que avaliem a auto percepção dos alunos em relação ao seu status (fumante regular, fumante ocasional, por exemplo), e muitos usam o termo "uso social", referindo-se ao uso apenas em eventos sociais.

Portanto, outro ponto que merece destaque quando da avaliação sobre percepção de risco em estudantes de Medicina, seria justamente a respeito do uso ocasional de tabaco e do risco de transição desse uso para dependência e quais os fatores associados ao uso ocasional e ao uso regular.

\subsection{Justificativa}

O tabagismo é uma pandemia, sendo considerado o principal fator evitável de morbimortalidade ao redor do mundo. Apesar de recente decréscimo nas taxas de fumantes nos 
países desenvolvidos nas últimas décadas, os países em desenvolvimento serão os mais afetados pela mortalidade e impacto econômico associado ao tabaco nas próximas décadas.

Além disso, apesar do foco das ações antitabaco serem o cigarro manufaturado, nos últimos anos vem crescendo o número de usuários, principalmente jovens, de formas alternativas de tabaco, como o narguilé, cachimbos, charutos e cigarrilhas com sabores, além de formas não emissoras de fumaça (tabaco mascado ou em pó para uso oral) e mesmo dispositivos eletrônicos de liberação de nicotina (os chamados e-cigarettes ou cigarros eletrônicos). Todas essas formas alternativas de tabaco representam riscos para a saúde e têm potencial para causar dependência.

Uma das medidas de combate ao tabagismo, sem dúvida, é a ação dos profissionais da área de saúde, tanto na promoção de prevenção quanto na promoção de tratamento visando à cessação, bem como através de seu papel como modelo de hábito saudável. É inegável a importância, portanto, de que os futuros médicos, ao longo do curso de Medicina, recebam treinamento adequado a este respeito e tenham segurança para colocá-lo em prática. Além disso, como o início do tabagismo ocorre geralmente na adolescência ou início da idade adulta, muitos desses alunos ou já são ou estão em risco de tornarem-se usuários durante o curso. Portanto, a correta percepção do risco associado ao tabaco (tanto em relação ao cigarro quanto em relação às formas alternativas) pelos estudantes de Medicina é essencial para si e para seu papel de promotor de saúde.

Com a mudança de foco da indústria do tabaco dos cigarros para as formas alternativas, parece estar ocorrendo uma minimização dos riscos associados a estas e isto pode ter reflexo no conhecimento, comportamento e atitudes dos futuros médicos em relação ao tabagismo. Ou seja, como a pandemia de tabagismo é dinâmica e a percepção de risco varia com fatores culturais e sociais, é necessário que a caracterização dos níveis de conhecimento, atitudes e percepção de risco desses estudantes seja sempre a mais atualizada possível, e que contemple as mudanças de panorama surgidas recentemente. O panorama do tabagismo atual é completamente diverso daquele de duas ou três décadas atrás, portanto, tanto o ensino médico quanto a prática clínica têm que ser adaptados e adequados.

Desta forma, justifica-se um estudo aprofundado que caracterize no presente momento, tanto os alunos ingressantes (ou seja, que ainda não tiveram qualquer treinamento formal a respeito de tabagismo) quanto os alunos ao final do curso médico em termos de consumo de produtos de tabaco, crenças, percepção de risco e atitudes a respeito tanto de cigarros quanto 
de outras formas de tabaco e motivação para cessação (dentre os usuários), bem como a avaliação de aquisição de conhecimento sobre tabagismo durante o curso.

\section{OBJETIVOS}

Este estudo objetivou caracterizar o perfil de consumo, crenças, atitudes e conhecimentos a respeito de tabagismo em estudantes de Medicina que ainda não tiveram qualquer treinamento médico formal ou prática clínica, e em estudantes de Medicina que já passaram por todo o período de treinamento formal (teórico e prático) do curso de graduação.

Adotou-se como objetivos específicos:

1) Descrever o perfil dos alunos ingressantes e formandos do curso de Medicina em termos de:

- Consumo de produtos de tabaco (prevalência de uso de tabaco) e de álcool e outras drogas;

- Atitudes em relação ao tabagismo (por exemplo: opiniões sobre o papel dos profissionais de saúde na cessação do tabagismo);

- Comportamento em relação ao tabaco: desejo e motivação de abandonar o uso, grau de percepção de risco associado ao uso das diversas formas de tabaco, auto avaliação sobre seu estado de usuário/não usuário;

- Grau de percepção de risco a respeito do uso dos diversos tipos de tabaco;

- Conhecimento específico, ou seja o grau de conhecimento técnico sobre aspectos gerais do tabagismo e de seu tratamento.

2) Descrever o perfil dos alunos formandos do curso de Medicina em relação às atitudes na prática clínica quanto ao tema tabagismo (por exemplo: hábitos de identificação e abordagem de pacientes tabagistas).

3) Investigar se os perfis descritos acima diferem entre jovens sem qualquer treinamento médico (alunos ingressantes) e jovens que estão finalizando o curso médico (formandos). Isto é:

- Investigar se há diferença de perfil de consumo, atitudes, comportamento e conhecimento específico entre ingressantes e formandos. 


\subsection{Hipóteses}

Este foi um estudo exploratório, que buscou principalmente descrever um perfil de determinada amostra e não baseado em hipóteses a priori. No entanto, com base na literatura correlata, esperava-se que:

- A prevalência de uso de cigarro tanto no primeiro como no último ano do curso seria baixa (menor do que a descrita em estudos de prevalência para a população geral brasileira atualmente). Poucos alunos seriam identificados como dependentes de nicotina, e a maioria dos usuários de tabaco faria uso ocasional e de outras formas de tabaco que não o cigarro.

- A prevalência de uso de álcool ou outras drogas seria mais elevada do que a prevalência de uso de tabaco e haveria uma associação entre esse uso.

- Alunos ingressantes e formandos teriam bom nível de conhecimento sobre os riscos associados do uso crônico de cigarro, mas minimizariam os riscos associados ao uso intermitente ou ocasional e ao uso de outras formas de tabaco.

- Alunos formandos iriam relatar que obtiveram algum treinamento formal para abordagem do fumante, mas que não o praticavam com frequência ou adequadamente ao longo dos estágios clínicos.

\section{MÉTODOS}

\subsection{Delineamento:}

Tratou-se de estudo exploratório, observacional, analítico transversal. Apesar do componente descritivo principal, foram investigados: perfil de uso de tabaco e percepção de risco, uso de outras substâncias, atitudes e práticas, bem como realizou-se a comparação de perfis entre ingressantes e formandos, razão pela qual o estudo teve um componente analítico. 
3.2 Sujeitos do estudo

Neste estudo foi empregada uma amostra de conveniência, composta por alunos regularmente matriculados nos anos de 2016 e 2017 no primeiro e último semestres de graduação em Medicina da Faculdade de Medicina da Universidade de São Paulo (FMRPUSP), do Centro Universitário Barão de Mauá (CBM), da Universidade de Ribeirão Preto (UNAERP) e por alunos regularmente matriculados no primeiro semestre da graduação em Medicina do Centro Universitário Estácio de Ribeirão Preto (UniSEB), todas as faculdades localizadas na cidade de Ribeirão Preto, Estado de São Paulo. A primeira faculdade (FMRPUSP) pertence a uma universidade pública e as demais são de instituições privadas. Todos os cursos eram oferecidos em período integral, com duração de 12 semestres.

O número de vagas disponíveis para ingresso nestes cursos eram de: 100 vagas na FMRP-USP, 62 vagas no CBM, de 66 vagas na UniSEB, 60 vagas na UNAERP, totalizando 288 vagas de ingresso por ano.

Foi oferecida a participação a todos os alunos ingressantes das quatro unidades, durante o primeiro semestre letivo e a todos os formandos da CBM, UNAERP, e FMRP-USP durante seu último $\left(12^{\circ}\right)$ semestre letivo.

\subsection{Critérios de inclusão e exclusão}

Usou-se como critério de exclusão menores de 18 anos e o não preenchimento do instrumento.

Após aplicação dos critérios de inclusão e exclusão, 420 sujeitos foram incluídos no estudo, conforme a Figura1. 


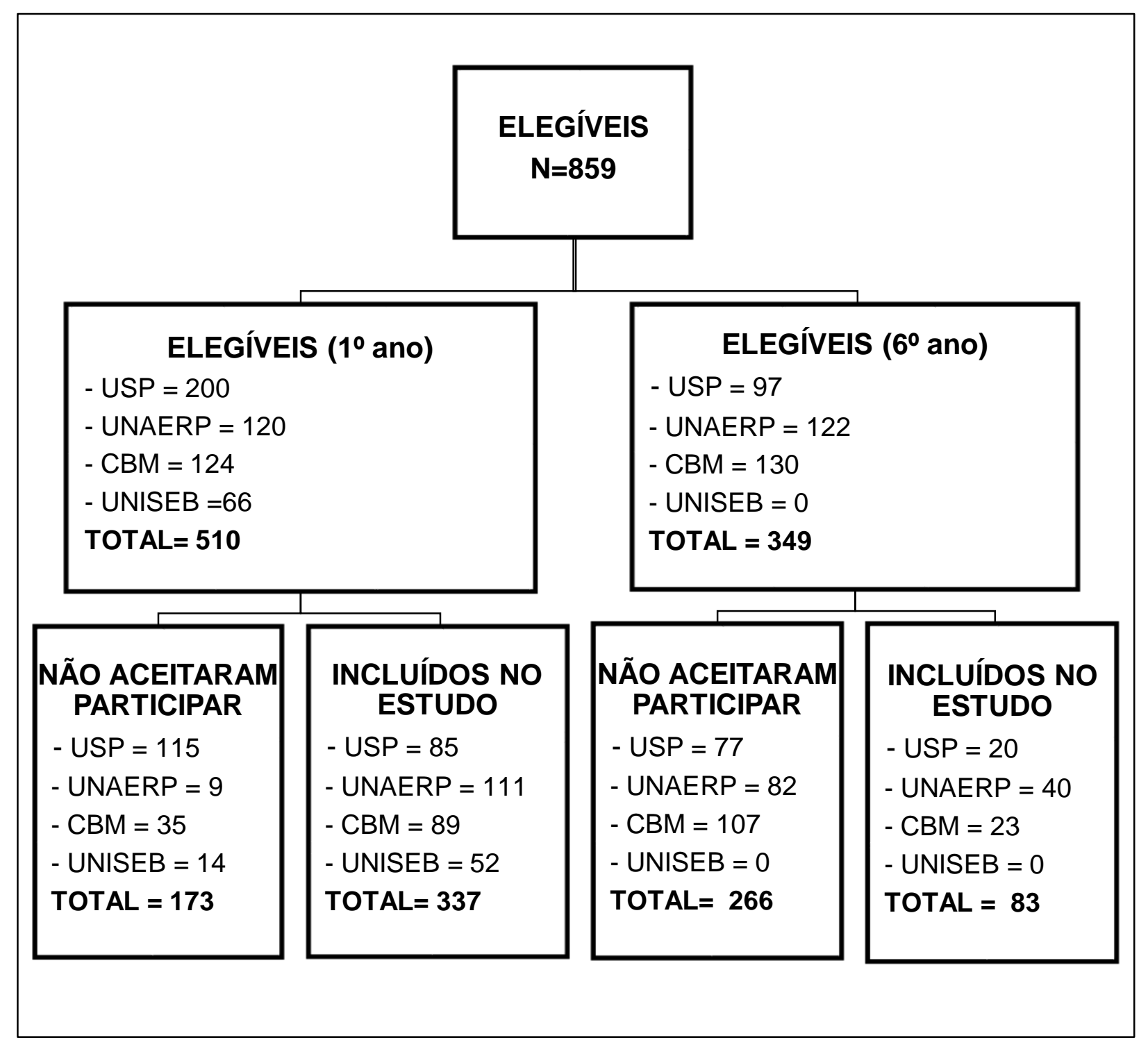

Figura1. Fluxograma de inclusão e exclusão de sujeitos na amostra.

\subsection{Instrumento:}

Para o estudo foi desenvolvido um questionário, que continha questões em comum para o $1^{\circ}$ e $6^{\circ}$ ano de Medicina e questões específicas para o $6^{\circ}$ ano. Foi composto de 83 questões comuns e seis questões específicas para os $6^{\circ}$ anistas. (Apêndice A)

Para a construção do questionário utilizou-se como referência um estudo prévio realizado na Inglaterra que tinha como objetivo determinar a cobertura curricular das faculdades de Medicina no país (RAUPACH, 2009). Utilizou-se também alguns instrumentos, os quais serão descritos a seguir: 
Instrumentos de referência:

- ASSIST: Alcohol, Smoking and Substance Involvment Screening Test, que foi desenvolvido pela OMS, traduzido para o português por Maria Lúcia Formigoni do Departamento de Psicobiologia da Universidade Federal de São Paulo e Roseli Boerngen de Lacerda, da Universidade Federal do Paraná; permite detectar a gravidade do consumo de várias substâncias, incluindo o tabaco e seus derivados. Esse instrumento foi desenvolvido com o objetivo de detectar precocemente o uso de álcool, tabaco e outras substâncias de forma validada, confiável e passível de ser utilizada nos serviços de atenção primária à saúde.

- GHPSS: "Tobacco Profile among University Students of Brazil: Tobacco Smoking Surveillance Project among Healthcare University Students" ou "Perfil do tabagismo entre estudantes universitários, PETuni”, parte do Sistema Internacional de Vigilância do Tabagismo da OMS, realizado pelo INCA.

- LENAD: - questionário do Levantamento Nacional de Álcool e Drogas Desenvolvido pela equipe coordenada por Ronaldo Laranjeira.

- PETab: - Pesquisa Especial de Tabagismo - Global Adult Tobacco Survey (GATS), desenvolvida pela OMS para coletar dados sobre medidas-chave de controle de tabaco em adultos.

- VIGESCOLA: foi desenvolvido pela Organização Pan-Americana de Saúde, pela OMS e pelo Centro de Controle de Doenças dos Estados Unidos, tendo sido validado pelo "Global Youth Tobacco Survey” (GYTS), o objetivo desse instrumento é monitorar a magnitude do tabagismo em estudantes de 13 a 15 anos através de inquéritos repetidos.

Seções que compuseram o instrumento:

1) “DADOS DE IDENTIFICAÇÃO”, referente aos dados sociodemográficos: contendo questões relativas a sexo, idade, anos de escolaridade, renda, moradia, estado civil, cursos anteriores. Para a composição deste bloco, foram desenvolvidas para a pesquisa três questões (questões 8, 9 e 10), e outras sete foram adaptadas do LENAD (questões 1,2,3,4,5,6 e 7).

2) "USO DE TABACO- GERAL", referente ao uso de tabaco ao longo da vida, comportamento em relação ao próprio uso (desejo de cessação, por exemplo), além de uma questão, referente ao uso abusivo ou dependência de álcool, tabaco e outras substâncias, incluindo maconha, cocaína/crack, anfetaminas, ecstasy, inalantes, hipnóticos, sedativos, alucinógenos, opioides. Também permite que o participante relate o uso de outras drogas que 
não as descritas acima (item “outras"), este bloco foi composto por 15 questões, sendo 10 questões adaptadas do LENAD (questões 11, 12, 13, 14, 15, 16, 19, 20, 21, 22 e 23), duas questões adaptadas do PETab (questões 17 e 18), uma questão do estudo do VIGESCOLA (questão 24) e uma questão do ASSIST (questão 25).

3) “USO ESPECÍFICO DE PRODUTOS DE TABACO” relacionado ao uso específico de produtos de tabaco. Este bloco foi composto por quinze questões, sendo nove adaptadas do PETab (questões 26, 27, 31, 32, 33, 36, 37, 38 e 40), cinco adaptadas do LENAD (questões 29, 30, 34, 35, e 39) e uma desenvolvida para a pesquisa (questão 28). Neste bloco verificou-se frequência de uso passado e atual, incluindo cigarro eletrônico e cessação.

4) "USO DO TABACO NO CURSO DE MEDICINA" abordou o uso de produtos de tabaco relacionados ao ingresso na faculdade de Medicina, esta questão foi elaborada para a pesquisa.

5) “EXPOSIÇÃO AMBIENTAL À FUMAÇA DO TABACO” referiu-se à exposição ambiental, foi composto por uma questão adaptada do LENAD (questão 42), uma questão adaptada do VIGIESCOLA (questão 43) e duas adaptadas do PETab (questões 44 e 45).

6) “ATITUDES E PERCEPÇÃO” abordou atitudes e percepções em relação ao tabaco. Este bloco foi composto de dezoito questões, sendo uma desenvolvida para a pesquisa (questão 56), uma questão adaptada do LENAD (questão 46), três questões adaptadas do PETab (questões 53, 54 e 55) e as outras adaptadas do VIGESCOLA (questões 47,48, 49, 50, 51, 52, $57,58,59,60,61,62$ e 63$)$.

7) “CONHECIMENTO MÉDICO” referente a questões sobre conhecimentos técnicos a respeito de tabagismo e de seu impacto, 20 questões compuseram esse bloco, destas, quatro foram desenvolvidas para a pesquisa $(74,75,82$ e 83), 12 foram adaptadas do estudo de Raupach (2009) (questões 64 a 73, 88 e 89), sete adaptadas do GHPSS (questões 76 a 80, 84 e 85), uma adaptada do VIGESCOLA (questão 81), duas adaptadas do estudo de Mattos (2009) (questões 86 e 87).

\subsection{Aspectos éticos}

Foram seguidas as diretrizes e normas regulamentadoras de pesquisas envolvendo seres humanos, de acordo com a Resolução no. 466/2012 do Conselho Nacional de Saúde (CNS). 
Este estudo foi aprovado pelo Comitê de Ética em Pesquisa do Hospital das Clínicas da Faculdade de Medicina de Ribeirão Preto da Universidade de São Paulo, juntamente com o TCLE (Processo HCRP no 204/2015, Anexo A).

\subsection{Coleta de dados}

Iniciou-se a coleta de dados no mês de Abril de 2016 e finalizou-se em Maio de 2017. Foi realizada coleta com alunos do primeiro ano e sexto ano do curso de Medicina, nas universidades particulares: UNAERP, CBM e UNISEB e na universidade pública FMRP-USP. A universidade UNISEB não possuía sexto ano até o fim da coleta.

O estudo e seus objetivos foram apresentados para a coordenação dos cursos através de e-mail e reuniões de esclarecimento. Foi então definido quais eram os melhores períodos para a abordagem dos alunos. A apresentação do projeto aos alunos e a distribuição dos termos de consentimento livre e esclarecido (TCLE) e dos questionários, foram feitas em horários de aulas regulares, de acordo com períodos pré-estabelecidos junto à coordenação do curso e com a concordância do docente responsável pela aula na qual a pesquisa foi realizada. A pesquisadora responsável fez a apresentação do projeto e as orientações sobre a participação. Os alunos que manifestaram interesse em participar receberam o TCLE (Apêndice B) e o questionário da pesquisa impresso. Neste questionário o aluno não era identificado, de modo que todos os questionários permaneceram anônimos. Após o preenchimento do questionário, foi encerrada a coleta de dados que teve em média 20 minutos de duração.

\subsection{Análise de dados}

Os dados foram codificados e inseridos no banco de dados com auxílio do programa estatístico Statistical Package for the Social Sciences (SPSS) versão 20 (IBM Corporate), o qual foi utilizado para as análises estatísticas.

Para análise dos dados inicialmente foi utilizada estatística descritiva (frequência, porcentagem, média, mediana, desvio padrão). Para a comparação dos grupos (alunos $1^{\circ}$ e $6^{\circ}$ ano), utilizou-se de testes estatísticos como: Qui-quadrado ou teste, Exato de Fisher e teste T 
de Student. Para verificação de onde ocorreram as diferenças entre os grupos, usou-se o teste para 2 proporções com correção de Bonferroni.

Adotou-se como nível de significância para todas as análises $\mathrm{p} \leq 0,05$.

\section{RESULTADOS}

Dos 859 alunos inscritos nos diferentes cursos de Medicina, 48,9\% responderam ao questionário, obtendo assim um percentual de perda de 51,1\%; sendo que o percentual de perda dos alunos do primeiro ano foi de $33,9 \%$ e dos alunos do sexto ano foi de $76,2 \%$.

\subsection{Caracterização dos dados sociodemográficos da amostra}

Ambos os grupos eram compostos predominantemente por mulheres, apesar desse percentual ser superior no grupo do $6^{\circ}$ ano $(\mathrm{p}=0,008)$. A média de idade dos participantes ficou entre 20 e 25 anos, sendo o grupo do $6^{\circ}$ ano mais velho.

Os participantes eram procedentes principalmente das regiões Sul e Sudeste $(p=0,03)$, solteiros, de etnia branca, renda familiar de 1 da 10 salários mínimos sem diferença entre os grupos.

Em relação à universidade, é possível notar uma diferença significativa entre os grupos, verificou-se que esta diferença deve-se ao fato da UNISEB não ter o sexto ano de Medicina, e a UNAERP ter a maior amostra de alunos do sexto ano.

Estes dados podem ser melhor visualizados na Tabela 1. 
Tabela1- Características sociodemográficas da amostra de estudantes do $1^{\circ}(\mathrm{N}=337)$ e $6^{\circ}$ ano $(\mathrm{N}=83)$ de Medicina

\begin{tabular}{|c|c|c|c|c|c|}
\hline \multirow[t]{2}{*}{ Variáveis } & \multicolumn{2}{|c|}{$1^{\circ} \mathrm{ANO}$} & \multicolumn{2}{|c|}{$6^{\circ} \mathrm{ANO}$} & \multirow[t]{2}{*}{ Estatística } \\
\hline & $\mathbf{N}$ & $\%$ & $\mathbf{N}$ & $\%$ & \\
\hline \multicolumn{6}{|l|}{ Idade } \\
\hline Média/(DP) & \multicolumn{2}{|c|}{$20,6(3,2)$} & \multicolumn{2}{|c|}{$25,4(2,2)$} & $\mathbf{t}<0,001 *$ \\
\hline \multicolumn{6}{|l|}{ Sexo } \\
\hline Masculino & 134 & 39,8 & 20 & 24,1 & $X^{2}=7,04$ \\
\hline Feminino & 203 & 60,2 & 63 & 75,9 & $p=0,008 *$ \\
\hline \multicolumn{6}{|l|}{ Estado civil } \\
\hline Solteiro & 330 & $\mathbf{9 7 , 9}$ & 78 & 94,0 & $X^{2}=3,74$ \\
\hline Casado & 7 & 2,1 & 5 & 6,0 & $\mathbf{p}=\mathbf{0 , 0 7}$ \\
\hline \multicolumn{6}{|l|}{ Etnia (auto referência) } \\
\hline Branco & 283 & 84,0 & 69 & 83,1 & \\
\hline Negro & 4 & 1,2 & 2 & 2,4 & \\
\hline Pardo & 39 & 11,6 & 12 & 14,5 & $X^{2}=3,87$ \\
\hline Amarelo & 9 & 2,7 & 0 & 0 & $\mathbf{p}=\mathbf{0 , 3 9}$ \\
\hline NI & 2 & 0,6 & $\mathbf{0}$ & $\mathbf{0}$ & \\
\hline \multicolumn{6}{|l|}{ Renda } \\
\hline 1 a $10(\mathrm{SM})$ & 189 & 56,1 & 41 & 49,4 & $X^{2}=1,52$ \\
\hline$>10(\mathrm{SM})$ & 74 & 22 & 23 & 27,7 & $p=0,47$ \\
\hline NI & 74 & 22,0 & 19 & 22,9 & \\
\hline \multicolumn{6}{|l|}{ Procedência } \\
\hline Sul/Sudeste & 295 & 87,5 & 64 & 77,1 & $X^{2}=7,33$ \\
\hline Centro Oeste/DF & 39 & 11,6 & 16 & 19,3 & $\mathrm{p}=\mathbf{0 , 0 3} *$ \\
\hline Norte/ Nordeste & 3 & 0,9 & 3 & 3,6 & \\
\hline \multicolumn{6}{|l|}{ Reside com } \\
\hline Familiares/Cônjuge & 85 & 25,2 & 19 & 22,9 & \\
\hline Amigos/pensionato & 107 & 31,8 & 19 & 22,9 & $\mathrm{X}^{2}=3,73$ \\
\hline Sozinho & 145 & 43,0 & 45 & 54,2 & $p=0,16$ \\
\hline \multicolumn{6}{|l|}{ Graduação prévia } \\
\hline Sim & 58 & 17,2 & 10 & 12,0 & $X^{2}=1,31$ \\
\hline Não & 279 & 82,8 & 73 & 88,0 & $p=0,25$ \\
\hline \multicolumn{6}{|l|}{ Universidade } \\
\hline FMRP & 85 & 25,2 & 20 & 24,1 & \\
\hline UNISEB & 52 & 15,4 & $\mathbf{0}$ & 0 & 17,194 \\
\hline CBM & 89 & 26,4 & 23 & 27,7 & $\mathrm{p}=\mathbf{0 , 0 0 1} *$ \\
\hline UNAERP & 111 & 32,9 & 40 & 48,2 & \\
\hline
\end{tabular}

\subsection{Uso de tabaco - geral (substâncias psicoativas)}

$\mathrm{Na}$ Tabela 2 e Figuras 2, 3 e 4 caracterizou-se o uso do cigarro ao longo da vida, pelos estudantes do $1^{\circ}$ e $6^{\circ}$ ano de Medicina. 
Tabela 2- Caracterização do uso de cigarro comum pelos estudantes do $1^{\circ}(\mathrm{N}=120)$ e $6^{\circ}$ ano $(\mathrm{N}=47)$ de Medicina

\begin{tabular}{|c|c|c|c|c|c|}
\hline \multirow[t]{2}{*}{ Variáveis } & \multicolumn{2}{|c|}{$1^{\circ}$ ano } & \multicolumn{2}{|c|}{$6^{\circ}$ ano } & \multirow[t]{2}{*}{ Estatístic: } \\
\hline & $\mathrm{N}$ & $\%$ & $\mathrm{~N}$ & $\%$ & \\
\hline \multicolumn{6}{|l|}{ Uso do cigarro ao longo da vida } \\
\hline Sim & 120 & 35,6 & 47 & 56,6 & $\begin{array}{l}X^{2}=12,28 \\
p<0,001 *\end{array}$ \\
\hline $\begin{array}{l}\text { Idade } \\
\text { Idade de início } \bar{x} \text { (DP) }\end{array}$ & \multicolumn{2}{|c|}{$17,0(1,9)$} & \multicolumn{2}{|c|}{$18,0(3,4)$} & $\begin{array}{c}\mathrm{t}=-2,07 \\
\mathrm{p}=0,08\end{array}$ \\
\hline Idade mínima/máxima & \multicolumn{2}{|c|}{$13 / 23$} & \multicolumn{2}{|c|}{$10 / 26$} & \\
\hline Uso do cigarro nos últimos 12 meses & 67 & 55,8 & 20 & 42,5 & $\begin{array}{c}\mathrm{X}^{2}=3,32 \\
\mathrm{p}=0,68\end{array}$ \\
\hline Uso mensal do cigarro & 37 & 30,8 & 19 & 40,4 & $\begin{array}{c}X^{2}=1,11 \\
p=0,29\end{array}$ \\
\hline Idade inicial de uso mensal $\bar{x}$ (DP) & \multicolumn{2}{|c|}{$18,6(2,7)$} & \multicolumn{2}{|c|}{$20,2(4,5)$} & $\begin{array}{c}\mathrm{t}=-1,19 \\
\mathrm{p}=0,24\end{array}$ \\
\hline Uso semanal de cigarro & 26 & 21,7 & 9 & 19,1 & $\begin{array}{c}X^{2}=2,92 \\
p=0,08\end{array}$ \\
\hline Idade inicial de uso semanal $\bar{x}$ (DP) & \multicolumn{2}{|c|}{$20,1(2,9)$} & \multicolumn{2}{|c|}{$21,5(3,7)$} & $\begin{array}{l}t=-0,87 \\
p=0,39\end{array}$ \\
\hline Uso superior a 100 cigarros na vida & 21 & 17,5 & 14 & 29,8 & $\begin{array}{l}\mathrm{X}^{2}=2,77 \\
\mathrm{p}=0,096\end{array}$ \\
\hline Uso atual do cigarro & 32 & 26,7 & 11 & 23,4 & $\begin{array}{l}X^{2}=1,02 \\
P=0,31\end{array}$ \\
\hline $\begin{array}{l}\text { Desejo atual em relação ao tabaco } \\
\text { Ouero parar de fumar }\end{array}$ & & & & & \\
\hline Não quero parar de fumar & 4 & 3,3 & 2 & $\begin{array}{l}0,4 \\
4,2\end{array}$ & $X^{2}=0,49$ \\
\hline Não sei & 70 & 58,3 & 30 & 63,8 & $\mathrm{p}=0,85$ \\
\hline NI & 35 & 29,1 & 12 & 25,5 & \\
\hline Previsão de consumo & & & & & \\
\hline Nos próximos 12 meses & & & & & \\
\hline Sim & 50 & 41,7 & 14 & 29,8 & $X^{2}=31,69$ \\
\hline Não & 28 & 23,3 & 33 & 70,8 & $\mathrm{p}<0,001^{*}$ \\
\hline Nos próximos 5 anos & & & & & \\
\hline $\begin{array}{l}\text { Sim } \\
\text { Não }\end{array}$ & 9 & 7,5 & 5 & 10,6 & $X^{2}=14,98$ \\
\hline Não & 46 & 38,3 & 34 & 72,3 & $\mathrm{p}=0,001^{*}$ \\
\hline $\begin{array}{l}\text { Uso de álcool e outras drogas otimiza } \\
\text { o consumo do cigarro }\end{array}$ & & & & & \\
\hline Sim & 46 & 38,3 & 13 & 27,7 & \\
\hline Não & 7 & 5,8 & 4 & 8,5 & $X^{2}=3,72$ \\
\hline Não fumo mais cigarros & 55 & 45,8 & 30 & 63,8 & $\mathrm{p}=0,62$ \\
\hline NI & 12 & 10,0 & 0 & 0 & \\
\hline
\end{tabular}

$\overline{\boldsymbol{x}}=$ média, $\mathrm{DP}=$ desvio padrão, $\mathrm{NI}=$ não informado, $\mathrm{N}=$ frequência, $\%=$ percentual, $*=$ diferença significativa entre as amostras do $1^{\circ}$ e do $6^{\circ}$ ano, $\mathrm{X}^{2}=$ Qui-quadrado, $\mathrm{p}=$ nível de significância

Em relação a ter experimentado cigarros comuns, verificou-se uma diferença significativa entre os grupos, mais estudantes do $6^{\circ}$ ano experimentaram cigarro ao longo da 
vida $(\mathrm{p}<0,001)$. Não houve diferença significativa em relação a prevalência de uso atual de cigarro comum da amostra.

A prevalência de tabagismo foi de $6,2 \%$ para o $1^{\circ}$ ano e $16,9 \%$ para o $6^{\circ}$ ano considerando a amostra total. Levando em conta apenas a amostra de estudantes que experimentaram cigarro esses números passam a ser $17,1 \%$ para os estudantes do $1^{\circ}$ ano e $29,8 \%$ para os estudantes do $6^{\circ}$ ano. Foram considerados tabagistas aqueles que fumaram 100 cigarros ou mais ao longo da vida e não houve diferença significativa entre os grupos.

A maioria dos fumantes atuais revelou fumar o primeiro cigarro após mais de 60 minutos depois te acordar e não houve diferença significativa entre os grupos $(\mathrm{p}=0,35)$.

Observou-se uma tendência dos alunos do $6^{\circ}$ ano terem experimentado cigarros comuns em idade mais avançada do que os alunos do $1^{\circ}$ ano.

O uso de álcool e outras drogas foi considerado um facilitador para o consumo de tabaco, entretanto, não houve diferença significativa entre os grupos.

No que diz respeito a perspectiva de consumir tabaco nos próximos 12 meses, alunos do $6^{\circ}$ ano $(68,8 \%)$, acreditam que com certeza não fumarão e alunos do $1^{\circ}$ ano $(31,0 \%)$ acreditam que provavelmente não irão fumar $(\mathrm{p}<0,001)$.

Quando questionados se acreditam que estarão fumando em 5 anos, alunos do $6^{\circ}$ ano mais frequentemente acreditam que não $(70,8 \%)$, e alunos do $1^{\circ}$ ano $(51,3 \%)$ acreditam que provavelmente não fumarão nos próximos $5 \operatorname{anos}(\mathrm{p}=0,001)$. A maioria dos alunos disse não saber se quer parar de fumar, 3,6\% não quer parar de fumar e 9,6\% dos alunos do $1^{\circ}$ ano e 6 , $4 \%$ dos alunos do $6^{\circ}$ ano tem o desejo de parar de fumar, não houve diferença significativa entre os grupos.

Pode-se perceber que o uso de cigarro mensal aumentou conforme os alunos foram ficando mais velhos.

Na Figura 2, caracterizou-se os motivos para não fumar cigarros comuns pelos diferentes grupos. 


\section{Motivos para não fumar}

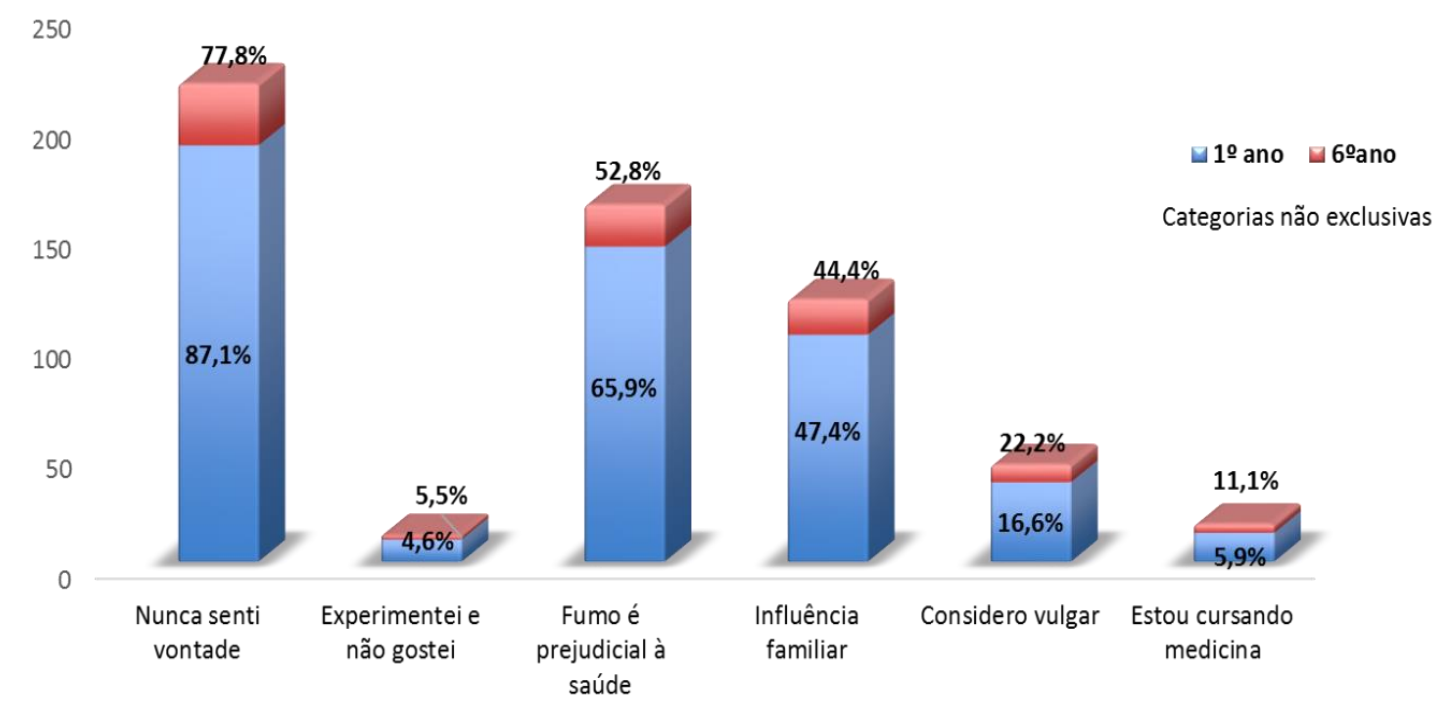

Figura 2- Caracterização dos motivos para não fumar cigarro comum pelos estudantes do $1^{\circ}$ $(\mathrm{N}=120)$ e $6^{\circ}$ ano $(\mathrm{N}=47)$ de Medicina

Dos sujeitos que nunca fumaram, não houve diferença significativa entre os grupos quanto aos motivos para não fumar. A maioria considera o motivo mais importante para não ter fumado, "nunca ter sentido vontade". Destaca-se que o fato de estar cursando medicina foi citado somente por $11,1 \%$ ( $6^{\circ}$ ano) e $5,9 \%$ ( $1^{\circ}$ ano) dos sujeitos como um dos motivos para não experimentar o cigarro comum.

$\mathrm{Na}$ Figura 3, caracterizou-se os motivos dos diferentes grupos, para experimentar cigarros comuns. 


\section{Motivos para fumar}

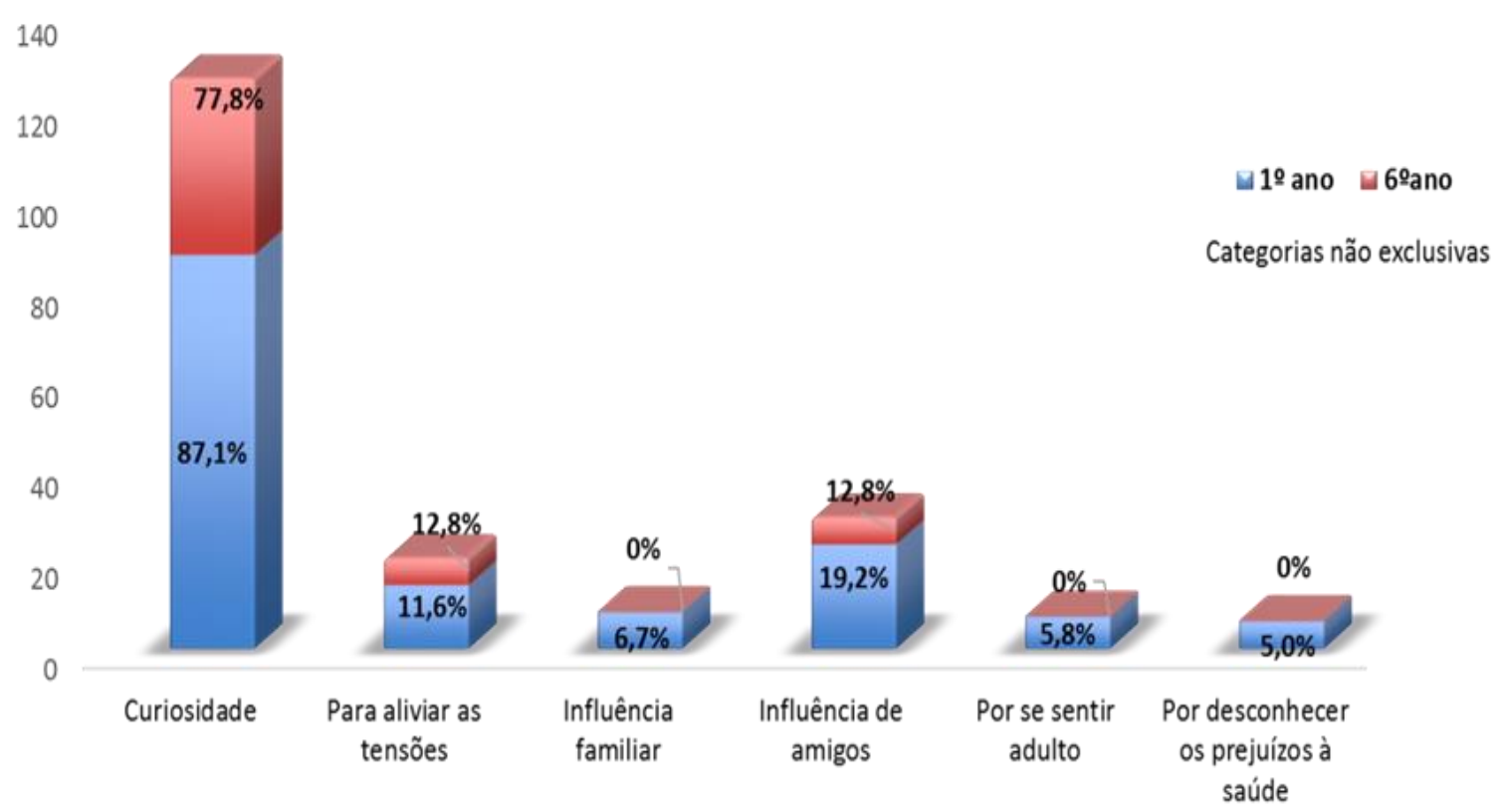

Figura 3- Caracterização dos motivos para fumar cigarro comum pelos estudantes do $1^{\circ}$ $(\mathrm{N}=120)$ e $6^{\circ}$ ano $(\mathrm{N}=47)$ de Medicina

A partir da figura 3, pode-se observar que dos sujeitos que já fumaram, o principal motivo para o início do consumo de cigarros foi a curiosidade. Não houve diferença significativa entre os grupos em nenhuma das categorias relacionadas aos motivos para fumar.

$\mathrm{Na}$ Figura 4, caracterizou-se os motivos que os estudantes do $1^{\circ}$ e $6^{\circ}$ ano consideraram ter para fumar atualmente. 


\section{Motivos para fumar atualmente}

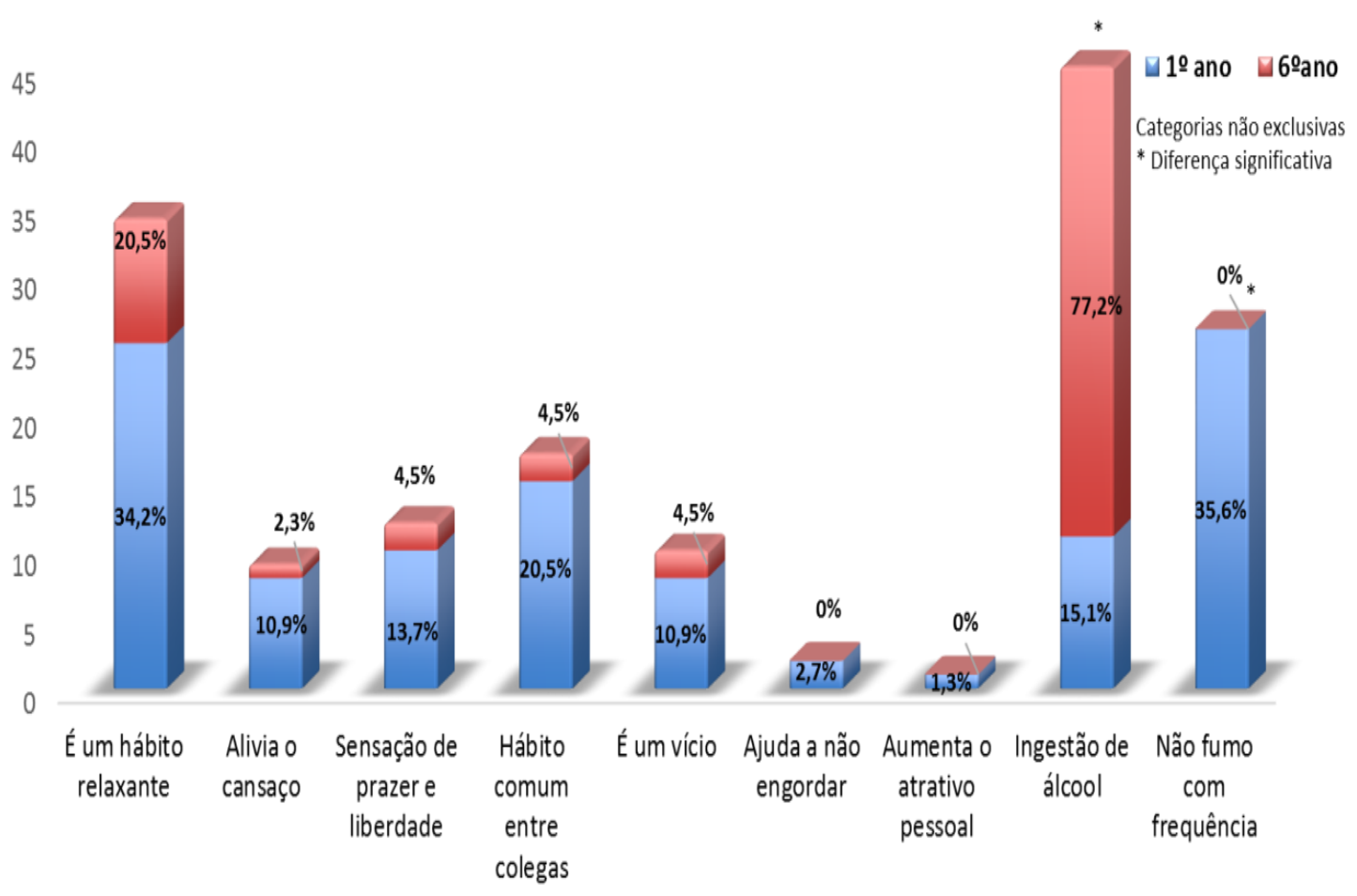

Figura 4- Caracterização dos estudantes do $1^{\circ}(\mathrm{N}=73)$ e $6^{\circ}$ ano $(\mathrm{N}=44)$ de Medicina quanto as motivos para fumar atualmente

Para os fumantes atuais, o principal motivo para continuar a fumar é o fato de considerarem esta prática um hábito relaxante. Verificou-se que houve diferença significativa entre os grupos apenas para os motivos ingestão de álcool e não fumo com frequência, apontados na categoria "outros". Alunos do $6^{\circ}$ ano fazem uso de tabaco mais frequentemente que alunos do $1^{\circ}$ ano quando ingerem álcool $(\mathrm{p}<0,001)$; e alunos do $1^{\circ}$ ano relataram não fumar com frequência $(\mathrm{p}<0,001)$.

Na Tabela 3 o consumo de álcool e outras substâncias pelos estudantes do $1^{\circ}$ ano e $6^{\circ}$ ano de Medicina foi caracterizado quanto à frequência de uso. 
Tabela 3- Frequência de uso de substâncias psicoativas nos últimos doze meses pela amostra de estudantes do $1^{\circ}(\mathrm{N}=337)$ e $6^{\circ}(\mathrm{N}=83)$ ano de Medicina

\begin{tabular}{|c|c|c|c|c|c|c|c|c|c|c|c|c|c|c|}
\hline \multirow{3}{*}{ Substâncias } & \multirow{3}{*}{ Ano } & & & \multicolumn{11}{|c|}{ Periodicidade de uso } \\
\hline & & \multicolumn{2}{|c|}{ Nunca } & \multicolumn{2}{|c|}{$\begin{array}{l}1 \text { a } 2 \\
\text { vezes }\end{array}$} & \multicolumn{2}{|c|}{ Mensal } & \multicolumn{2}{|c|}{ Semanal } & \multicolumn{2}{|c|}{ Diária } & \multicolumn{2}{|c|}{ NI } & \multirow[t]{2}{*}{ Estatística } \\
\hline & & $\mathrm{N}$ & $\%$ & $\mathrm{~N}$ & $\%$ & $\mathrm{~N}$ & $\%$ & $\mathrm{~N}$ & $\%$ & $\mathrm{~N}$ & $\%$ & $\mathrm{~N}$ & $\%$ & \\
\hline \multirow[t]{2}{*}{ Álcool } & $\mathbf{1}^{\mathbf{0}}$ & 42 & 12,5 & 68 & 20,2 & 77 & 22,9 & 140 & 41,5 & 9 & 2,7 & 1 & 0,2 & $X^{2}=6,26$ \\
\hline & $6^{0}$ & 5 & 6,0 & 15 & 18,1 & 27 & 32,5 & 32 & 38,6 & 4 & 4,8 & 0 & 0 & $\mathrm{p}=0,18$ \\
\hline \multirow[t]{2}{*}{ Maconha } & $\mathbf{1}^{\mathbf{o}}$ & 266 & 78,2 & 45 & 13,4 & 14 & 4,1 & 5 & 1,5 & 2 & 0,6 & 5 & 1,5 & $X^{2}=6,62$ \\
\hline & $6^{0}$ & 73 & 88,0 & 6 & 7,2 & 1 & 1,2 & 1 & 1,2 & 2 & 2,2 & 0 & 0 & $\mathrm{p}=0,14$ \\
\hline \multirow{2}{*}{$\begin{array}{l}\text { Cocaína/ } \\
\text { Crack }\end{array}$} & $\mathbf{1}^{\mathbf{o}}$ & 330 & 97,9 & 2 & 0,6 & 0 & 0 & 0 & 0 & 0 & 0 & 5 & 1,5 & $\mathrm{X}^{2}=0,34$ \\
\hline & $6^{\circ}$ & 82 & 98,8 & 1 & 1,2 & 0 & 0 & 0 & 0 & 0 & 0 & 0 & 0 & $\mathrm{p}=1,00$ \\
\hline \multirow{2}{*}{$\begin{array}{l}\text { Anfetamina/ } \\
\text { êxtase }\end{array}$} & $1^{\circ}$ & 318 & 94,4 & 12 & 3,5 & 2 & 0,6 & 0 & 0 & 0 & 0 & 5 & 1,5 & $\mathrm{X}^{2}=3,99$ \\
\hline & $6^{\mathbf{o}}$ & 76 & 91,6 & 7 & 8,4 & 0 & 0 & 0 & 0 & 0 & 0 & 0 & 0 & $\mathrm{p}=0,11$ \\
\hline \multirow[t]{2}{*}{ Inalantes } & $\mathbf{1}^{\mathbf{o}}$ & 300 & 89,0 & 27 & 8,0 & 5 & 1,5 & 0 & 0 & 0 & 0 & 5 & 1,5 & $X^{2}=4,25$ \\
\hline & $6^{0}$ & 71 & 85,5 & 12 & 14,5 & 0 & 0 & 0 & 0 & 0 & 0 & 0 & 0 & $\mathrm{p}=0,12$ \\
\hline \multirow{2}{*}{$\begin{array}{l}\text { Hipnóticos/ } \\
\text { Sedativos }\end{array}$} & $1^{o}$ & 316 & 93,8 & 9 & 2,7 & 3 & 0,9 & 3 & 0,9 & 1 & 0,2 & 5 & 1,5 & $X^{2}=1,95$ \\
\hline & $6^{0}$ & 80 & 96,4 & 3 & 3,6 & 0 & 0 & 0 & 0 & 0 & 0 & 0 & 0 & $\mathrm{p}=0,71$ \\
\hline \multirow[t]{2}{*}{ Alucinógenos } & $1^{o}$ & 321 & 95,3 & 7 & 2,0 & 4 & 1,2 & 0 & 0 & 0 & 0 & 5 & 1,5 & $X^{2}=2,86$ \\
\hline & $6^{0}$ & 79 & 95,2 & 4 & 4,8 & 0 & 0 & 0 & 0 & 0 & 0 & 0 & 0 & $\mathrm{p}=0,25$ \\
\hline \multirow[t]{2}{*}{ Opioides } & $\mathbf{1}^{\mathbf{o}}$ & 330 & 97,9 & 2 & 0,6 & 0 & 0 & 0 & 0 & 0 & 0 & 5 & 1,5 & $X^{2}=0,50$ \\
\hline & $6^{\circ}$ & 83 & 100 & 0 & 0 & 0 & 0 & 0 & 0 & 0 & 0 & 0 & 0 & $\mathrm{p}=1,00$ \\
\hline
\end{tabular}

$\mathrm{NI}=$ não informado, $\mathrm{N}=$ frequência, $\%=$ percentual, $*=$ diferença significativa entre as amostras do $1^{\circ}$ e do $6^{\circ}$ ano, $\mathrm{X}^{2}=\mathrm{Qui}-\mathrm{quadrado}$, $\mathrm{p}=$ nível de significância

De acordo com a Tabela 3, verificou-se que não há diferença significativa entre os grupos quanto ao uso de substâncias nos últimos doze meses.

Apesar do álcool ser mais frequentemente utilizado de forma semanal pelos estudantes do $1^{\circ}$ ano, foi mais frequentemente utilizado de forma mensal pelos alunos do $6^{\circ}$ ano. A maconha foi percentualmente mais utilizada pelos alunos do $1^{\circ}$ ano.

A substância mais utilizada pelos estudantes da amostra foi o álcool, seguido da maconha, que foi utilizada diariamente por 2,2 \% dos estudantes de Medicina do $6^{\circ}$ ano. 


\subsection{Uso específico de produtos de tabaco}

Na Tabela 4 caracterizou-se a frequência de uso dos produtos derivados do tabaco.

Tabela 4- Frequência de uso atual de produtos do tabaco pelos estudantes do $1^{\circ}(\mathrm{N}=337)$ e $6^{\circ}$ ano $(\mathrm{N}=83)$ de Medicina

\begin{tabular}{|c|c|c|c|c|c|c|c|c|c|c|c|c|}
\hline \multirow{3}{*}{$\begin{array}{l}\text { Produtos de } \\
\text { Tabaco }\end{array}$} & \multirow{3}{*}{ Ano } & \multicolumn{11}{|c|}{ Periodicidade de uso } \\
\hline & & \multicolumn{2}{|c|}{ Diária } & \multicolumn{2}{|c|}{ Semanal } & \multicolumn{2}{|c|}{ Ocasional } & \multicolumn{2}{|c|}{ Não fuma } & \multicolumn{2}{|c|}{ NI } & \multirow[t]{2}{*}{ Estatística } \\
\hline & & $\mathrm{N}$ & $\%$ & $\mathrm{~N}$ & $\%$ & $\mathrm{~N}$ & $\%$ & $\mathrm{~N}$ & $\%$ & $\mathrm{~N}$ & $\%$ & \\
\hline \multirow[t]{2}{*}{ Cig. comum } & $1^{\mathbf{o}}$ & 4 & 1,2 & 5 & 1,5 & 23 & 6,8 & 304 & 90,2 & 1 & 0,3 & $X^{2}=1,53$ \\
\hline & $6^{0}$ & 1 & 1,2 & 1 & 1,2 & 9 & 10,8 & 72 & 86,7 & 0 & 0 & $\mathrm{p}=0,74$ \\
\hline \multirow[t]{2}{*}{ Charutos } & $1^{\mathbf{o}}$ & 0 & 0 & 0 & 0 & 5 & 1,5 & 331 & 98,2 & 1 & 0,3 & $\mathrm{X}^{2}=0,38$ \\
\hline & $6^{\mathbf{0}}$ & 0 & 0 & 0 & 0 & 1 & 1,2 & 82 & 98,8 & 0 & 0 & $\mathrm{p}=1,00$ \\
\hline \multirow[t]{2}{*}{ Cigarrilhas } & $\mathbf{1}^{\mathbf{o}}$ & 1 & 0,3 & 0 & 0 & 3 & 0,9 & 332 & 98,5 & 1 & 0,3 & $X^{2}=1,22$ \\
\hline & $6^{\mathbf{0}}$ & 1 & 1,2 & 0 & 0 & 1 & 1,2 & 81 & 97,6 & 0 & 0 & $\mathrm{p}=0,74$ \\
\hline \multirow[t]{2}{*}{ Cig. Cravo } & $\mathbf{1}^{\mathbf{o}}$ & 0 & 0 & 0 & 0 & 3 & 0,9 & 332 & 98,5 & 2 & 0,6 & $X^{2}=0,75$ \\
\hline & $6^{\mathbf{0}}$ & 0 & 0 & 0 & 0 & 0 & 0 & 83 & 100 & 0 & 0 & $\mathrm{p}=0,62$ \\
\hline \multirow[t]{2}{*}{ Cig. indianos } & $1^{o}$ & 0 & 0 & 0 & 0 & 2 & 0,6 & 333 & 98,8 & 2 & 0,6 & $X^{2}=0,49$ \\
\hline & $6^{0}$ & 0 & 0 & 0 & 0 & 0 & 0 & 83 & 100 & 0 & 0 & $\mathrm{p}=1,00$ \\
\hline \multirow[t]{2}{*}{ Narguilé } & $1^{0}$ & 1 & 0,3 & 5 & 1,5 & 48 & 14,2 & 282 & 83,7 & 1 & 0,3 & $X^{2}=2,65$ \\
\hline & $6^{0}$ & 0 & 0 & 0 & 0 & 16 & 19,3 & 67 & 80,7 & 0 & 0 & $\mathrm{p}=0,41$ \\
\hline \multirow[t]{2}{*}{ E- Cigarro } & $1^{0}$ & 1 & 0,3 & 0 & 0 & 9 & 2,7 & 326 & 96,7 & 1 & 0,3 & $X^{2}=6,5$ \\
\hline & $6^{0}$ & 0 & 0 & 1 & 1,2 & 0 & 0 & 82 & 98,8 & 0 & 0 & $\mathrm{p}=0,12$ \\
\hline
\end{tabular}

Cig= cigarro, E= eletrônico, $\mathrm{NI}=$ não informado, $\mathrm{N}$ = frequência, \%= percentual, $\mathrm{X}^{2}$ = Qui-quadrado, p=nível de significância

Segundo a Tabela 4, não houve diferença significativa entre os grupos quanto à frequência de uso dos diferentes produtos do tabaco, apenas $1,2 \%$ ( $1^{\circ}$ e $6^{\circ}$ ano) eram fumantes diários de cigarro comum, $6,8 \%$ dos alunos do $1^{\circ}$ ano e $10,8 \%$ dos alunos do $6^{\circ}$ fizeram uso ocasional de cigarro comum e outros produtos derivados do tabaco.

O narguilé foi o produto mais utilizado ocasionalmente pelos estudantes da amostra $(14,2 \%)$ do $1^{\circ}$ ano e $(19,3 \%)$ do $6^{\circ}$ ano e foi o segundo produto mais utilizado de forma geral.

A seguir descrever-se-á na Tabela 5 o consumo prévio dos produtos de tabaco. Nesta tabela pode-se verificar que o consumo prévio foi estatisticamente superior que o consumo atual pelos estudantes de Medicina do $1^{\circ}$ e $6^{\circ}$ ano. 
Tabela 5- Frequência de uso prévio de produtos de tabaco pelos estudantes do $1^{\circ}(\mathrm{N}=337)$ e do $6^{\circ}$ ano $(\mathrm{N}=83)$ de Medicina

\begin{tabular}{|c|c|c|c|c|c|c|c|c|c|c|c|c|}
\hline \multirow{3}{*}{$\begin{array}{l}\text { Produtos de } \\
\text { Tabaco }\end{array}$} & \multirow{3}{*}{ Ano } & \multicolumn{11}{|c|}{ Periodicidade de uso } \\
\hline & & \multicolumn{2}{|c|}{ Diária } & \multicolumn{2}{|c|}{ Semanal } & \multicolumn{2}{|c|}{ Ocasional } & \multicolumn{2}{|c|}{ Não fuma } & \multicolumn{2}{|c|}{ NI } & \multirow[t]{2}{*}{ Estatística } \\
\hline & & $\mathbf{N}$ & $\%$ & $\mathbf{N}$ & $\%$ & $\mathbf{N}$ & $\%$ & $\mathbf{N}$ & $\%$ & $\mathbf{N}$ & $\%$ & \\
\hline \multirow[t]{2}{*}{ Cig. comum } & $1^{\mathbf{o}}$ & 4 & 1,2 & 3 & 0,9 & 68 & 20,2 & 261 & 77,4 & 1 & 0,3 & $\mathrm{X}^{2=} 18,80$ \\
\hline & $6^{0}$ & 2 & 2,4 & 1 & 1.2 & 35 & 42,2 & 45 & 54,2 & 0 & 0 & $\mathrm{p}=0,001 *$ \\
\hline \multirow[t]{2}{*}{ Charutos } & $1^{o}$ & 1 & 0,3 & 0 & 0 & 12 & 3,6 & 322 & 95,5 & 2 & 0,6 & $X^{2=} 1,23$ \\
\hline & $6^{0}$ & 0 & 0 & 0 & 0 & 5 & 6,0 & 78 & 94,0 & 0 & 0 & $\mathrm{p}=0,48$ \\
\hline \multirow[t]{2}{*}{ Cigarrilhas } & $1^{\circ}$ & 2 & 0,6 & 0 & 0 & 6 & 1,8 & 327 & 97,0 & 2 & 0,6 & $X^{2}=4,67$ \\
\hline & $6^{\circ}$ & 0 & 0 & 1 & 1,2 & 1 & 1,2 & 81 & 97,6 & 0 & 0 & $\mathrm{p}=0,25$ \\
\hline \multirow[t]{2}{*}{ Cig. cravo } & $1^{\circ}$ & 1 & 0,3 & 1 & 0,3 & 6 & 1,8 & 327 & 97,0 & 2 & 0,6 & $X^{2=} 1,53$ \\
\hline & $6^{0}$ & 0 & 0 & 0 & 0 & 3 & 3,6 & 80 & 96,4 & 0 & 0 & $\mathrm{p}=0,61$ \\
\hline \multirow[t]{2}{*}{ Cig. indianos } & $1^{o}$ & 1 & 0,3 & 2 & 0 & 0 & 0,6 & 331 & 98,2 & 3 & 0,9 & $X^{2}=0,75$ \\
\hline & $6^{0}$ & 0 & 0 & 0 & 0 & 0 & 0 & 83 & 100 & 0 & 0 & $\mathrm{p}=1,00$ \\
\hline \multirow[t]{2}{*}{ Narguilé } & $1^{\circ}$ & 3 & 0,9 & 6 & 1,8 & 71 & 21,1 & 256 & 75,9 & 1 & 0,3 & $X^{2}=9,71$ \\
\hline & $6^{0}$ & 0 & 0 & 2 & 2,4 & 30 & 36,1 & 51 & 61,4 & 0 & 0 & $\mathrm{p}=0,028$ \\
\hline \multirow[t]{2}{*}{ E- cigarro } & $1^{\circ}$ & 2 & 0,6 & 1 & 0,3 & 18 & 5,3 & 315 & 93,5 & 1 & 0,3 & $\mathrm{X}^{2=1,03}$ \\
\hline & $6^{0}$ & 1 & 1,2 & 0 & 0 & 6 & 7,2 & 76 & 91,6 & 0 & 0 & $\mathrm{p}=0,79$ \\
\hline
\end{tabular}

Cig.= cigarro, E= eletrônico, $\mathrm{NI}=\mathrm{Não}$ informado, $\mathrm{N}=$ frequência, \%= percentual; * = diferença significativa entre as amostras do $1^{\circ}$ e do $6^{\circ}$ ano, $\mathrm{X}^{2}=$ Qui-quadrado, $\mathrm{p}=$ nível de significância

Ainda conforme Tabela 5, observa-se que o cigarro comum foi o produto com maior uso prévio ocasional. A partir do teste para 2 proporções com correção de Bonferroni, pode-se identificar que os alunos do $6^{\circ}$ ano $(42.2 \%)$ fizeram mais uso prévio ocasional do que os alunos do $1^{\circ}$ ano $(20,2 \%)$ e mais alunos do $1^{\circ}$ ano $(77,7 \%)$ não fizeram uso prévio de cigarros $(\mathrm{p}=0,001)$. Contudo, se comparado ao uso ocasional atual, o consumo de cigarros foi reduzido em $13,4 \%$ para o $1^{\circ}$ ano e em $31,4 \%$ para o $6^{\circ}$ ano.

Os estudantes foram questionados em relação a quantidade de vezes que fez uso do cigarro eletrônico e não houve diferença significativa entre os grupos.

A idade média de início de uso diário de produtos de tabaco, para os estudantes do $1^{\circ}$ ano de Medicina foi de $19(\mathrm{DP}=1,4)$ anos, apenas quatro alunos eram fumantes diários. Entre os alunos do $6^{\circ}$ ano, três alunos eram fumantes diários e iniciaram o consumo diário com 19,0 (DS=8.1) anos em média. Por outro lado, os estudantes do $1^{\circ}$ ano informaram ter usado cigarro 
comum no último mês, por cinco dias em média e cigarro de palha por 14 dias, em média; já os estudantes do $6^{\circ}$ ano relataram ter usado cigarro comum por 14 dias em média.

Na Tabela 6, o perfil de consumo semanal dos produtos de tabaco será descrito em função da quantidade média de uso.

Tabela 6- Perfil de consumo atual semanal dos produtos de tabaco pelos estudantes do $1^{\circ}$ $(\mathrm{N}=337)$ e $6^{\circ}$ ano $(\mathrm{N}=83)$ de Medicina

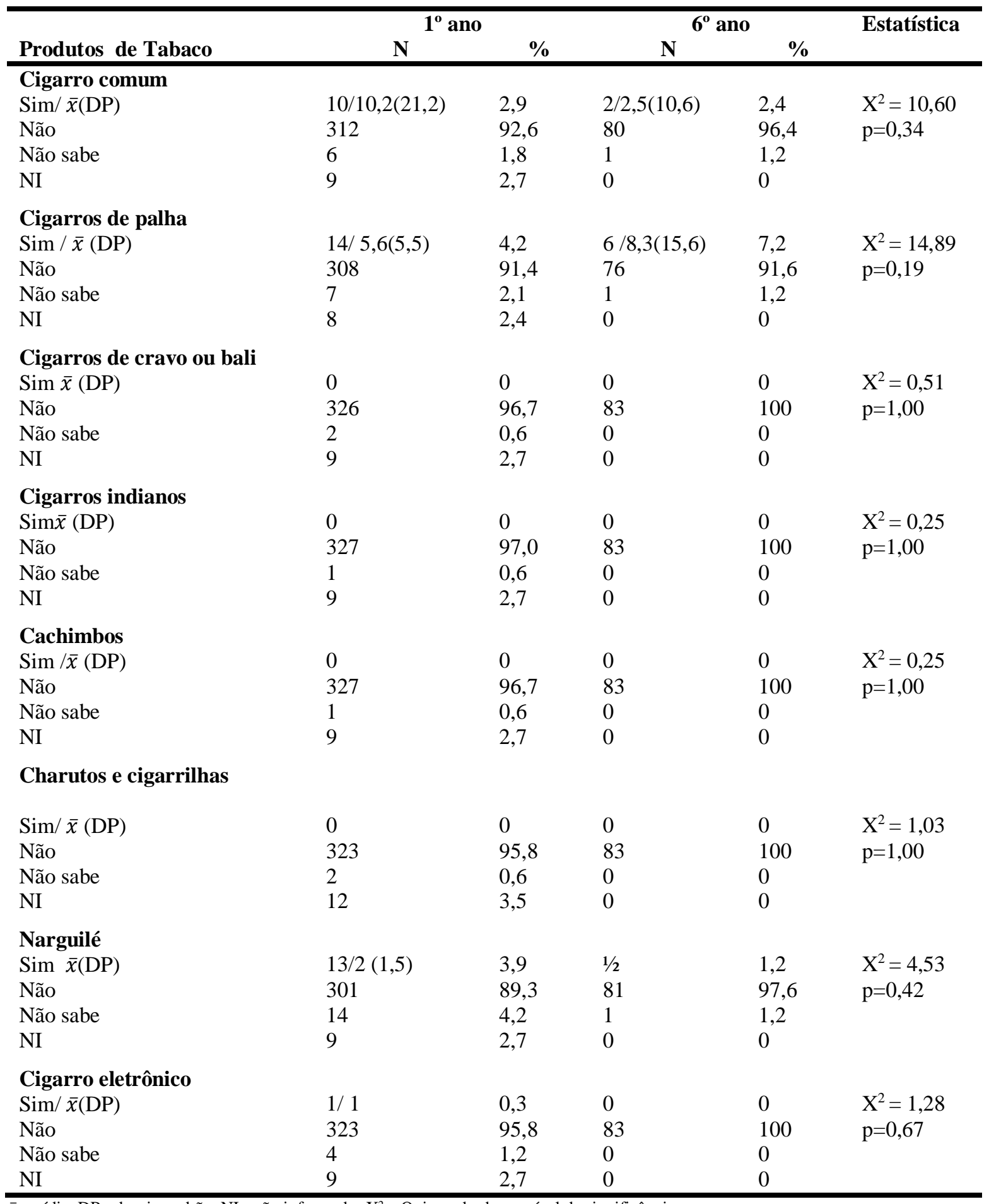

$\bar{x}=$ média, $\mathrm{DP}=$ desvio padrão, $\mathrm{NI}=$ não informado, $\mathrm{X}^{2}$ = Qui-quadrado, $\mathrm{p}=$ nível de significância 
Não houve diferença significativa entre os grupos em relação ao consumo semanal de produtos do tabaco. Pode-se verificar que o produto mais consumido pelos alunos era o cigarro comum. Entretanto, um número maior de alunos do $1^{\circ}$ ano estava consumindo narguilé $(3,9 \%)$ e cigarro de palha $(5,5 \%)$; no $6^{\circ}$ ano, os alunos faziam uso semanal de cigarro de palha $(7,2 \%)$ mais frequentemente. Produtos como cigarro de cravo, cigarros indianos e cachimbos não eram consumidos semanalmente pela amostra.

Quando questionados sobre cessação dos produtos de tabaco, verificou-se que dos sujeitos do $1^{\circ}$ ano que já experimentaram cigarro comum e outros produtos de tabaco, 5,8\% deixaram de fumar cigarro comum há mais ou menos cinco anos $(\mathrm{DP}=4,2)$ e 5,0\% deixaram de usar narguilé há mais ou menos dois anos $(\mathrm{DP}=1,1)$. No que se refere aos alunos do $6^{\circ}$ ano, 14,9\% deixaram de fumar cigarros há mais ou menos 3,7 anos $(\mathrm{DP}=2,0)$ e 4,3\% deixaram de usar narguilé há mais ou menos 2,5 anos $(\mathrm{DP}=0,7)$.

Quanto ao uso de produtos de tabaco sem fumaça, 99,7\% dos estudantes de Medicina do $1^{\circ}$ ano e $98,8 \%$ dos estudantes do $6^{\circ}$ ano alegaram nunca ter experimentado.

Nenhum estudante relatou ter feito uso de snus até o momento da coleta de dados.

\subsection{Uso do tabaco no curso de Medicina}

Abaixo será descrito o perfil de consumo de tabaco antes e depois do ingresso no curso de Medicina. 
Tabela 7- Uso de produtos de tabaco em relação ao ingresso no curso de Medicina por alunos do $1^{\circ}$ ano $(\mathrm{N}=337)$ e $6^{\circ}$ ano $(\mathrm{N}=83)$

\begin{tabular}{|c|c|c|c|c|c|c|c|c|c|c|}
\hline \multirow{2}{*}{$\begin{array}{c}\text { Produtos de } \\
\text { Tabaco }\end{array}$} & \multirow[t]{2}{*}{ Ano } & \multicolumn{2}{|c|}{ Uso anterior } & \multicolumn{2}{|c|}{ Uso posterior } & \multicolumn{2}{|c|}{$\begin{array}{c}\text { Nunca } \\
\text { experimentei }\end{array}$} & \multicolumn{2}{|c|}{ NI } & \multirow[t]{2}{*}{ Estatística } \\
\hline & & $\mathbf{N}$ & $\%$ & $\mathbf{N}$ & $\%$ & $\mathbf{N}$ & $\%$ & $\mathbf{N}$ & $\%$ & \\
\hline \multirow[t]{2}{*}{ Narguilé } & $1^{0}$ & 105 & 31,2 & 6 & 1,8 & 223 & 66,1 & 3 & 0,9 & $X^{2}=5,27$ \\
\hline & $6^{0}$ & 32 & 38,6 & 14 & 16,9 & 37 & 44,6 & 0 & 0 & $\mathrm{p}<0,001^{*}$ \\
\hline \multirow[t]{2}{*}{ Cachimbos } & $1^{0}$ & 7 & 2,1 & 0 & 0 & 325 & 96,4 & 5 & 1,5 & $X^{2}=8,73$ \\
\hline & $6^{\mathbf{0}}$ & 3 & 3,6 & 2 & 2,4 & 78 & 94,0 & 0 & 0 & $\mathrm{p}=0,02^{*}$ \\
\hline \multirow[t]{2}{*}{ Charuto } & $1^{\circ}$ & 15 & 4,4 & 1 & 0,3 & 318 & 94,4 & 3 & 0,9 & $X^{2}=5,27$ \\
\hline & $6^{\mathbf{0}}$ & 6 & 7,2 & 2 & 2,4 & 75 & 90,4 & 0 & 0 & $\mathrm{p}=0,08$ \\
\hline \multirow[t]{2}{*}{ Cigarrilhas } & $1^{0}$ & 10 & 3,0 & 0 & 0 & 324 & 96,1 & 3 & 0,9 & $X^{2}=14,56$ \\
\hline & $6^{\mathbf{0}}$ & 0 & 0 & 3 & 3,6 & 80 & 96,4 & 0 & 0 & $\mathrm{p}=0,003^{*}$ \\
\hline \multirow{2}{*}{$\begin{array}{l}\text { Cigarro de } \\
\text { cravo }\end{array}$} & $1^{\mathbf{o}}$ & 14 & 4,1 & 2 & 0,6 & 318 & 94,4 & 3 & 0,9 & $X^{2}=16,98$ \\
\hline & $6^{\mathbf{0}}$ & 1 & 1,2 & 6 & 7,2 & 76 & 91,6 & 0 & 0 & $\mathrm{p}=0,001^{*}$ \\
\hline \multirow{2}{*}{$\begin{array}{l}\text { Cigarro de } \\
\text { palha }\end{array}$} & $\mathbf{1}^{\mathbf{o}}$ & 64 & 19,0 & 9 & 2,7 & 261 & 77,4 & 3 & 0,9 & $X^{2}=44,25$ \\
\hline & $6^{\mathbf{0}}$ & 9 & 10,8 & 19 & 22,9 & 55 & 66,3 & 0 & 0 & $\mathrm{p}<0,001^{*}$ \\
\hline \multirow[t]{2}{*}{ Rapé } & $1^{\mathbf{o}}$ & 5 & 1,5 & 1 & 0,3 & 328 & 97,3 & 3 & 0,9 & $X^{2}=1,18$ \\
\hline & $6^{0}$ & 1 & 1,2 & 1 & 1,2 & 81 & 97,6 & 0 & 0 & $\mathrm{p}=0,75$ \\
\hline \multirow{2}{*}{$\begin{array}{l}\text { Cigarro } \\
\text { eletrônico }\end{array}$} & $1^{0}$ & 20 & 5,9 & 2 & 0,6 & 312 & 92,5 & 3 & 0,9 & $X^{2}=14,68$ \\
\hline & $6^{0}$ & 1 & 1,2 & 5 & 6,0 & 77 & 92,8 & 0 & 0 & $\mathrm{p}=0,002^{*}$ \\
\hline \multirow{2}{*}{$\begin{array}{l}\text { Fumo de } \\
\text { mascar }\end{array}$} & $\mathbf{1}^{\mathbf{o}}$ & 4 & 1,2 & 0 & 0 & 330 & 97,9 & 3 & 0,9 & $X^{2}=1,00$ \\
\hline & $6^{0}$ & 0 & 0 & 0 & 0 & 83 & 100 & 0 & 0 & $\mathrm{p}=0,59$ \\
\hline
\end{tabular}

$\mathrm{NI}=\mathrm{Não}$ informado; * = diferença significativa entre as amostras do $1^{\circ}$ e do $6^{\circ}$ ano, $\mathrm{X}^{2}=$ Qui-quadrado, $\mathrm{p}=$ nível de significância

Segundo a Tabela 7, os grupos se diferenciaram em relação a ocorrência do primeiro uso dos produtos de tabaco, após a correção de Bonferroni foi possível verificar onde estavam as diferenças. No que diz respeito à ocorrência de uso de Narguilé, a maioria dos alunos do $1^{\circ}$ ano nunca experimentaram e alunos do $6^{\circ}$ ano começaram a usar Narguilé após de ingressarem no curso de Medicina $(\mathrm{p}<0,001)$. A maioria dos alunos do $1^{\circ}$ ano nunca experimentaram cigarro de palha ( $\mathrm{p}<0,001)$. Alunos do $6^{\circ}$ ano iniciaram o uso de produtos do tabaco como: cachimbo $(\mathrm{p}=0,02)$, cigarrilha $(\mathrm{p}=0,003)$, cigarro indiano $(\mathrm{p}=0,001)$, cigarro de palha $(\mathrm{p}<0,001)$ e cigarro eletrônico $(\mathrm{p}=0,002)$ após ingressarem na faculdade. 


\subsection{Exposição ambiental}

Segue abaixo a caracterização de exposição ambiental ao tabaco nos contextos familiar, de trabalho/estudo e social.

Tabela 8- Caracterização da exposição ao tabaco no contexto ambiental por estudantes do $1^{\circ}$ $(\mathrm{N}=337)$ e $6^{\circ}(\mathrm{N}=83)$ ano de Medicina

\begin{tabular}{|c|c|c|c|c|c|}
\hline \multirow[b]{2}{*}{ Contexto ambiental } & \multicolumn{2}{|c|}{$1^{\circ}$ ano } & \multicolumn{2}{|c|}{$6^{\circ}$ ano } & \multirow[t]{2}{*}{ Estatística } \\
\hline & $\mathbf{N}$ & $\%$ & $\mathbf{N}$ & $\%$ & \\
\hline \multicolumn{6}{|c|}{ Familiar (ter ou já ter tido) } \\
\hline Sim & 271 & 80,4 & 56 & 67,5 & $X^{2}=6,47$ \\
\hline Não & 66 & 19,6 & 27 & 32,5 & $\mathrm{p}=0,01 *$ \\
\hline \multicolumn{6}{|c|}{ Amigos mais próximos } \\
\hline Sim & 261 & 77,4 & 67 & 80,7 & $X^{2}=5,50$ \\
\hline Não & 76 & 22,6 & 16 & 19,3 & $\mathrm{p}=0,14$ \\
\hline NI & 0 & 0 & 0 & & \\
\hline \multicolumn{6}{|c|}{ Exposição ao fumo em ambiente } \\
\hline \multicolumn{6}{|c|}{ fechado onde trabalha ou estuda } \\
\hline Sim & 103 & 30,6 & 23 & 27,7 & $X^{2}=0,28$ \\
\hline Não & 197 & 58,5 & 51 & 61,4 & $\mathrm{p}=0,87$ \\
\hline NI & 1 & 0,3 & 0 & 0 & \\
\hline
\end{tabular}

No que diz respeito ao contexto familiar, houve diferença significativa entre os grupos quanto a ter ou já ter tido parentes fumantes, alunos do $1^{\circ}$ ano o relataram com maior frequência.

Os locais onde aconteciam maior exposição semanal ao tabaco eram no trabalho ou na faculdade, $1^{\circ}$ ano $(30,7 \%)$ e $6^{\circ}$ ano $(27,7 \%)$. Em relação à frequência de exposição, constatouse que o mesmo ocorria principalmente de forma semanal no $1^{\circ}$ ano $(35,8 \%)$, no $6^{\circ}$ ano $(30,4 \%)$ e diária no $1^{\circ}$ ano $(16,5 \%)$ e no $6^{\circ}$ ano $(17,4 \%)$.

\subsection{Atitudes e percepção}

Quando questionados sobre sua opinião quanto a acreditar que é difícil para as pessoas deixarem de fumar, constatou-se que a maioria dos estudantes fumantes ou não, considera difícil, (>92\%), sem diferença significativa entre as amostras.

Segue abaixo a descrição do uso do tabaco nas situações sociais e a percepção que os sujeitos tinham acerca dos fumantes e não fumantes neste contexto. 
Tabela 9- Percepção quanto ao uso do tabaco em situações sociais por estudantes do $1^{\circ}(\mathrm{N}=337)$ e $6^{\circ}(\mathrm{N}=83)$ ano de Medicina

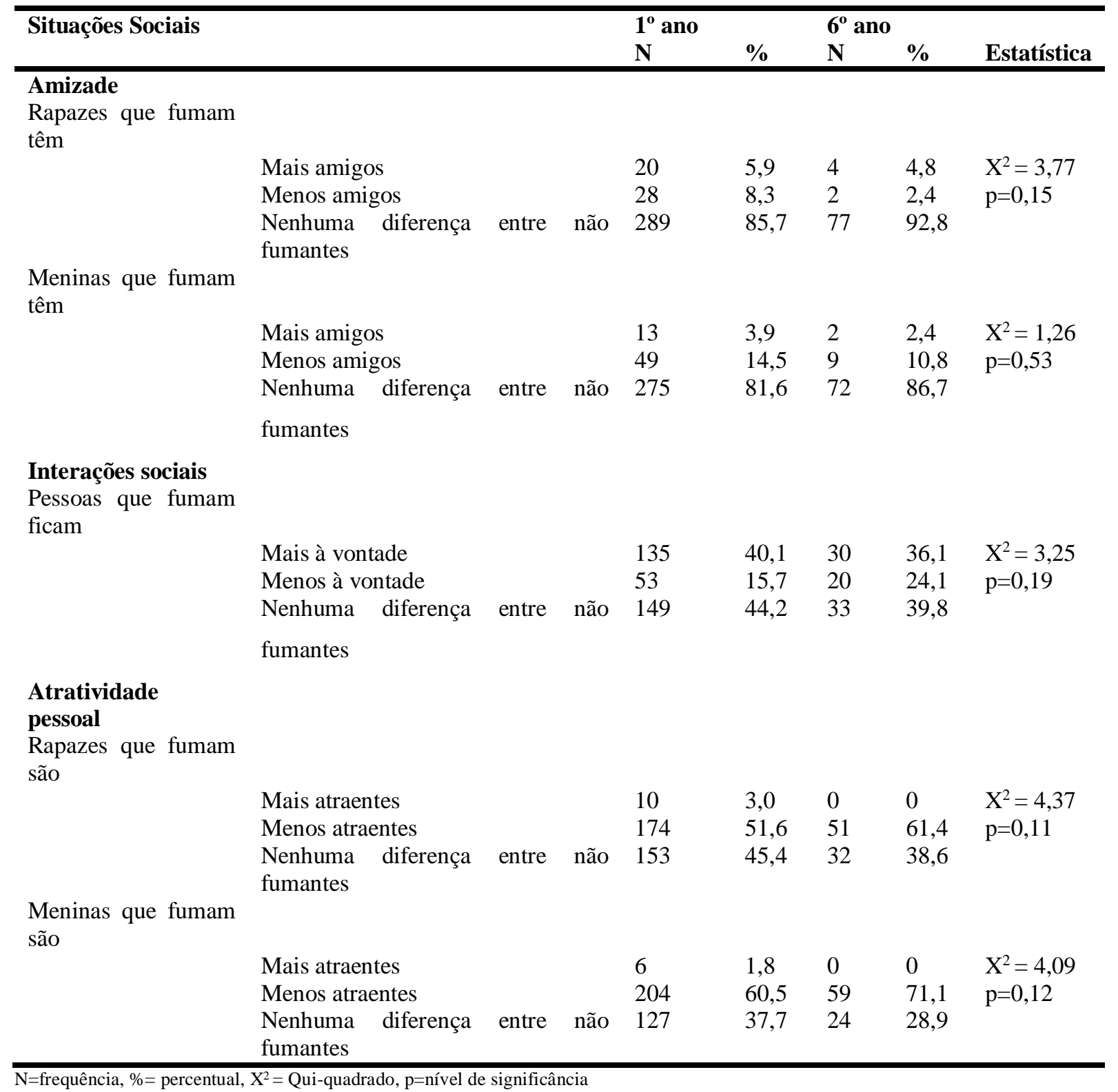

No que se refere à situações relacionadas ao contexto social, a maioria considerou não haver diferença entre fumantes e não fumantes, não houve diferença significativa entre os grupos. Destaca-se que muitos alunos entrevistados consideram que o tabagismo deixa as pessoas mais à vontade para interagir socialmente, apesar de não acreditarem que haja diferença entre fumantes e não fumantes em relação a quantidade de amigos, conforme visto na Tabela 9. De modo geral, os alunos consideram fumantes, independente do sexo, menos atraentes que não fumantes.

Segue abaixo os dados referentes à percepção de risco à saúde com o consumo de tabaco pelos estudantes do $1^{\circ}$ e $6^{\circ}$ ano de Medicina. 
Tabela 10- Percepção de risco à saúde relacionada ao consumo de tabaco por estudantes do $1^{\circ}$ $(\mathrm{N}=337)$ e $6^{\circ}$ ano $(\mathrm{N}=83)$ de Medicina

\begin{tabular}{|c|c|c|c|c|c|c|}
\hline \multirow[t]{2}{*}{ Risco à saúde } & & \multicolumn{2}{|c|}{$1^{\circ}$ ano } & \multicolumn{2}{|c|}{$6^{\circ}$} & \multirow[t]{2}{*}{ Estatística } \\
\hline & & $\mathrm{N}$ & $\%$ & $\mathrm{~N}$ & $\%$ & \\
\hline \multicolumn{7}{|l|}{ Peso } \\
\hline \multirow{4}{*}{ Uso de cigarros } & Favorece ganho de peso & 44 & 13,1 & 6 & 7,2 & $X^{2}=2,90$ \\
\hline & Não interfere no peso & 110 & 32,6 & 33 & 39,8 & $\mathrm{p}=0,24$ \\
\hline & Favorece a perda & 182 & 54,0 & 44 & 53,0 & \\
\hline & NI & 1 & 0,3 & 0 & 0 & \\
\hline \multicolumn{7}{|l|}{ Doenças } \\
\hline \multicolumn{7}{|l|}{ Uso de cigarro } \\
\hline & Favorece doenças graves & 329 & 97,6 & 82 & 98,8 & $X^{2}=0,54$ \\
\hline & Não favorece doenças graves & 2 & 0,6 & 0 & 0 & $\mathrm{p}=1,00$ \\
\hline & Não sei & 5 & 1,5 & 1 & 1,2 & \\
\hline & NI & 1 & 0,3 & 0 & 0 & \\
\hline \multicolumn{7}{|l|}{ Cigarro causa derrame } \\
\hline & Sim & 205 & 60,8 & 82 & 98,8 & $X^{2}=44,37$ \\
\hline & Não sei & 116 & 34,4 & 1 & 1,2 & $\mathrm{p}<0,001^{*}$ \\
\hline & Não & 16 & 4,7 & 0 & 0 & \\
\hline \multicolumn{7}{|l|}{$\begin{array}{l}\text { Cigarro causa ataques } \\
\text { cardíacos }\end{array}$} \\
\hline & Sim & 263 & 78,0 & 82 & 98,8 & $X^{2}=19,29$ \\
\hline & Não sei & 65 & 19,3 & 1 & 1,2 & $\mathrm{p}<0,001^{*}$ \\
\hline & Não & 8 & 2,4 & 0 & 0 & \\
\hline & NI & 1 & 0,3 & 0 & 0 & \\
\hline \multicolumn{7}{|l|}{$\begin{array}{l}\text { Cigarro causa câncer de } \\
\text { pulmão }\end{array}$} \\
\hline & Sim & 329 & 97,6 & 82 & 98,8 & $X^{2}=0,63$ \\
\hline & Não sei & 6 & 1,8 & 1 & 1,2 & $\mathrm{p}=1,00$ \\
\hline & Não & 2 & 0,6 & 0 & 0 & \\
\hline
\end{tabular}

$\mathrm{NI}=$ não informado, $\mathrm{N}=$ frequência, $\%=$ percentual, *= diferença significativa entre as amostras do $1^{\circ}$ e do $6^{\circ}$ ano, p=nível de significância

Observou-se na Tabela 10, que não houve diferença entre os grupos no que diz respeito à percepção de associação entre o uso do tabaco, o peso e prejuízos à saúde causados pelo tabagismo.

Verificou-se dúvida dos alunos do $1^{\mathrm{o}}$ ano $(34,4 \%)$ quanto ao tabaco a ser um preditor de derrame, apesar da maioria acreditar que sim (60,8\%). Em relação ao $6^{\circ}$ ano, 98,9\% considerou que fumar causa derrame $(\mathrm{p}<0,001)$. Os estudantes do primeiro ano também apresentaram dúvidas quanto ao uso de tabaco causar ataque cardíaco (19,3\%), dúvida essa menos frequente nos estudantes do $6^{\circ}$ ano $(\mathrm{p}<0,001)$. Não houve diferença significativa entre os grupos do $1^{\circ} \mathrm{e}$ $6^{\circ}$ ano quanto a associação do fumo com câncer de pulmão, já que a maioria dos estudantes $(97,9 \%)$ acreditava que $\operatorname{sim}(\mathrm{p}=1,00)$. 
Quando questionados quanto a associação aos produtos do tabaco sem fumaça, 71,1\% dos sujeitos do $1^{\circ}$ ano e $79,5 \%$ do $6^{\circ}$ ano acreditavam que os mesmos podiam causar doenças graves; não houve diferença significativa entre as amostras $(p=0,374)$.

A seguir, descreve-se a percepção de prejuízos à saúde causado por cada produto de tabaco comparado ao cigarro comum.

Tabela 11- Indicadores comparativos de potencial de prejuízos à saúde dos diferentes produtos de tabaco tendo-se por referência o cigarro comum pelo $1^{\circ}(\mathrm{N}=337)$ e $6^{\circ}$ ano de Medicina

\begin{tabular}{|c|c|c|c|c|c|c|c|c|c|c|}
\hline \multirow[t]{2}{*}{ Produto Tabaco } & \multirow[t]{2}{*}{ Ano } & \multicolumn{2}{|c|}{$\begin{array}{c}\text { Mais } \\
\text { prejudiciais }\end{array}$} & \multicolumn{2}{|c|}{$\begin{array}{c}\text { Menos } \\
\text { prejudiciais }\end{array}$} & \multicolumn{2}{|c|}{$\begin{array}{l}\text { Igualmente } \\
\text { prejudiciais }\end{array}$} & \multicolumn{2}{|c|}{ Não sei } & \multirow[t]{2}{*}{ Estatística } \\
\hline & & $\mathrm{N}$ & $\%$ & $\mathrm{~N}$ & $\%$ & $\mathrm{~N}$ & $\%$ & $\mathrm{~N}$ & $\%$ & \\
\hline \multirow[t]{2}{*}{ Narguilé } & $\mathbf{1}^{\mathbf{o}}$ & 151 & 44,8 & 71 & 21,1 & 64 & 19,0 & 51 & 15,1 & $X^{2}=18,34$ \\
\hline & $6^{0}$ & 55 & 66,3 & 4 & 4,8 & 17 & 20,5 & 7 & 8,4 & $\mathrm{p}<0,001^{*}$ \\
\hline \multirow[t]{2}{*}{ Cachimbo } & $1^{\circ}$ & 111 & 32,9 & 33 & 9,8 & 98 & 29,1 & 95 & 28,2 & $X^{2}=31,69$ \\
\hline & $6^{\mathbf{0}}$ & 53 & 63,9 & 2 & 2,4 & 21 & 25,3 & 7 & 8,4 & $\mathrm{p}<0,001^{*}$ \\
\hline \multirow[t]{2}{*}{ Charuto } & $1^{o}$ & 108 & 32,0 & 36 & 10,7 & 96 & 28,5 & 97 & 28,8 & $X^{2}=25,09$ \\
\hline & $6^{0}$ & 46 & 55,4 & 2 & 2,4 & 27 & 32,5 & 8 & 9,6 & $\mathrm{p}<0,001^{*}$ \\
\hline \multirow[t]{2}{*}{ Cigarrilhas } & $1^{o}$ & 36 & 10,7 & 34 & 10,1 & 105 & 31,2 & 42 & 50,6 & $X^{2}=21,54$ \\
\hline & $6^{\mathbf{0}}$ & 16 & 19,3 & 6 & 7,2 & 42 & 50,6 & 19 & 22,9 & $\mathrm{p}<0,001^{*}$ \\
\hline \multirow[t]{2}{*}{ Cigarro de cravo } & $1^{o}$ & 30 & 8,9 & 48 & 14,2 & 100 & 29,7 & 159 & 47,2 & $X^{2}=35,27$ \\
\hline & $6^{\mathbf{0}}$ & 19 & 22,9 & 3 & 3,6 & 42 & 50,6 & 19 & 22,9 & $\mathrm{p}<0,001^{*}$ \\
\hline \multirow[t]{2}{*}{ Cigarros de palha } & $1^{o}$ & 84 & 24,9 & 81 & 24,0 & 92 & 27,3 & 80 & 23,7 & $X^{2}=34,86$ \\
\hline & $6^{0}$ & 43 & 51,8 & 6 & 7,2 & 28 & 33,7 & 6 & 7,2 & $\mathrm{p}<0,001 *$ \\
\hline \multirow[t]{2}{*}{ Rapé } & $\mathbf{1}^{\mathbf{o}}$ & 53 & 15,7 & 45 & 13,4 & 86 & 25,5 & 153 & 45,4 & $X^{2}=6,46$ \\
\hline & $6^{0}$ & 17 & 20,5 & 8 & 9,6 & 30 & 36,1 & 28 & 33,7 & $\mathrm{p}=0,09$ \\
\hline \multirow[t]{2}{*}{ Cigarro eletrônico } & $1^{\circ}$ & 19 & 5,6 & 139 & 41,2 & 72 & 21,4 & 107 & 31,8 & $X^{2}=11,21$ \\
\hline & $6^{0}$ & 8 & 9,6 & 25 & 30,1 & 30 & 36,1 & 0 & 0 & $\mathrm{p}=0,01^{*}$ \\
\hline \multirow[t]{2}{*}{ Fumo de mascar } & $\mathbf{1}^{\mathbf{o}}$ & 37 & 11,0 & 78 & 23,1 & 78 & 23,1 & 144 & 42,7 & $X^{2}=4,15$ \\
\hline & $6^{0}$ & 9 & 10,8 & 17 & 20,5 & 28 & 33,7 & 29 & 34,9 & $\mathrm{p}=0,25$ \\
\hline
\end{tabular}

$\mathrm{NI}=$ Não informado, $\mathrm{N}=$ frequência, \%= percentual; *= diferença significativa entre as amostras do $1^{\circ}$ e do $6^{\circ}$ ano, p=nível de significância

$\mathrm{O}$ produto considerado mais prejudicial que o cigarro com maior frequência foi o Narguilé e a percepção de prejuízo associado ao Narguilé foi maior nos estudantes do $6^{\circ}$ ano ( $p>0,001)$. O cachimbo foi um produto que causou mais dúvida nos estudantes do $1^{\circ}$ ano 
$(29,1 \%)$, entretanto foi considerado por parte desses alunos $(9,8 \%)$ menos prejudicial que o cigarro comum; a maioria amostra do $6^{\circ}$ ano $(63,9 \%)$ o considerou mais prejudicial $(\mathrm{p}<0,001)$.

$\mathrm{O}$ cigarro de palha foi considerado mais prejudicial que o cigarro comum pela maioria dos alunos do $6^{\circ}$ ano $(51,8 \%)$, enquanto que entre os alunos do $1^{\circ}$ ano apenas $24 \%$ consideraram prejudicial e $23,7 \%$ tiveram mais dúvida em relação ao seu potencial de prejuízo ( $\mathrm{p}<0,001$ ).

Estudantes do $6^{\circ}$ ano $(36,1 \%)$ consideraram mais frequentemente o cigarro eletrônico como igualmente prejudicial ao cigarro comum $(\mathrm{p}=0,01)$. Os grupos se mantiveram sem diferença significativa quanto aos prejuízos do rapé e tabaco mascado.

Os grupos se diferenciaram quanto à percepção sobre os cigarros de baixo teor. Estudantes do $1^{\circ}$ ano consideraram com maior frequência os cigarros de baixo teor menos prejudiciais que os cigarros comuns; entretanto, os estudantes do $6^{\circ}$ ano consideraram essa afirmativa falsa, demonstrando não acreditar que estes cigarros são menos prejudiciais $(\mathrm{p}<0,001)$.

Em relação aos riscos do fumo passivo como causa de câncer, não houve diferença significativa entre os grupos, tanto alunos do $1^{\mathrm{o}}$ ano como alunos do $6^{\circ}$ percebem o fumo passivo como preditor. No que diz respeito a doenças cardiovasculares terem o risco aumentado por causa do fumo passivo, os grupos se diferenciaram significativamente $(p=0,002)$, alunos do primeiro ano apresentaram mais dúvida em relação a essa afirmativa.

Pode-se observar que alunos do $6^{\circ}$ ano relataram acreditar, mais frequentemente, que a fumaça do cigarro de outras pessoas lhes é prejudicial $(91,6 \%)$ e alunos do $1^{\circ}$ ano $(19,0 \%)$ acreditam que é provável que haja prejuízo ( $\mathrm{p}=0,03)$.

Não houve diferença significativa em relação às seguintes percepções: a maioria dos sujeitos $(94,7 \%)$, respondeu que a nicotina causa dependência e 52,5\% deles referiu não ser seguro fumar por apenas um período de tempo, mesmo que um ou dois anos.

Ao serem questionados sobre sua atitude caso houvesse alguém fumando ao seu lado, $0,3 \%$ ( $1^{\circ}$ ano) e $1,2 \%\left(6^{\circ}\right.$ ano) dos alunos responderam que dariam orientações quanto aos malefícios do cigarro. $18,0 \%$ ( $1^{\circ}$ ano) e 8,4\% ( $6^{\circ}$ ano) disseram não se importar, mesmo sabendo dos riscos do fumo passivo e 55,1\% ( $1^{\circ}$ ano) e $66,3 \%$ ( $6^{\circ}$ ano) referiram que se retirariam do local, não houve diferença significativa entre os grupos.

\subsection{Conhecimento médico}

Destacar-se-á, na Tabela 12, dados acerca do conhecimento médico dos alunos do $1^{\circ}$ ano e $6^{\circ}$ ano quanto à dependência de nicotina. 
Tabela 12- Conhecimento médico em relação à dependência de nicotina em estudantes do $1^{\circ}$ ano $(\mathrm{N}=337)$ e $6^{\circ}$ ano $(\mathrm{N}=83)$ de Medicina

\begin{tabular}{|c|c|c|c|c|c|c|}
\hline \multirow[t]{2}{*}{ Crença } & & \multicolumn{2}{|c|}{$1^{\circ}$ ano } & \multicolumn{2}{|c|}{$6^{\circ}$ ano } & \multirow[t]{2}{*}{ Estatística } \\
\hline & & $\mathbf{N}$ & $\%$ & $\mathbf{N}$ & $\%$ & \\
\hline \multicolumn{7}{|l|}{ Nicotina é tão viciante quanto heroína e cocaína } \\
\hline & Sim & 172 & 51,0 & 63 & 75,9 & \\
\hline & Não & 86 & 25,5 & 14 & 16,9 & $X^{2}=17,609$ \\
\hline & Não sei & 77 & 22,8 & 6 & 7,2 & $\mathrm{p}<0,001 *$ \\
\hline & NI & 2 & 0,6 & 0 & 0 & \\
\hline
\end{tabular}

Os malefícios do cigarro ocorrem somente com uso diário

$\begin{array}{lccccc}\text { Sim } & 9 & 2,7 & 3 & 3,6 & \\ \text { Não } & 316 & 93,8 & 79 & 95,2 & \mathrm{X}^{2}=1,01 \\ \text { Não sei } & 10 & 2,9 & 1 & 1,2 & \mathrm{p}=0,66 \\ \text { NI } & 2 & 0,6 & 0 & 0 & \end{array}$

Os malefícios do cigarro só ocorrem após uso por vários anos

$\begin{array}{lccccc}\text { Sim } & 22 & 6,5 & 8 & 9,6 & \\ \text { Não } & 299 & 88,7 & 72 & 86,7 & \mathrm{X}^{2}=0,97 \\ \text { Não sei } & 14 & 4,2 & 3 & 3,6 & \mathrm{p}=0,66 \\ \text { NI } & 2 & 0,6 & 0 & 0 & \end{array}$

Só pode ser considerado fumante quem faz uso diário

$\begin{array}{lccccc}\text { Sim } & 53 & 15,7 & 4 & 4,8 & \\ \text { Não } & 261 & 77,4 & 76 & 91,6 & \mathrm{X}^{2}=8,26 \\ \text { Não sei } & 21 & 6,2 & 3 & 3,6 & \mathrm{p}=0,016^{*} \\ \text { NI } & 2 & 0,6 & 0 & 0 & \end{array}$

São dependentes do cigarro somente aqueles que fumam diariamente

$\begin{array}{lccccc}\text { Sim } & 56 & 16,6 & 5 & 6,0 & \\ \text { Não } & 264 & 78,3 & 74 & 89,2 & \mathrm{X}^{2}=6,11 \\ \text { Não sei } & 15 & 4,5 & 4 & 4,8 & \mathrm{p}=0,05^{*} \\ \text { NI } & 2 & 0,6 & 0 & 0 & \end{array}$

Mesmo quem fuma esporadicamente pode sofrer com a síndrome de abstinência

\begin{tabular}{lccccc} 
Sim & 233 & 69,1 & 57 & 68,7 & \\
Não & 35 & 10,4 & 11 & 13,3 & $\mathrm{X}^{2}=0,61$ \\
Não sei & 67 & 19,9 & 15 & 18,1 & $\mathrm{p}=0,74$ \\
NI & 2 & 0,6 & 0 & 0 & \\
\hline
\end{tabular}

$\mathrm{NI}=$ não informado, $\mathrm{N}=$ frequência, $\%=$ percentual, * = diferença significativa entre as amostras do $1^{\circ}$ e do $6^{\circ}$ ano, $\mathrm{p}=$ nível de significância

Os estudantes do $6^{\circ}$ ano, em grande parte, demonstraram ter conhecimento quanto ao potencial de dependência da nicotina, entretanto, alunos do $1^{\circ}$ ano demonstraram ter mais dúvida. Após teste para duas proporções com correção de Bonferroni, foi possível identificar quais eram as diferenças significativas entre os grupos. 
No que se refere a nicotina ser tão viciante quanto a cocaína, essa diferença se deu por alunos do $1^{\circ}$ ano $(23,0 \%)$ não saberem e alunos do $6^{\circ}$ ano $(75,9 \%)$ considerarem a nicotina tão viciante quanto a cocaína $(\mathrm{p}<0,001)$.

O grupo de alunos do $1^{\mathrm{o}}$ ano $(15,8 \%)$ considerou fumantes as pessoas que faziam uso do tabaco diariamente; já os alunos do $6^{\circ}$ ano $(91,6 \%)$ não relacionaram o status de fumante ao fumo diário $(\mathrm{p}=0,016)$.

Quando avaliada qual substância é a principal responsável pelo risco de doenças coronárias, a maioria dos alunos acreditava ser a nicotina. Não houve diferença significativa entre os grupos.

Os grupos apresentaram diferença significativa quanto ao conhecimento sobre a porcentagem de fumantes no Brasil, a partir do teste para duas proporções com correção de Bonferroni, pode verificar que as diferenças estavam na falta de conhecimento mais frequente nos alunos do $1^{\circ}$ ano $(58,8 \%)$. Os alunos do $6^{\circ}$ ano $(21,7 \%)$ acreditavam mais frequentemente que 10 a $20 \%$ da população brasileira é fumante $(\mathrm{p}=0,009)$.

Não houve diferença significativa quanto ao conhecimento sobre os danos que o fumo ocasional pode causar; a maioria dos alunos acredita que fumar, mesmo que por apenas 1 ou 2 anos, pode trazer prejuízos à saúde.

Os alunos de ambos os grupos não se percebiam fumantes ou dependentes do tabaco.

Na tabela 13 descrever-se-á o conhecimento quanto aos métodos usados para cessação do tabagismo, bem como a avaliação de eficácia de cada um deles. 
Tabela 13- Efetividade de métodos para cessação do tabagismo na avaliação dos estudantes do $1^{\circ}(\mathrm{N}=337)$ e $6^{\circ}(\mathrm{N}=83)$ ano de Medicina

\begin{tabular}{|c|c|c|c|c|c|c|c|c|c|c|c|c|c|c|}
\hline \multirow{3}{*}{ Procedimento } & \multirow{3}{*}{ Ano } & \multicolumn{13}{|c|}{ Efetividade } \\
\hline & & \multicolumn{2}{|c|}{$\begin{array}{c}\text { Nada } \\
\text { efetivo }\end{array}$} & \multicolumn{2}{|c|}{$\begin{array}{l}\text { Pouco } \\
\text { efetivo }\end{array}$} & \multicolumn{2}{|c|}{ Efetivo } & \multicolumn{2}{|c|}{ Muito efetivo } & \multicolumn{2}{|c|}{ Não sei } & \multicolumn{2}{|c|}{ NI } & \multirow[t]{2}{*}{ Estatístic: } \\
\hline & & $\mathbf{N}$ & $\%$ & $\mathbf{N}$ & $\%$ & $\mathbf{N}$ & $\%$ & $\mathbf{N}$ & $\%$ & $\mathbf{N}$ & $\%$ & $\mathbf{N}$ & $\%$ & \\
\hline \multirow[t]{2}{*}{ Força de vontade } & $\mathbf{1}^{\mathbf{o}}$ & 2 & 0,6 & 16 & 4,7 & 80 & 23,7 & 218 & 64,7 & 19 & 5,6 & 2 & 0,6 & $X^{2}=2,68$ \\
\hline & $6^{\mathbf{0}}$ & 0 & 0 & 7 & 8,4 & 19 & 22,9 & 54 & 65,1 & 3 & 3,6 & 0 & 0 & $\mathrm{p}=0,61$ \\
\hline \multirow[t]{2}{*}{ Acupuntura } & $1^{\mathbf{o}}$ & 6 & 1,8 & 33 & 9,8 & 103 & 30,6 & 25 & 7,4 & 168 & 49,8 & 2 & 0,6 & $X^{2}=18,08$ \\
\hline & $6^{0}$ & 2 & 2,4 & 20 & 24,1 & 29 & 34,9 & 8 & 9,6 & 24 & 28,9 & 0 & 0 & $\mathrm{p}<0,001^{*}$ \\
\hline \multirow[t]{2}{*}{ Aconselhamento médico } & $\mathbf{1}^{\mathbf{o}}$ & 7 & 2,1 & 61 & 18,1 & 162 & 48,1 & 78 & 23,1 & 27 & 8,0 & 2 & 0,6 & $\mathrm{X}^{2}=5,09$ \\
\hline & $6^{0}$ & 0 & 0 & 14 & 16,9 & 38 & 45,8 & 27 & 32,5 & 4 & 4,8 & 0 & 0 & $\mathrm{p}=0,277$ \\
\hline \multirow[t]{2}{*}{ Material de Auto ajuda } & $1^{\mathbf{o}}$ & 14 & 4,2 & 111 & 32,9 & 117 & 34,7 & 33 & 9,8 & 60 & 17,8 & 2 & 0,6 & $X^{2}=16,82$ \\
\hline & $6^{0}$ & 1 & 1,2 & 23 & 27,7 & 34 & 41,0 & 19 & 22,9 & 6 & 7,2 & 0 & 0 & $\mathrm{p}=0,002 *$ \\
\hline \multirow[t]{2}{*}{ TRN } & $1^{\circ}$ & 5 & 1,5 & 21 & 6,2 & 134 & \multirow{2}{*}{$\begin{array}{l}39,8 \\
51,8\end{array}$} & 69 & 20,5 & 105 & 31,1 & 3 & 0,9 & $X^{2}=10,52$ \\
\hline & $6^{0}$ & 0 & 0 & 7 & 8,4 & 43 & & 20 & 24,1 & 13 & 15,7 & 0 & 0 & $\mathrm{p}=0,04 *$ \\
\hline \multirow[t]{2}{*}{ Bupropiona } & $\mathbf{1}^{\mathbf{o}}$ & 3 & 0,9 & 23 & 6,8 & 117 & 34,7 & 60 & 17,8 & 132 & 39,2 & 2 & 0,6 & $X^{2}=36,38$ \\
\hline & $6^{0}$ & 0 & 0 & 5 & 6,0 & 38 & 45,8 & 33 & 39,8 & 7 & 8,4 & 0 & 0 & $\mathrm{p}<0,001^{*}$ \\
\hline \multirow[t]{2}{*}{ Vareniclina } & $1^{\mathrm{o}}$ & 5 & 1,5 & 17 & 5,0 & 83 & 24,6 & 45 & 13,4 & 184 & 54,6 & 3 & 0,9 & $X^{2}=20,62$ \\
\hline & $6^{\circ}$ & 1 & 1,2 & 6 & 7,2 & 34 & 41,0 & 19 & 22,9 & 23 & 27,7 & 0 & 0 & $\mathrm{p}=0,001 *$ \\
\hline
\end{tabular}

$\mathrm{NI}=$ não informado, TRN= Terapia de Reposição de Nicotina, ${ }^{*}=$ diferença significativa entre as amostras do $1^{\circ} \mathrm{e}$ do $6^{\circ}$ ano, $\mathrm{p}=$ nível de significância 
De acordo com a Tabela 13, verificou-se que alunos do $1^{\circ}$ ano apresentaram dúvidas com maior frequência, quanto à efetividade de procedimentos como acupuntura $(50,1 \%)$. Em contrapartida, alunos do $6^{\circ}$ ano consideraram mais frequentemente este procedimento como pouco eficaz para a cessação do tabagismo $(\mathrm{p}=0,001)$.

Os grupos não apresentaram diferenças significativas quanto à percepção de eficácia do aconselhamento médico na cessação do tabagismo $(\mathrm{p}=0,28)$, considerando o procedimento eficaz para este fim.

Alunos do $6^{\circ}$ ano $(22,9 \%)$ consideraram material de auto ajuda eficaz mais frequentemente $(\mathrm{p}=0,002)$. No que diz respeito a TRN, alunos do $1^{\circ}$ ano $(31,4 \%)$ tiveram dúvidas com maior frequência $(\mathrm{p}=0,04)$.

Verificou-se que os estudantes ingressantes disseram com maior frequência não saber se Vareniclina $(\mathrm{p}=0,001)$, Bupropiona $(\mathrm{p}<0,001)$ eram eficazes para a cessação do tabagismo. No entanto, estudantes do $6^{\circ}$ ano, consideraram com mais frequência Bupropiona muito eficaz e Vareniclina eficaz para a cessação.

Quando questionados sobre se os profissionais de saúde deveriam aconselhar seus pacientes a parar de fumar, os grupos não apresentaram diferenças significativas, 93,1\% dos estudantes respondeu acreditar que sim. Profissionais de saúde fumantes foram considerados menos propensos a aconselhar seus pacientes por $63,7 \%$ dos estudantes. Observou-se que $81,3 \%$ dos sujeitos responderam que os profissionais de saúde deveriam aconselhar seus pacientes a evitar outras formas de tabaco. A maioria dos estudantes que participaram do estudo consideraram profissionais de saúde como modelo para pacientes e público em geral $(78,2 \%)$.

Pode-se observar que os grupos se diferenciaram significativamente quanto à crença de que o aconselhamento médico aumentaria a probabilidade da cessação $(53,6 \%)$ e após a correção de Bonferroni, foi possível verificar quais eram essas diferenças. O grupo do $1^{\circ}$ ano disse não saber $(12,2 \%)$ e não acreditar no aumento da probabilidade de cessação com aconselhamento médico $(27,8 \%)$ com maior frequência, já o grupo do $6^{\circ}$ ano $(86,7 \%)$ relatou acreditar que o aconselhamento facilita a cessação $(\mathrm{p}<0,001)$.

Na Tabela 14, será destacada a percepção de risco quanto ao uso dos produtos de tabaco na gestação. 
Tabela 14- Conhecimento quanto aos malefícios dos produtos de tabaco em relação ao uso na gestação pelos estudantes do $1^{\circ}(\mathrm{N}=337)$ e $6^{\circ}(\mathrm{N}=83)$ ano de Medicina

\begin{tabular}{|c|c|c|c|c|c|c|c|c|}
\hline \multirow{4}{*}{ Produtos } & \multicolumn{7}{|c|}{ São seguros na gestação } & \multirow{4}{*}{ Estatística } \\
\hline & Ano & & & & & & & \\
\hline & & \multicolumn{2}{|c|}{ Sim } & \multicolumn{2}{|c|}{ Não sei } & \multicolumn{2}{|c|}{ Não } & \\
\hline & & $\mathbf{N}$ & $\%$ & $\mathbf{N}$ & $\%$ & $\mathbf{N}$ & $\%$ & \\
\hline \multirow[t]{2}{*}{ Narguilé } & $1^{\circ}$ & 8 & 2,4 & 21 & 6,2 & 305 & 90,5 & $X^{2}=5,50$ \\
\hline & $6^{0}$ & 2 & 2,4 & 0 & 0 & 81 & 97,6 & $\mathrm{p}=0,06$ \\
\hline \multirow[t]{2}{*}{ Cachimbo } & $\mathbf{1}^{\mathbf{o}}$ & 4 & 1,2 & 14 & 4,2 & 316 & 93,8 & $X^{2}=2,77$ \\
\hline & $6^{0}$ & 0 & 0 & 1 & 1,2 & 82 & 98,8 & $\mathrm{p}=0,23$ \\
\hline \multirow[t]{2}{*}{ Charuto } & $\mathbf{1}^{\mathbf{o}}$ & 4 & 1,2 & 14 & 4,2 & 316 & 93,8 & $X^{2}=2,77$ \\
\hline & $6^{\mathbf{0}}$ & 0 & 0 & 1 & 1,2 & 82 & 98,8 & $\mathrm{p}=0,23$ \\
\hline \multirow[t]{2}{*}{ Cigarrilhas } & $\mathbf{1}^{\mathrm{o}}$ & 3 & 0,9 & 17 & 5,0 & 314 & 93,2 & $X^{2}=1,88$ \\
\hline & $6^{\mathbf{0}}$ & 0 & 0 & 2 & 2,4 & 81 & 97,6 & $\mathrm{p}=0,39$ \\
\hline \multirow[t]{2}{*}{ Cigarro de cravo } & $1^{\mathbf{o}}$ & 3 & 0,9 & 21 & 6,2 & 310 & 91,9 & $X^{2}=2,72$ \\
\hline & $6^{0}$ & 0 & 0 & 2 & 2,4 & 81 & 97,6 & $\mathrm{p}=0,24$ \\
\hline \multirow[t]{2}{*}{ Cigarro de palha } & $1^{\circ}$ & 5 & 1,5 & 11 & 3,3 & 318 & 94,4 & $X^{2}=4,14$ \\
\hline & $6^{0}$ & 0 & 0 & 0 & 0 & 83 & 0 & $\mathrm{p}=0,13$ \\
\hline \multirow[t]{2}{*}{ Rapé } & $1^{o}$ & 5 & 1,5 & 20 & 5,9 & 310 & 91,9 & $X^{2}=0,39$ \\
\hline & $6^{\mathbf{0}}$ & 1 & 1,2 & 5 & 6,0 & 77 & 92,8 & $\mathrm{p}=1,00$ \\
\hline \multirow[t]{3}{*}{ Cigarro eletrônico } & $1^{\circ}$ & 8 & 2,4 & 31 & 9,2 & 295 & 87,5 & $X^{2}=3,91$ \\
\hline & $6^{0}$ & 0 & 0 & 4 & 4,8 & 79 & 95,2 & $\mathrm{p}=0,14$ \\
\hline & $1^{\circ}$ & 6 & 1,8 & 24 & 7,1 & 304 & 90,2 & $X^{2}=3,01$ \\
\hline Fumo de mascar & $6^{0}$ & 0 & 0 & 3 & 3,6 & 80 & 96,4 & $\mathrm{p}=0,25$ \\
\hline
\end{tabular}

$\mathrm{N}=$ frequência, \%= percentual, $\mathrm{X}^{2}=$ Qui-quadrado, $\mathrm{p}=$ nível de significância

Observou-se que os alunos estavam conscientes quanto aos malefícios do tabaco na gestação. As dúvidas quanto aos prejuízos causados por alguns produtos estavam relacionadas principalmente ao cigarro eletrônico $(8,4 \%)$. Cachimbo e charutos foram mais frequentemente considerados arriscados na gestação. Não houve diferença significativa entre os grupos.

Na tabela 15, destacou-se a percepção de risco à saúde relacionado ao consumo dos diferentes produtos de tabaco aumentar a chance de desenvolver algum tipo de câncer. 
Tabela 15- Conhecimento quanto aos malefícios dos produtos de tabaco em relação a aumentar o risco de alguns tipos de câncer pelos estudantes do $1^{\circ}(\mathrm{N}=337)$ e $6^{\circ}(\mathrm{N}=83)$ ano de Medicina

\begin{tabular}{|c|c|c|c|c|c|c|c|c|}
\hline \multirow{4}{*}{ Produtos } & \multirow{4}{*}{ Ano } & \multicolumn{6}{|c|}{ Aumentam o risco de alguns tipos de câncer } & \multirow{4}{*}{ Estatística } \\
\hline & & & & & & & & \\
\hline & & \multicolumn{2}{|c|}{ Sim } & \multicolumn{2}{|c|}{ Não sei } & \multicolumn{2}{|c|}{ Não } & \\
\hline & & $\mathbf{N}$ & $\%$ & $\mathbf{N}$ & $\%$ & $\mathbf{N}$ & $\%$ & \\
\hline \multirow[t]{2}{*}{ Narguilé } & $\mathbf{1}^{\mathbf{o}}$ & 278 & 82,5 & 44 & 13,1 & 13 & 3,9 & $X^{2}=9,98$ \\
\hline & $6^{\mathbf{0}}$ & 80 & 96,4 & 3 & 3,6 & 0 & 0 & $\mathrm{p}=0,007^{*}$ \\
\hline \multirow[t]{2}{*}{ Cachimbo } & $\mathbf{1}^{\mathbf{0}}$ & 307 & 91,1 & 26 & 7,7 & 2 & 0,6 & $X^{2}=7,15$ \\
\hline & $6^{\mathbf{0}}$ & 82 & 98,8 & 0 & 0 & 1 & 1,2 & $\mathrm{p}=0,02 *$ \\
\hline \multirow[t]{2}{*}{ Charuto } & $1^{o}$ & 303 & 89,9 & 27 & 8,0 & 5 & 1,5 & $X^{2}=6,41$ \\
\hline & $6^{\mathbf{0}}$ & 82 & 98,8 & 1 & 1,2 & 0 & 0 & $\mathrm{p}=0,03^{*}$ \\
\hline \multirow[t]{2}{*}{ Cigarrilhas } & $1^{\mathbf{o}}$ & 287 & 85,2 & 45 & 13,4 & 4 & 1,2 & $X^{2}=4,74$ \\
\hline & $6^{\circ}$ & 78 & 94,0 & 4 & 4,8 & 1 & 1,2 & $\mathrm{p}=0,09$ \\
\hline \multirow[t]{2}{*}{ Cigarro de cravo } & $1^{\mathbf{o}}$ & 286 & 84,7 & 46 & 13,6 & 4 & 1,2 & $X^{2}=4,71$ \\
\hline & $6^{\mathbf{0}}$ & 74 & 89,2 & 6 & 7,2 & 3 & 3,6 & $\mathrm{p}=0,09$ \\
\hline \multirow[t]{2}{*}{ Cigarro de palha } & $1^{0}$ & 299 & 88,7 & 31 & 9,2 & 4 & 1,2 & $X^{2}=8,33$ \\
\hline & $6^{0}$ & 82 & 98,8 & 0 & 0 & 1 & 1,2 & $\mathrm{p}=0,02 *$ \\
\hline \multirow[t]{2}{*}{ Rapé } & $1^{\mathbf{o}}$ & 273 & 81,0 & 73 & 21,7 & 5 & 1,5 & $X^{2}=2,71$ \\
\hline & $6^{\mathbf{0}}$ & 73 & 88,0 & 10 & 12,0 & 0 & 0 & $\mathrm{p}=0,23$ \\
\hline \multirow[t]{2}{*}{ Cigarro eletrônico } & $1^{o}$ & 242 & 71,8 & 75 & 22,3 & 19 & 5,3 & $X^{2}=3,45$ \\
\hline & $6^{0}$ & 66 & 79,5 & 11 & 13,3 & 6 & 7,2 & $\mathrm{p}=0,18$ \\
\hline \multirow[t]{2}{*}{ Fumo de mascar } & $1^{\mathbf{o}}$ & 267 & 79,2 & 62 & 18,4 & 7 & 2,1 & $X^{2}=3,60$ \\
\hline & $6^{0}$ & 69 & 83,1 & 10 & 12,0 & 4 & 4,8 & $\mathrm{p}=0,17$ \\
\hline
\end{tabular}

$\mathrm{N}=$ frequência, \%= percentual, *= diferença significativa entre as amostras do $1^{\circ}$ e do $6^{\circ}$ ano, $\mathrm{X}^{2}=$ Qui-quadrado, $\mathrm{p}=$ nível de significância

Os grupos apresentaram algumas diferenças significativas quanto à percepção de risco. Alunos do $1^{\circ}$ ano apresentaram mais frequentemente dúvidas quanto aos malefícios dos produtos do tabaco em relação ao aumento da probabilidade de causar algum tipo de câncer. Entre esses produtos estavam o narguilé ( $p=0,007)$, o cachimbo $(p=0,02)$, o charuto $(p=0,04)$ e o cigarro de palha $(\mathrm{p}=0,02)$. Os alunos do $6^{\circ}$ ano demonstraram ter maior conhecimento em relação aos malefícios desses produtos, consideraram o narguilé e o cigarro de palha produtos com potencial para aumentar o risco de alguns tipos de câncer.

Na tabela 16, destaca-se a percepção de risco quanto ao consumo dos diferentes produtos de tabaco aumentarem as chances de desenvolver doenças cardiovasculares. 
Tabela 16- Conhecimento quanto aos malefícios dos produtos de tabaco em relação ao aumento do risco de doenças cardiovasculares pelos estudantes do $1^{\circ}(\mathrm{N}=337)$ e $6^{\circ}(\mathrm{N}=83)$ ano de Medicina

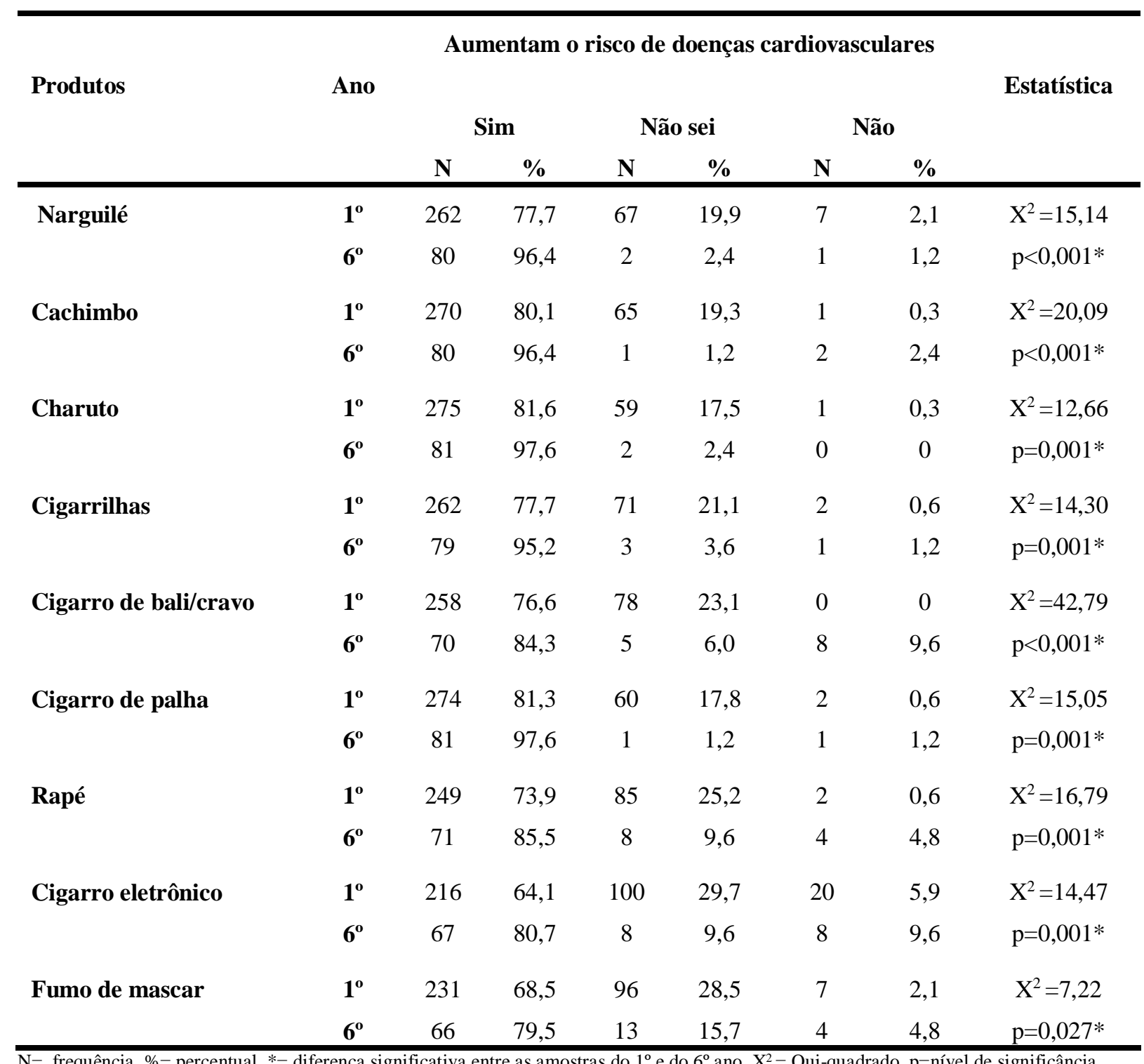

$\mathrm{N}=$ frequência, \%= percentual, *= diferença significativa entre as amostras do $1^{\circ}$ e do $6^{\circ}$ ano, $\mathrm{X}^{2}=$ Qui-quadrado, $\mathrm{p}=$ nível de significância

Os grupos apresentaram diferenças significativas quanto ao conhecimento dos malefícios de alguns produtos de tabaco. Os estudantes do $1^{\circ}$ ano apresentaram dúvidas com mais frequência em relação a todos os produtos que foram questionados.

Os estudantes do $6^{\circ}$ ano consideraram o narguilé ( $\left.\mathrm{p}<0,001\right)$, o charuto $(\mathrm{p}=0,001)$, as cigarrilhas $(p<0,001)$, o cigarro de palha $(p=0,001)$, o rapé $(p=0,001)$ e o cigarro eletrônico $(\mathrm{p}=0,001)$ produtos que aumentam o risco de doenças cardiovasculares. Entretanto, também 
consideraram mais frequentemente o rapé e o cigarro indiano $(\mathrm{p}<0,001)$ produtos que não aumentam o risco de doenças cardiovasculares.

$\mathrm{Na}$ Tabela 17, caracterizou-se o conhecimento quanto aos produtos de tabaco que contém nicotina pelos estudantes ingressantes e formandos do curso de Medicina.

Tabela 17- Conhecimento quanto aos produtos de tabaco que contém Nicotina por estudantes do $1^{\circ}(\mathrm{N}=337)$ e $6^{\circ}(\mathrm{N}=83)$ ano de Medicina

\begin{tabular}{|c|c|c|c|c|c|c|c|c|}
\hline \multirow{3}{*}{ Produtos de Tabaco } & \multirow{3}{*}{ Ano } & \multicolumn{6}{|c|}{ Contém Nicotina } & \multirow{3}{*}{ Estatística } \\
\hline & & \multicolumn{2}{|c|}{ Sim } & \multicolumn{2}{|c|}{ Não } & \multicolumn{2}{|c|}{ Não sei } & \\
\hline & & $\mathbf{N}$ & $\%$ & $\mathbf{N}$ & $\%$ & $\mathbf{N}$ & $\%$ & \\
\hline \multirow[t]{2}{*}{ Narguilé } & $1^{\mathbf{o}}$ & 118 & 35,0 & 80 & 23,7 & 138 & 40,9 & $X^{2}=17,55$ \\
\hline & $6^{0}$ & 50 & 60,2 & 13 & 15,7 & 20 & 24,1 & $\mathrm{p}<0,001 *$ \\
\hline \multirow[t]{2}{*}{ Cachimbo } & $\mathbf{1}^{\mathbf{o}}$ & 165 & 48,9 & 29 & 8,6 & 142 & 42,1 & $X^{2}=9,49$ \\
\hline & $6^{0}$ & 55 & 66,3 & 8 & 9,6 & 20 & 24,1 & $\mathrm{p}=0,009^{*}$ \\
\hline \multirow[t]{2}{*}{ Charuto } & $\mathbf{1}^{\mathbf{0}}$ & 175 & 51,9 & 20 & 5,9 & 141 & 41,8 & $X^{2}=20,51$ \\
\hline & $6^{0}$ & 66 & 79,5 & 2 & 2,4 & 15 & 18,1 & $\mathrm{p}<0,001 *$ \\
\hline \multirow[t]{2}{*}{ Cigarrilhas } & $\mathbf{1}^{\mathbf{o}}$ & 154 & 45,7 & 13 & 3,9 & 168 & 49,9 & $X^{2}=18,49$ \\
\hline & $6^{0}$ & 60 & 72,3 & 2 & 2,4 & 21 & 25,3 & $\mathrm{p}<0,001^{*}$ \\
\hline \multirow[t]{2}{*}{ Cigarro de bali/cravo } & $1^{\mathbf{o}}$ & 135 & 40,1 & 20 & 5,9 & 181 & 53,7 & $X^{2}=9,69$ \\
\hline & $6^{0}$ & 46 & 55,4 & 8 & 9,6 & 29 & 34,9 & $\mathrm{p}=0,008^{*}$ \\
\hline \multirow[t]{2}{*}{ Cigarro de palha } & $1^{\mathbf{o}}$ & 153 & 45,4 & 51 & 15,1 & 132 & 39,1 & $X^{2}=13,33$ \\
\hline & $6^{0}$ & 55 & 66,3 & 12 & 14,5 & 16 & 19,3 & $\mathrm{p}=0,001^{*}$ \\
\hline \multirow[t]{2}{*}{ Rapé } & $1^{\mathbf{o}}$ & 128 & 37,9 & 28 & 8,3 & 180 & 53,4 & $X^{2}=12,27$ \\
\hline & $6^{0}$ & 48 & 57,8 & 8 & 9,6 & 27 & 32,5 & $\mathrm{p}=0,002 *$ \\
\hline \multirow[t]{2}{*}{ Cigarro eletrônico } & $\mathbf{1}^{\mathbf{o}}$ & 102 & 30,3 & 67 & 19,9 & 166 & 49,3 & $X^{2}=4,46$ \\
\hline & $6^{0}$ & 34 & 41,0 & 18 & 21,7 & 31 & 37,3 & $\mathrm{p}=0,11$ \\
\hline \multirow[t]{2}{*}{ Fumo de mascar } & $\mathbf{1}^{\mathbf{o}}$ & 142 & 42,1 & 30 & 8,9 & 163 & 48,4 & $X^{2}=7,51$ \\
\hline & $6^{0}$ & 49 & 59,0 & 6 & 7,2 & 28 & 33,7 & $\mathrm{p}=0,02^{*}$ \\
\hline
\end{tabular}

Verificou-se que houve uma diferença significativa quanto ao conhecimento dos produtos derivados do tabaco conterem nicotina. Estudantes do $1^{\mathrm{o}}$ ano apresentaram mais dúvidas em relação aos produtos questionados, por outro lado, estudantes do $6^{\circ}$ ano demonstraram ter maior conhecimento quanto à existência de nicotina nos produtos derivados de tabaco. 
Não houve diferença significativa entre os grupos em relação ao cigarro eletrônico. $\mathrm{O}$ produto que mais gerou dúvida nos alunos do $1^{\circ}$ foi o cigarro de cravo $(53,7 \%)$ e nos alunos do $6^{\circ}$ ano foi o cigarro eletrônico $(37,3 \%)$.

Na Tabela 18, observou-se o conhecimento quanto ao potencial de dependência de cada substância derivada do tabaco.

Tabela 18- Conhecimento quanto ao potencial de dependência dos produtos de tabaco pelos estudantes do $1^{\circ}(\mathrm{N}=337)$ e $6^{\circ}(\mathrm{N}=83)$ ano de Medicina

\begin{tabular}{|c|c|c|c|c|c|c|c|c|}
\hline \multirow{3}{*}{ Produtos de Tabaco } & \multirow{3}{*}{ Ano } & \multicolumn{6}{|c|}{ Causa dependência } & \multirow{3}{*}{ Estatística } \\
\hline & & \multicolumn{2}{|c|}{ Sim } & \multicolumn{2}{|c|}{ Não } & \multicolumn{2}{|c|}{ Não sei } & \\
\hline & & $\mathbf{N}$ & $\%$ & $\mathbf{N}$ & $\%$ & $\mathbf{N}$ & $\%$ & \\
\hline \multirow[t]{2}{*}{ Narguilé } & $\mathbf{1}^{\mathbf{o}}$ & 220 & 65,3 & 56 & 16,6 & 59 & 17,5 & $X^{2}=9,87$ \\
\hline & $6^{0}$ & 68 & 81,9 & 4 & 4,8 & 11 & 13,3 & $\mathrm{p}=0,007^{*}$ \\
\hline \multirow[t]{2}{*}{ Cachimbo } & $1^{\mathbf{o}}$ & 271 & 80,4 & 12 & 3,6 & 52 & 15,4 & $X^{2}=5,42$ \\
\hline & $6^{0}$ & 76 & 91,6 & 1 & 1,2 & 6 & 7,2 & $\mathrm{p}=0,07$ \\
\hline \multirow[t]{2}{*}{ Charuto } & $\mathbf{1}^{\mathrm{o}}$ & 269 & 79,8 & 15 & 4,5 & 51 & 15,1 & $X^{2}=6,00$ \\
\hline & $6^{0}$ & 76 & 91,6 & 1 & 1,2 & 6 & 7,2 & $\mathrm{p}=0,05^{*}$ \\
\hline \multirow[t]{2}{*}{ Cigarrilhas } & $\mathbf{1}^{\mathbf{o}}$ & 257 & 76,3 & 5 & 1,5 & 73 & 21,7 & $X^{2}=4,50$ \\
\hline & $6^{0}$ & 72 & 86,1 & 0 & 0 & 11 & 13,3 & $\mathrm{p}=0,11$ \\
\hline \multirow[t]{2}{*}{ Cigarros de bali/cravo } & $1^{\circ}$ & 251 & 74,4 & 4 & 1,2 & 80 & 23,7 & $X^{2}=3,95$ \\
\hline & $6^{0}$ & 69 & 83,1 & 2 & 2,4 & 12 & 14,5 & $\mathrm{p}=0,13$ \\
\hline \multirow[t]{2}{*}{ Cigarros de palha } & $\mathbf{1}^{\mathbf{o}}$ & 276 & 81,9 & 5 & 1,5 & 53 & 15,7 & $X^{2}=8,41$ \\
\hline & $6^{0}$ & 79 & 95,2 & 0 & 0 & 4 & 4,8 & $\mathrm{p}=0,02 *$ \\
\hline \multirow[t]{2}{*}{ Rapé } & $1^{\circ}$ & 256 & 75,9 & 4 & 1,2 & 75 & 22,3 & $X^{2}=2,93$ \\
\hline & $6^{0}$ & 65 & 78,3 & 3 & 3,6 & 15 & 18,1 & $\mathrm{p}=0,23$ \\
\hline \multirow[t]{2}{*}{ Cigarro eletrônico } & $\mathbf{1}^{\mathbf{o}}$ & 207 & 61,4 & 36 & 10,7 & 92 & 27,3 & $X^{2}=3,50$ \\
\hline & $6^{0}$ & 60 & 72,3 & 5 & 6,0 & 18 & 21,7 & $\mathrm{p}=0,17$ \\
\hline \multirow[t]{2}{*}{ Fumo de mascar } & $1^{0}$ & 249 & 73,4 & 12 & 3,6 & 74 & 21,9 & $X^{2}=2,51$ \\
\hline & $6^{0}$ & 67 & 80,7 & 4 & 4,8 & 12 & 14,5 & $\mathrm{p}=0,28$ \\
\hline
\end{tabular}

Os grupos não apresentaram diferenças significativas em relação a maioria dos produtos de tabaco. No entanto, houve diferença significativa entre o conhecimento do potencial de dependência do narguilé, charuto e cigarro de palha. A partir a correção de Bonferroni, foi possível identificar onde essas diferenças estavam, no caso do narguilé alunos do $1^{\circ}$ ano 
consideram mais frequentemente que este produto não causa dependência ( $p=0,007)$; já alunos do $6^{\circ}$ ano consideram que pode causar dependência.

O charuto foi considerado pelos estudantes do $6^{\circ}$ ano um produto que causa dependência $(\mathrm{p}=0,05)$. Já o cigarro de palha gerou mais dúvida nos alunos do $1^{\circ}$ ano e foi considerado pelos alunos do $6^{\circ}$ ano um produto que pode causar dependência $(\mathrm{p}=0,02)$.

Na tabela 19, observou-se o treinamento recebido e conduta em atendimentos realizados pelos alunos do $6^{\circ}$ ano de Medicina. 
Tabela 19- Treinamento recebido e conduta em atendimentos realizados pelos estudantes do $6^{\circ}$ ano de Medicina $(\mathrm{N}=83)$

\begin{tabular}{|c|c|c|c|c|c|c|c|c|c|c|c|c|c|}
\hline & \multicolumn{4}{|c|}{ FMRP } & \multicolumn{4}{|c|}{ CBM } & \multicolumn{4}{|c|}{ UNAERP } & \multirow[t]{3}{*}{ Estatística } \\
\hline & \multicolumn{2}{|c|}{ Sim } & \multicolumn{2}{|c|}{ Não } & \multicolumn{2}{|c|}{ Sim } & \multicolumn{2}{|c|}{ Não } & \multicolumn{2}{|c|}{ Sim } & \multicolumn{2}{|c|}{ Não } & \\
\hline & $\mathbf{N}$ & $\%$ & $\mathbf{N}$ & $\%$ & $\mathbf{N}$ & $\%$ & $\mathbf{N}$ & $\%$ & $\mathbf{N}$ & $\%$ & $\mathbf{N}$ & $\%$ & \\
\hline Aula perigos do cigarro para a saúde (A) $^{(\mathrm{A})}$ & 17 & 85,0 & 0 & 0 & 19 & 86,9 & 1 & 4,3 & 30 & 75,0 & 7 & 17,5 & $\begin{array}{l}X^{2}=6,20 \\
p=0,19\end{array}$ \\
\hline Treinamento para avaliar e tratar tabagismo $^{(\mathrm{A})}$ & 13 & 65,0 & 5 & 25,0 & 18 & 78,3 & 3 & 13,0 & 30 & 75,0 & 8 & 20,0 & $\begin{array}{l}X^{2}=1,65 \\
p=0,81\end{array}$ \\
\hline Pergunta para o paciente sobre tabagismo ${ }^{(\mathrm{B})}$ & 16 & 80,0 & 0 & 0 & 21 & 91,3 & 0 & 0 & 33 & 82,5 & 2 & 5,0 & $\begin{array}{l}X^{2}=3,41 \\
p=0,49\end{array}$ \\
\hline $\begin{array}{l}\text { Discute o assunto e orienta sobre cessação com } \\
\text { tabagistas }^{(\mathbf{B})}\end{array}$ & 10 & 50,0 & 0 & 0 & 13 & 56,5 & 1 & 4,3 & 25 & 62,5 & 1 & 2,5 & $\begin{array}{l}X^{2}=1,97 \\
p=0,81\end{array}$ \\
\hline Sente-se confiante para aconselhar sobre cessação & 16 & 80,0 & 4 & 20,0 & 22 & 95,7 & 1 & 4,3 & 36 & 90,0 & 4 & 10,0 & $\begin{array}{l}X^{2}=2,77 \\
p=0,29\end{array}$ \\
\hline $\begin{array}{l}\text { Capacitação para prescrição de tratamento farmacológico } \\
\text { para cessação }\end{array}$ & 18 & 90,0 & 2 & 10,0 & 15 & 65,2 & 8 & 34,8 & 29 & 72,5 & 12 & 30,0 & $\begin{array}{l}X^{2}=3,86 \\
p=0,15\end{array}$ \\
\hline
\end{tabular}

$\mathrm{N}=$ frequência, \%= percentual, $(\mathrm{A})=$ variável "não sei" não foi inserida na tabela, $(\mathrm{B})=$ variável "sim, mas apenas em alguns casos" não foi inserida na tabela, FMRP=Faculdade de Medicina de Ribeirão Preto, $\mathrm{CBM}=$ Centro Universitário Barão de Mauá, UNAERP=Universidade de Ribeirão Preto 
Para esta análise comparou-se grupos das diferentes universidades participantes do estudo. Não houve diferença significativa entre os grupos quanto ao treinamento recebido e a maneira como os alunos participantes da pesquisa abordavam seus pacientes. Pode-se observar que os alunos tiveram aulas sobre os malefícios e perigos do tabagismo.

A maioria considerou ter recebido treinamento para avaliar e tratar o tabagismo e relatou perguntar e discutir com seus pacientes sobre tabagismo e orientação para cessação. Revelaram sentir-se confiantes para aconselhamento quanto à cessação e capacitados para a prescrição de tratamento farmacológico para este fim.

\section{DISCUSSÃO}

Este estudo investigou estudantes de Medicina do $1^{\circ}$ e $6^{\circ}$ ano para verificar prevalência e uso de produtos de tabaco, comparado com álcool e outras drogas, comportamentos e atitudes em relação ao tabagismo, à percepção de risco a respeito dos diversos tipos de tabaco e o grau de conhecimento técnico sobre os aspectos gerais do tabagismo e de seu tratamento.

O presente estudo obteve um percentual de resposta de 48,9\%. No que diz respeito a este percentual, em relação aos alunos do $1^{\circ}$ ano obteve-se uma taxa de resposta de $66,1 \%$. Já no $6^{\circ}$ ano esse percentual foi de $23,8 \%$. Essa taxa de resposta pode ser atribuída ao fato do $6^{\circ}$ ano estar em estágio clínico, com maior número de atividades. Resultados semelhantes foram encontrados em um estudo nacional relacionado ao tema, que obteve o percentual de resposta de 62\% (MARTINS et al., 2017). Em estudos internacionais, na Arábia Saudita, um estudo obteve o percentual de resposta de 44,9\% (ALMUTAIRI, 2014); nos Estados Unidos um estudo com estudantes de Medicina obteve taxa de resposta de 50\% (SPRINGER et al., 2008) e um estudo multicêntrico obteve um como taxa de resposta 38,7\% nos Estados Unidos e 36,9\% na Itália (ARMSTRONG et al., 2017), em um estudo no Canadá a taxa de resposta tanto dos alunos do $1^{\circ}$ ano quanto do $6^{\circ}$ ano foi semelhante ao presente estudo. Já no estudo de Jirad e Al-Shehri (2014), realizado na Arábia Saudita, a taxa de resposta foi de $89 \%$.

\subsection{Caracterização sociodemografica da amostra}

Os estudantes que compuseram a amostra eram na maioria, do sexo feminino, com idade entre 20 e 25 anos. Dados semelhantes foram encontrados em outros estudos 
brasileiros (BOTELHO, SILVA E MELO, 2011; PINHEIRO et al., 2017; DA SILVA et al., 2017) e em estudos internacionais (SIEMIŃSKA et al., 2009; SPRINGER et al., 2008; VANDERHOEK et al., 2013; ALSHAMMARI et al., 2015; CHIDIAC et al.,2016; BOOPATHIRAJAN e MUTHUNARAYANAN, 2017). Verificou-se resultados diferentes em 2 estudos da Arábia Saudita, no que diz respeito a prevalência do sexo feminino, em um deles a prevalência da amostra era do sexo masculino (ALMUTAIRI, 2014); em outro, duas faculdades de Medicina eram apenas para homens e na outra faculdade apenas 16\% eram mulheres (JIRAD e AL-SHEHRI, 2014).

\subsection{Uso de tabaco - geral (substâncias psicoativas)}

Observou-se, nesse estudo, que não houve diferença significativa entre os grupos no que se refere à prevalência de tabagismo. $\mathrm{O} 1^{\circ}$ ano teve uma prevalência de $6,3 \%$, que pode ser explicada pela idade da amostra, esses alunos estão entrando na vida adulta e em fase de experimentação, além disso, houve uma queda no número de fumantes no Brasil. Esses resultados vão em direção a revisão sistemática sobre a prevalência e consumo de álcool e tabaco entre adolescentes de 10 a 19 anos, mostrou uma prevalência média de 9\% de fumantes (BARBOSA FILHO, CAMPOS e LOPES, 2012). No ERICA (Estudo de Riscos Cardiovasculares em Adolescentes) a prevalência média foi de 5,7\% (FIGUEIREDO et al., 2015). Já o $6^{\circ}$ ano apresentou uma prevalência de tabagismo de 16,9\%; esses alunos estão inseridos há mais tempo no ambiente universitário, que pode ser um facilitador para o consumo do tabaco e já passaram da fase da experimentação, resultados semelhantes foram encontrados no estudo de Da Silva et al., (2017) a prevalência de uso de tabaco geral foi de 19,3\%. A prevalência de fumantes adultos no Brasil atualmente é de 16,6\% (TOBACCO ATLAS, 2017) e no mundo 21,0\% (WHO, 2017). Outros estudos com estudantes de Medicina apresentaram prevalência de tabagismo entre 5,3\% a 32,4\% (KUSMA et al., 2010; BOTELHO, SILVA e MELO,2011; ROSA et al., 2014; JRADI e AL-SHEHRI, 2014; RONCERO, 2015; SALGADO et al., 2017; ZHOU et al., 2016; KHUBAIB et al., 2016; MARTINS et al., 2014), esta variação pode estar relacionada aos países em que os estudos foram realizados, bem como anos em que os estudos foram realizados, sendo que a maior prevalência foi de um estudo alemão realizado em 2010 e a menor prevalência de tabagismo foi de um estudo realizado no Brasil no ano de 2014. 
No que diz respeito à experimentação de cigarro comum, alunos do $6^{\circ}$ ano experimentaram com maior frequência do que alunos do $1^{\circ}$ ano e o fizeram mais velhos. A taxa de experimentação variou de $35,6 \%$ ( $1^{\circ}$ ano) a $56,6 \%$ ( $6^{\circ}$ ano), maior que outros estudos com universitários e estudantes de Medicina (SPRINGER, 2008; VANDERHOEK et al., 2013; PINHEIRO et al., 2017; BOOPATHIRAJAN e MUTHUNARAYANAN, 2017), é sabido que um terço dos jovens que experimenta tabaco torna-se dependente, a amostra estudada apresenta risco de tornar-se dependente e manter o hábito de fumar, desse forma, é importante introduzir o ensino sobre prevenção, dependência de tabaco e cessação, já no início do curso de Medicina e mantêlo durante toda a graduação.

A média de idade para o início do consumo do tabaco foi de 17 anos $(\mathrm{DP}=1,9)$ para o $1^{\circ}$ ano e 18 anos $(\mathrm{DP}=3,4)$ para o $6^{\circ}$ ano, sem diferença significativa. Os estudantes de Medicina experimentaram tabaco próximo ao seu ingresso à universidade (LOPES et al., 2014; ROSA et al., 2014). De acordo com o INCA (2011) a iniciação precoce do consumo de tabaco é um importante fator prognóstico para o adoecimento e morte prematura, podendo potencializar os riscos à saúde e apesar do nível de escolaridade influenciar a idade de experimentação ou seja, quanto mais anos de estudo maior a tendência de experimentar cigarros mais tarde, tornando a escolaridade um valioso fator de proteção, verificou-se, no presente estudo, que os alunos do $6^{\circ}$ ano tiveram um alto índice de experimentação.

Em conformidade com a literatura, o uso de álcool e outras drogas foi considerado pela amostra, um facilitador para o consumo de tabaco (CUNHA E BIZZARO, 2011; RAMIS et al., 2012; SUTFIN et al., 2013; BADDINI-MARTINEZ et al., 2014; ROSA et al., 2014; LOPES et al., 2015; PINHEIRO et al., 2017).

Em relação ao uso futuro de tabaco, os alunos do $6^{\circ}$ ano acreditavam mais frequentemente que não usariam tabaco nos próximos 12 meses $(70,8 \%)$ ou 5 anos $(72,3 \%)$. Esse fato pode ser explicado pelo fato de alunos ingressantes estarem mais expostos à festas e locais em que o consumo de tabaco e outras drogas é intensificado, por estarem no fim da faculdade e considerarem médicos, modelos para pacientes e público em geral.

A curiosidade e a influência de amigos foram apontadas pelos estudantes entrevistados como principais motivos para experimentar cigarros. Esses dados vão em direção ao estudo de Rosa et al., (2009). Outro motivo apontado para a iniciação do consumo de cigarro comum foi o alívio de tensões, dado que está em concordância com 
a literatura (SIEMIŃSKA et al., 2009; CHIDIACH, KANSO e TALIF, 2016; KHUBAIB et al., 2016). O uso experimental de substâncias como o tabaco, pode levar ao uso abusivo e até a dependência na vida adulta. Destaca-se que a falta de conhecimento quanto aos prejuízos à saúde não foi considerada pela amostra do presente estudo um motivo para fumar. Como se trata de futuros profissionais da área da saúde, campanhas de prevenção ao consumo/experimentação do tabaco são de grande valia, entretanto, precisam ser elaboradas para atingir o público jovem. Além de campanhas, estudos significativos que possam identificar detalhadamente o padrão de uso do tabaco, os níveis de dependência e a própria percepção de risco por parte dos estudantes seriam muito importantes.

No presente estudo, os principais motivos apontados para fumar atualmente, foram os seguintes: o fato de considerarem esta prática um hábito relaxante assim como no estudo de Rosa et al. (2009) e fumar apenas quando ingere álcool, dado que está em conformidade com a literatura (LOPES et al., 2014; RONCERO et al., 2015) principalmente para os estudantes do $6^{\circ}$ ano. Alunos do $6^{\circ}$ ano, contudo, já tiveram treinamento referente aos prejuízos do uso de tabaco e acabam por desconsidera-los em seu uso ocasional. Dessa forma, é fundamental que campanhas de prevenção e conscientização abordem o uso de álcool e tabaco em conjunto, na tentativa de reduzir a morbidade futura decorrente do uso dessas substâncias. Há um alto índice de alunos do $1^{\circ}$ ano que consideram não fazer uso do cigarro com frequência, ou seja, por não reconhecerem que têm o hábito do fumo, continuam fumando.

A maioria dos alunos que fumam não sabe se quer parar de fumar. Esse dado é divergente dos resultados do Vigescola, no Espírito Santo, em que a maioria dos alunos que fumavam relataram desejar para de fumar, ou de dados de estudos nos Estados Unidos (KUSMA et al., 2010; HATSUKAMI et al., 2016) e da Índia (BOOPATHIRAJAN e MUTHUNARAYANAN, 2016). É possível que essa dúvida quanto a parar de fumar esteja relacionada ao fato dos alunos considerarem que não fumam com frequência, por consequência, não se consideram fumantes ou dependentes de tabaco.

As principais substâncias utilizadas (álcool e maconha) pelos alunos participantes desse estudo estão em concordância com os achados da revisão da literatura realizada por Roncero et al. (2015). Verifica-se um alto consumo de álcool pela amostra, inclusive diariamente; $41,5 \%$ dos alunos no $1^{\circ}$ ano e 38,6\% relataram fazer uso de álcool semanalmente, o álcool é uma substancia que frequentemente está presente na vida dos universitários (PADUANI et al., 2008; CARNEIRO et al., 2012; RAMIS et al., 2012) e muitas vezes é utilizado de forma exagerada. No que diz respeito ao uso de outras 
substâncias, uma porcentagem pequena dos estudantes participantes do presente estudo fez uso de uma a duas vezes de cocaína/crack, anfetaminas, hipnóticos e sedativos, alucinógenos e opioides, sendo os inalantes os mais experimentados.

\subsection{Uso específico de produtos de tabaco}

No presente estudo verificou-se que o cigarro comum não era o principal produto usado pelos estudantes de Medicina. Atualmente, produtos como Narguilé têm ganhado preferência entre os universitários (VANDERHOEK et al., 2013). A propagação do uso de outras formas de tabaco pode estar relacionada ao sucesso de programas de prevenção e cessação ao tabagismo, com foco principalmente no cigarro comum, fazendo com que os indivíduos suscetíveis ao uso de tabaco migrassem para outras formas de tabaco (MARTINS et al, 2014). O Narguilé foi o produto com maior prevalência de consumo no presente estudo, dado que está em concordância com os resultados obtidos no levantamento do Vigescola (SZLO et al., 2011) e PETab (INCA, 2011). Obteve-se um resultado diferente em um estudo nos Estados Unidos, (ZHOU et al., 2016) no qual a maconha foi o produto utilizado com maior prevalência.

Neste estudo pode-se observar que o cigarro de palha foi mais consumido que o cigarro comum num período de 30 dias. Produtos como cachimbos, charutos, cigarros indianos, cigarros de cravo ou bali não foram utilizados semanalmente pelos estudantes de Medicina.

Quanto ao uso de produtos de tabaco sem fumaça (rapé, fumo de mascar e snus), a maioria dos estudantes alegaram nunca ter experimentado esse tipo de produto. Este resultado é divergente de alguns estudos anteriores (MARTINS et al. 2014; LATIMER, 2014; ZHOU et al., 2015; BOOPATHIRAJAN e MUTHUNARAYANAN, 2016), mas mostra-se na mesma direção dos resultados do PETab 2008 (INCA, 2011). No estudo de Martins (2014) realizado com alunos de Medicina, o uso dos produtos de tabaco sem fumaça está na mesma pergunta que inclui o uso de cachimbo, cigarrilhas e charutos, comprometendo os resultados no que diz respeito apenas ao rapé, snus e fumo de mascar. Deve-se considerar, ainda, que os produtos de tabaco sem fumaça não são difundidos pela mídia nacional.

Os estudantes pesquisados fizeram mais uso ocasional dos produtos de tabaco do que uso diário ou semanal. Sabe-se, contudo, que não há um nível seguro de consumo de tabaco. Estudantes de Medicina Argentinos consideraram que o fumo ocasional não é 
nocivo à saúde (SALGADO et al., 2016). Em seu estudo Inoue-Choi (2018) aponta que fumantes ocasionais têm mais risco de desenvolverem doenças relacionadas ao tabagismo do que não fumantes.

Verificou-se que houve uma redução do consumo de cigarros para ambos os grupos; entretanto, o uso ocasional de cigarro comum foi mais frequente entre os alunos do $6^{\circ}$ ano, e o uso de cigarro eletrônico teve uma baixa prevalência.

A idade média de início de uso diário de produtos de tabaco, tanto para os estudantes do $1^{\circ}$ ano quanto para os do $6^{\circ}$ ano de Medicina foi 19 anos, período em que estes alunos estavam tentando entrar na universidade ou passando pela adaptação da entrada, o que sugere maior nível de estresse.

No que diz respeito à cessação, foi mais frequente entre alunos do $6^{\circ}$ ano e em relação ao cigarro comum. Não obstante, a cessação do uso de narguilé foi maior no $1^{\circ}$ ano e em proporções um pouco menores do que no estudo de Boopathirajan e Muthunarayanan (2016). O narguilé tem substituído o uso de cigarros e outros produtos de tabaco e é tido como a tendência do tabagismo no século XXI. Os aditivos químicos utilizados para alterar o sabor e reduzir a irritação causada pelo fumo neste produto podem dificultar a cessação.

\subsection{Uso do tabaco no curso de Medicina}

Observou-se com maior frequência que alunos do $6^{\circ}$ ano experimentaram produtos do tabaco mais tardiamente que os alunos do $1^{\circ}$ ano; e que o fizeram principalmente após o ingresso na faculdade. O ambiente universitário facilita a exposição dos jovens a esse tipo de substâncias e à aquisição de hábitos que podem se manter na vida profissional (PINHEIRO et al, 2017). Na revisão de Roncero et al. (2015) verificou-se que o uso de tabaco se intensifica com a idade. Esse fator nos leva a repetir sobre a necessidade de campanhas e programas relacionados ao tabaco e ao seu risco para o ser humano, especialmente para os jovens da área de saúde, futuros médicos.

\subsection{Exposição ambiental}

Alunos do $1^{\circ}$ ano relataram com maior frequência terem parentes fumantes. Os estudantes que participaram da pesquisa declararam ter amigos tabagistas. Estudos mostram que jovens com parentes e amigos fumantes tendem a experimentar tabaco e até 
tornar-se tabagista (CHIDIACH, KANSO e TALIF, 2016; BOOPATHIRAJAN e MUTHUNARAYANAN, 2016). A exposição ao fumo pelos estudantes pesquisados acontecia principalmente na faculdade e de maneira semanal. A taxa de exposição foi maior que a encontrada no estudo de Martins et al. (2014) e na pesquisa nacional de saúde realizada em 2013. No Brasil, há medidas regulatórias que proibiram o fumo em locais públicos fechados, o que abriu perspectivas promissoras para a redução do tabagismo (MALTA et al., 2015). Porém, o fato de não haver ações voltadas ao antitabagismo e a seus riscos na faculdade de Medicina, e as percepções e atitudes desta amostra de estudantes, que serão abordadas em seguida, tenham contribuído para essa maior taxa de exposição, observada neste estudo.

\subsection{Atitudes e percepção}

Em comparação com os dados obtidos pelo Vigescola na cidade de Florianópolis, os estudantes participantes do presente estudo consideraram difícil deixar de fumar, ao contrário da maioria dos escolares de Florianópolis. No que se refere a situações relacionadas ao contexto social, tanto no presente estudo quanto no Vigescola, a maioria considerou não haver diferença entre fumantes e não fumantes quanto a terem mais ou menos amigos (CORDEIRO, KUPEK e MARTINI, 2010). Todavia, obteve-se no presente estudo uma percepção de que o tabagismo deixa as pessoas mais à vontade para interagir em ambientes sociais. Além deste fato, consideraram fumantes, independentemente do sexo, menos atraentes que não fumantes.

A maioria dos alunos percebe o cigarro como um facilitador para a perda de peso e acredita que fumar causa doenças graves (CORDEIRO, KUPEK e MARTINI, 2010).

Alunos do $6^{\circ}$ ano apresentaram significativamente menor dúvida em relação ao tabagismo ser um preditor de derrame e ataque cardíaco, o que indica maior conhecimento sobre os prejuízos relacionados ao uso do tabaco. O tabagismo está diretamente relacionado a doenças pulmonares como DPOC e câncer de pulmão (VANDERHOEK et al., 2013; RAUPACH et al., 2009).

A percepção de que produtos de tabaco sem fumaça podiam causar doenças graves foi semelhante nos dois grupos. O conhecimento acerca dos prejuízos do tabagismo por futuros médicos pode colaborar para que abordem o assunto com seus pacientes, favorecendo a prevenção e tratamento de complicações provenientes do uso do tabaco. 
No presente estudo, ao comparar cigarro comum com outros produtos de tabaco, o Narguilé foi considerado mais prejudicial com maior frequência, demonstrando ter conhecimento em relação aos prejuízos causados por esse produto, já que em uma sessão de fumo com narguilé (uma hora), o fumante pode inalar de 100 a 200 vezes mais o volume de fumaça que um cigarro. Resultados semelhantes foram encontrados na literatura (CHIDIACH, KANSO e TALIF, 2016). Contudo, outras pesquisas encontraram resultados diferentes, ou seja, os estudantes consideraram o Narguilé menos prejudicial que o cigarro comum (VANDERHOEK et al., 2013; ZHOU et al., 2016).

De modo geral, os estudantes participantes do presente estudo demonstraram ter conhecimento quanto aos prejuízos à saúde provocados pelo uso dos produtos alternativos de tabaco, que foram considerados mais seguros que o cigarro comum.

No estudo de Wackowski e Delnevo (2016) realizado com jovens norteamericanos, os produtos derivados do tabaco foram considerados tão nocivos quanto o cigarro comum, com exceção do cigarro eletrônico, e o Narguilé foi considerado menos nocivo por $24,5 \%$ dos jovens. Fiore, Schroeder e Baker (2014) e o "Statement From Specialists in Nicotine Science and Public Health Policy," (2014), apontam que apesar do uso de qualquer produto de tabaco ser nocivo, os produtos combustíveis trazem maior prejuízo à saúde.

O produto mais consumido pelos alunos do $1^{\circ}$ ano era o cigarro de palha, que foi considerado menos prejudicial que o cigarro comum. Já o $6^{\circ}$ ano o considerou mais prejudicial que o cigarro comum. $\mathrm{O}$ cigarro de palha oferece os mesmos riscos para o fumante: dependência bioquímica, psicológica, doenças pulmonares e o aumento da pressão arterial e pode liberar maior quantidade de monóxido de carbono por cigarro. Subestimar os prejuízos do tabagismo pode ter um impacto negativo nos estudantes de Medicina quanto aos esforços para realizar intervenções com pacientes tabagistas no futuro, trazendo prejuízos à promoção de cessação.

A percepção de risco tem grande impacto no comportamento humano e favorece a formação de base para intervenções na saúde pública (ADKINSON et al, 2015). O fato dos alunos ingressantes considerarem esse produto menos nocivo pode potencializar o uso do mesmo.

O mesmo acontece no que diz respeito a cigarros de baixo teor de Alcatrão e Nicotina (cigarros light). Alunos do $1^{\circ}$ ano têm uma percepção de que são menos nocivos. De acordo com Leas et al. (2016) os termos light ou baixo teor, criaram uma percepção equivocada de que esses produtos eram menos nocivos; $8 \%$ dos fumantes 
entrevistados que usavam esse tipo de produto, consideraram a marca que fumavam menos nociva que outras marcas. Já os alunos do $6^{\circ}$ ano apresentaram maior conhecimento acerca do prejuízo causado por cigarros de baixo teor.

O cigarro eletrônico foi um produto utilizado principalmente por alunos do $6^{\circ}$ ano e foi considerado igualmente prejudicial ao cigarro comum.

A falta de informações dos profissionais de saúde quanto à utilização e riscos desse dispositivo podem contribuir para percepções distorcidas a seu respeito (SHEERAN et al., 2013). A implementação e eficácia de campanhas de prevenção do tabagismo são diretamente influenciadas pela percepção de risco individual, e a banalização do risco pode afetar negativamente o sucesso dessas campanhas.

Alunos do $6^{\circ}$ ano demonstraram ter mais conhecimento relacionado ao fumo passivo, do que os alunos do $1^{\circ}$. ano, considerando-o prejudicial e causador de doenças cardiovasculares e câncer, resultados semelhantes foram encontrados na literatura (JRADI e AL-SHEHRI, 2014). Esse conhecimento pode facilitar tomadas de decisões adequadas quanto à orientação e atendimento de seus pacientes. Fumar, mesmo que por um período curto de tempo, não foi considerado seguro. A maioria dos alunos relatou sair de perto de alguém que estivesse fumando ao seu lado. Destaca-se que não há um nível seguro de exposição ao tabaco, ambientes livres de tabaco diminuem a possibilidade de jovens tornarem-se tabagistas (WHO, 2017).

\subsection{Conhecimento médico}

Em concordância com estudos precedentes (BOTELHO, SILVA e MELO, 2011), a nicotina foi apontada como a substância que causa dependência por ambos os grupos. Foi considerada tão viciante quanto a cocaína pela maioria dos estudantes do $6^{\circ}$ ano (SIEMIŃSKA et al., 2009; JRADI e AL-SHEHRI, 2014) e considerada a substância responsável pelas doenças coronárias pelos dois grupos (RAUPACH et al., 2009; GRASSI et al., 2012).

O grupo do $1^{\circ}$ ano considerou fumantes as pessoas que faziam uso do tabaco diariamente; essa percepção pode ter influenciado no que diz respeito a estudantes que fazem uso ocasional do cigarro, não se perceberem fumantes. Já o grupo do $6^{\circ}$ ano, não relacionou o status de fumante ao fumo diário, possivelmente por ter maior conhecimento acerca do tabagismo e potencial de dependência da nicotina. 
Alunos do $1^{\circ}$ ano demonstraram não saber a prevalência de tabagistas no Brasil; já os alunos do $6^{\circ}$ ano a estimaram corretamente. Em outros países, esse conhecimento quanto à prevalência de fumantes no país é variado. No estudo de Springer et al. (2008), dois terços dos alunos estimaram corretamente; no estudo de Grassi et al. (2012) essa prevalência foi superestimada.

A força de vontade foi considerada muito efetiva para a cessação do tabagismo pela maioria dos alunos participantes da pesquisa, mais efetiva que o tratamento de reposição de nicotina (TRN), dado este que vai em direção ao estudo de Kusma et al. (2010). Em alguns estudos, contudo, foi considerada ineficaz (GRASSI et al., 2012; VANDERHOEK et al., 2013).

Considera-se que a força de vontade é de grande valia e o primeiro passo para a cessação do tabagismo, no entanto, medicamentos e tratamentos com reposição de nicotina e acompanhamento psicológico são fundamentais e tem papéis bem definidos nesse processo.

Em relação à percepção dos alunos de ambos os grupos, foram encontrados neste estudo, resultados semelhantes ao estudo de Grassi et al. (2012) quanto à pouca efetividade da acupuntura e à eficácia de material de auto ajuda. Já o aconselhamento médico foi considerado efetivo pelos dois grupos em conformidade com a literatura (GRASSI et al., 2012; DA SILVA et al., 2017; MARTINS et al., 2017).

A partir dos resultados, verificou-se que há pouco conhecimento dos alunos do $1^{\circ}$ ano, quanto à efetividade da terapia de reposição de nicotina e de uso de fármacos como a Vareniclina e Bupropiona para a cessação do tabagismo, assim como no estudo de Da Silva et al. (2017). Este dado pode ser explicado pelo fato de os alunos do $1^{\circ}$ ano ainda não terem recebido treinamento formal quanto ao tratamento do tabagismo. Os alunos do $6^{\circ}$ ano demonstraram ter maior conhecimento quanto a efetividade dos fármacos. No estudo de Springer et al. (2008), os alunos demonstraram ter maior conhecimento quanto a TRN e fármacos. Em outros estudos brasileiros, verificou-se que os estudantes apresentaram ter mais conhecimento quanto a TRN e outros tipos de terapias para cessação do tabagismo (BOTELHO, SILVA E MELO, 2011; MARTINS et al., 2017). Estudantes de Medicina europeus consideraram a efetividade da força de vontade semelhante ao aconselhamento médico (RAUPACH et al., 2009).

O tabagismo deve ser considerado uma doença crônica. As farmacoterapias para o tratamento da cessação do tabagismo podem aumentar consideravelmente as taxas de abandono. Terapia de reposição de nicotina e uso de Bupropiona são recomendados como 
tratamento de primeira linha no Brasil, Reino Unido e Estados Unidos (REICHERT et al., 2008; HATSUKAMI et al., 2016). É importante que os estudantes de Medicina tenham preparo efetivo quanto ao uso de fármacos e TRN no tratamento do tabagismo, afim de orientar corretamente seus pacientes.

Em conformidade com a literatura, os alunos participantes da pesquisa acreditavam que os profissionais de saúde deveriam aconselhar seus pacientes a parar de fumar (KUSMA et al., 2010; AWOPEJU et al., 2013; LA TORRE et al., 2014; MARTINS et al., 2014; JRADI e AL-SHEHRI, 2014; ALMUTAIRI, 2014; MARTINS et al., 2017; DA SILVA et al., 2017), o que é bastante positivo, pois aqueles que atribuem pouca importância ao aconselhamento médico, podem tender a não fazê-lo quando estiverem atendendo um paciente tabagista.

O papel do médico é fundamental para o controle do tabaco. No presente estudo, a maioria dos estudantes que participou da pesquisa considerou os profissionais de saúde como modelo para pacientes e público em geral, assim como encontrado na literatura (LA TORRE et al., 2011; AWOPEJU et al., 2013; VANDERHOEK et al., 2013; ALMUTAIRI, 2014; JRADI e AL-SHEHRI, 2014; BOOPATHIRAJAN e MUTHUNARAYANAN, 2016; SALGADO et al., 2016; DA SILVA et al., 2017; MARTINS et al., 2017). Em seu estudo, Hatsukami et al. (2016), revelou que o aconselhamento médico pode aumentar a taxa de cessação de 3 a 5 vezes. Os estudantes de Medicina do presente estudo, principalmente do $6^{\circ}$ ano, relataram acreditar que o aconselhamento médico facilita a cessação (SPRINGER et al, 2008; SIEMIŃSKA et al., 2009; LA TORRE et al., 2014; MARTINS et al., 2014; BOOPATHIRAJAN e MUTHUNARAYANAN, 2016; ZHOU et al., 2016; DA SILVA et al., 2017; MARTINS et al., 2017). Todavia, os alunos do primeiro ano apresentaram dúvidas quanto a isso.

A maioria dos participantes da pesquisa respondeu que os profissionais de saúde deveriam aconselhar seus pacientes a evitar outras formas de tabaco, em conformidade com o encontrado na literatura (LA TORRE et al., 2011; 2014; DA SILVA et al., 2017; MARTINS et al., 2017). Esses dados confirmam o quanto é importante a inserção do treinamento para a cessação do tabagismo no currículo das faculdades de Medicina.

Profissionais de saúde fumantes foram considerados menos propensos a aconselhar seus pacientes, tanto pelos alunos do $1^{\circ}$ quanto do $6^{\circ}$ ano, dado que também está de acordo com o que diz a literatura (ALMUTAIRI, 2014; BOOPATHIRAJAN e MUTHUNARAYANAN, 2016; ARSMSTRONG et al., 2017; MARTINS et al., 2017). 
Os alunos estavam conscientes quanto aos malefícios do tabaco na gestação, assim como demonstrado em estudos prévios (SIEMIŃSKA et al., 2009; VANDERHOEK et al., 2013). Apresentaram dúvidas quanto aos prejuízos causados por alguns produtos, principalmente pelo cigarro eletrônico $(8,4 \%)$. Desde sua introdução no mercado, o cigarro eletrônico vem ganhando popularidade (GRANA, BENOWITZ e STATON, 2014). Informações quanto a sua segurança são escassas e inconsistentes; sua regulamentação está em andamento em muitos países (PEPPER e BREWER, 2014). Deste modo, é natural que os alunos tenham dúvidas quanto aos prejuízos causados por este dispositivo.

Os grupos apresentaram algumas diferenças significativas quanto à percepção de risco. Alunos do $1^{\mathrm{o}}$ ano apresentaram mais frequentemente dúvidas quanto aos malefícios dos produtos do tabaco em relação ao aumento da probabilidade de causar algum tipo de câncer. Verifica-se que os estudantes de Medicina do $1^{\circ}$ ano conhecem pouco os produtos de tabaco e seus efeitos, assim como visto no estudo de Vanderhoek et al. (2013).

Os grupos apresentaram diferenças significativas também quanto ao conhecimento dos malefícios de alguns produtos de tabaco. Os estudantes do $1^{\circ}$ ano apresentaram dúvidas com mais frequência em relação a todos os produtos que foram questionados. Esse resultado pode ser explicado pelo fato desses estudantes ainda não terem recebido treinamento formal quanto a esse conhecimento. Todavia, a crença de que alguns produtos não ameaçam a vida ou não são nocivos à saúde pode prejudicar a promoção à cessação do tabagismo (KUSMA et al., 2010). É de grande valia que futuros médicos tenham conhecimento quanto ao tabagismo e doenças relacionadas para que possam promover a prevenção e cessação.

De modo geral, alunos do $1^{\circ}$ ano não tinham conhecimento quanto a produtos derivados do tabaco conterem nicotina; no entanto, os alunos do $6^{\circ}$ ano demonstraram ter conhecimento e uma percepção correta desses produtos ao considerarem que a maioria continha nicotina. A nicotina é o principal agente responsável pelo desenvolvimento da dependência, está presente na folha do tabaco, e em produtos derivados do mesmo (ROOSEMBERG, 2003).

Ambos os grupos consideraram que produtos derivados de tabaco causam dependência. Não obstante, o Narguilé foi considerado pelos estudantes de Medicina do $1^{\mathrm{o}}$ ano um produto que não causa dependência, dados que estão em conformidade com os estudos de Vanderhoek et al. (2013). 
A maioria dos alunos do $6^{\circ}$ ano considerou ter recebido treinamento para avaliar e tratar o tabagismo, o que segue na direção do encontrado na literatura (SPRINGER et al., 2008; SIEMIŃSKA et al., 2009; LA TORRE et al., 2011; AWOPEJU et al., 2013; JRADI e AL-SHEHRI, 2014; ALMUTAIRI, 2014; BOOPATHIRAJAN e MUTHUNARAYANAN, 2016; ARSMSTRONG et al., 2017). E, ao contrário da hipótese inicial deste estudo, de que não praticariam a orientação à cessação com frequência, relataram perguntar e discutir com seus pacientes sobre tabagismo e dar orientação para cessação, como também encontraram alguns autores em estudos semelhantes (MATTOS et al., 2009; BOOPATHIRAJAN e MUTHUNARAYANAN, 2016; ARMSTRONG et al., 2017). Esse dado pode ser explicado pelo fato dos alunos do $6^{\circ}$. ano terem recebido treinamento formal quanto ao tabagismo, acreditarem que a orientação médica faz diferença para o tratamento dessa doença e que devem abordar esse tema com pacientes, além de apresentarem conhecimento em relação a doenças tabacorelacionadas. Revelaram sentir-se confiantes para aconselhamento quanto à cessação e capacitados para a prescrição de tratamento farmacológico para este fim, conforme a literatura (SIEMIŃSKA et al., 2009; ZHOU et al., 2016). Resultados contraditórios foram obtidos em estudos com estudantes de Medicina dos Estados Unidos, Canadá e Líbano (SPRINGER et al., 2008; VANDERHOEK et al., 2013; CHIDIACH, KANSO e TALIF, 2016), nos quais os alunos declararam sentir-se desconfortáveis e não estarem preparados para fornecer aconselhamento para a cessação do tabagismo.

\subsection{Limitações do estudo}

Algumas limitações do estudo devem ser destacadas e são listadas a seguir.

Trata-se de estudo com amostra de conveniência, em que foram incluídas apenas faculdades de Medicina da cidade de Ribeirão Preto. Os estudantes de Medicina pesquisados não são necessariamente representativos dos estudantes de Medicina do Brasil.

O instrumento utilizado ficou muito extenso, o que pode ter influenciado a recusa em participar do estudo pelos estudantes do $6^{\circ}$ ano.

Em relação à análise estatística, uma amostra de tamanho maior seria ideal, uma vez que se tratou de estudo exploratório, observacional, com dois grupos e muitas variáveis de interesse. A baixa taxa de resposta dos alunos do $6^{\circ}$ ano pode comprometer os resultados, podendo haver diferenças não mensuradas entre os alunos que participaram 
da pesquisa e aqueles que não participaram. Uma amostra maior talvez permitisse evidenciar diferenças significativas mais relevantes entre os grupos.

\section{CONCLUSÃO}

A prevalência de tabagismo encontrada foi semelhante a prevalência de tabagismo no Brasil, o que contradiz a hipótese inicial, entretanto, houve uma prevalência menor em alunos do $1^{\mathrm{o}}$ ano, esta sim, foi abaixo da prevalência de tabagismo nacional. Medidas preventivas como campanhas anti-tabágicas, devem ser realizadas logo nos primeiros anos de faculdade, já que a idade média de experimentação foi de 17,5 anos e os alunos que já estão saindo da faculdade demonstraram estar mais propensos ao uso do tabaco.

Essas medidas devem abordar também os riscos do abuso de álcool e outras substâncias. O consumo de álcool foi elevado e descrito como um facilitador para o uso de tabaco, ou seja, há uma associação entre o uso dessas substâncias.

Apesar das limitações mencionadas, os achados do presente estudo vão ao encontro com o que vem sendo descrito na literatura. Existe concordância dos achados neste estudo quanto à percepção do papel dos profissionais de saúde na cessação do tabagismo, os estudantes os apontaram como modelo para seus pacientes e o público em geral, além de acreditarem que o aconselhamento favorece a cessação e que o médico deve abordar o tabagismo com seus pacientes.

Os achados reforçam a hipótese de que a maioria dos alunos que usavam tabaco faria uso ocasional e de outras formas de tabaco que não o cigarro: a maioria dos estudantes não se via como dependente de tabaco, fazia uso ocasional e utilizava principalmente o Narguilé.

Entre os estudantes entrevistados, havia pouca motivação para o abandono do consumo de produtos do tabaco, apesar dos estudantes acreditarem que esses produtos traziam prejuízo à saúde; os estudantes do $6^{\circ}$ ano acreditavam mais frequentemente que não utilizariam tabaco nos próximos 12 meses.

Verificou-se que os estudantes do $1^{\circ}$ ano participantes da pesquisa, tinham pouco conhecimento quanto ao potencial de dependência dos produtos alternativos de tabaco e da efetividade de métodos para a cessação do tabagismo, contrariando as hipóteses iniciais deste trabalho. Porém, especialmente os alunos do $6^{\circ}$ ano, demonstraram conhecer os riscos do tabagismo e prejuízos à saúde. Apesar desse conhecimento, tanto os alunos 
do $1^{\circ}$ quanto os alunos do $6^{\circ}$ ano minimizam os riscos associados ao uso intermitente e ocasional de tabaco, ou seja, demonstram não acreditar na sua dependência. A falta de conhecimento e percepção de risco distorcida (crenças) quanto ao potencial de dependência dos produtos alternativos de tabaco e riscos do tabagismo, pode levar os alunos a subestimar os prejuízos causados pelo mesmo, além de comprometer seus esforços no futuro quanto a intervenções e promoção à cessação.

A exposição ao fumo passivo ocorria principalmente na universidade, e este foi reconhecido como nocivo.

Os alunos do $6^{\circ}$ ano relataram ter recebido treinamento formal para abordagem do fumante e cessação do tabagismo, sentem-se seguros para aconselhar seus pacientes e o fazem com frequência, diferente da hipótese inicial.

Medidas de prevenção e cessação do tabagismo vêm se mostrando muito eficazes para a redução do uso do tabaco. É importante, além do treinamento formal dos futuros médicos, oferecer auxílio para os alunos fumantes, pois a maioria experimentou tabaco e iniciou seu uso após o ingresso na universidade.

Sabe-se que os médicos têm um papel relevante por serem modelo de saúde para seus pacientes e para a população em geral, o que demanda uma maior responsabilidade social e acadêmica por parte dos estudantes de Medicina, futuros profissionais de saúde. O investimento em ações que trabalhem especialmente as crenças, percepções de risco e atitudes a respeito do cigarro comum e de formas alternativas de tabaco, são necessários para que ocorra uma maior conscientização quanto uso e prejuízos à saúde causados por esses produtos.

\section{REFERÊNCIAS}

Adkison S.E, O'Connor R.J, Bansal-Travers M, Hyland A, Borland R, Yong H.H, Cummings KM, McNeill A, Thrasher JF, Hammond D, Fong GT. (2013).Electronic nicotine delivery systems: international tobacco control four- country survey. American Journal of Preventive Medicine.;44:207-215.

Almutairi, K. M. (2014). Prevalence of Tobacco Use and Exposure to Environmental Tobacco Smoke Among Saudi Medical Students in Riyadh, Saudi Arabia. Jounal Community Health, 39:668-673. 
Akl, E. A., Gaddam, S., Gunukula, S. K., Honeine, R., Jaoude, P. A., \& Irani, J. (2010). The effects of waterpipe tobacco smoking on health outcomes: a systematic review. International Journal of Epidemiology, 39(3), 834-57.

Akl, E. A., Jawad, M., Lam, W. Y., Co, C. N., Obeid, R., \& Irani, J. (2013). Motives, beliefs and attitudes towards waterpipe tobacco smoking: a systematic review. Harm Reduction Journal,10,12.

ANVISA. (2014). Derivados do Tabaco. Retrieved October 31, 2014, from http://portal.anvisa.gov.br/wps/content/Anvisa+Portal/Anvisa/Inicio/Derivados+do+Tab aco

Armstrong, G.W., George, P. F., Veronese,G., Montroni, I., UgoliniG., (2017). Assessment of Tobacco Habits, Attitudes, and Education Among Medical Students in the United States and Italy: A Cross-sectional Survey. Journal of Preventive Medicine e Public Health, 50:177-187.

Awopeju, O. F., Erhabor, G. E., Awosusi, B., Awopeju, O. A, Adewole, O. O., Irabor, I. (2013). Smoking prevalence among health professional students. Annals of Medical and Health Sciences Research , Jul-Sep 2013, Vol 3, Issue 3

Barbosa Filho, V. C., Campos, W. de, \& Lopes, A. da S. (2012). Prevalence of alcohol and tobacco use among Brazilian adolescents: a systematic review. Revista de Saúde Pública, 46(5), 901-17.

Biener, L., McCausland, K., Curry, L., \& Cullen, J. (2011). Prevalence of trial of snus products among adult smokers. American Journal of Public Health, 101(10), 1874-6.

Bonilha, A. G., Ruffino-Netto, A., Sicchieri, M. P., Achcar, J.A., Rodrigues-Junior, A. L., Baddini- Martinez, J. (2014). Correlatos de experimentação e consumo atual de cigarros entre adolescentes. Jornal Brasileiro de Pneumologia. 2014 Nov-Dec; 40(6):63442 .

Botelho, C., Da Silva., AM. P., Melo, C.D., (2011). Tabagismo em universitários de ciências da saúde: prevalência e conhecimento. Jornal Brasileiro de Pneumologia. 2011; 37(3):360-366.

Boopathirajan, R., Muthunarayanan, L. (2017). Awareness, Attitude and Use of Tobacco among Medical Students in Chennai. Journal of Lifestyle Medicine Vol. 7, No. 1, January 2017.

Butler, K. M., Ickes, M.J., Rayens, Mary Kay., Wiggns, A. T., Hahn, E. J., (2016). Polytobacco Use Among College Students. Nicotine \& Tobacco Research, Volume 18, Issue 2, 1 February 2016, Pages 163-169.

Chidiac, A., Tamim, H., Kanso, M., Tfalyli, A., (2016) Smoking among Lebanese medical students: Prevalence and attitudes. Ann Thoracic Medicine, 2016;11:183-90. 
Cordeiro, E. A. K., Kupek, E., Martini, J. G. (2010). Prevalência do tabagismo entre escolares de Florianópolis, SC, Brasil e as contribuições da enfermagem. Revista Brasileira de Enfermagem, Brasília 2010 set-out; 63(5): 706-11.

Da Silva, A.C., Teixeira, E. R., Gonçalvez S.J.C., de Souza M.C.A.(2017). Tabagismo entre estudantes de profissões de saúde: prevalência,conhecimento, atitudes e opiniões. Revista de Saúde. 2017 Jan./Jun.; 08(1): 23-27.

Daudt, A. W., Alberg, A. J., Prola, J. C., Fialho, L., Petracco, A., Wilhelms, A., Estery, C. (1999). A first step incorporating smoking education into a Brazilian medical school curriculum: results of a survey to assess the cigarette smoking knowledge, attitudes, behaviour, and clinical practices of medical students. Journal of Addictive Diseases, 18(1), 19-29.

Eriksen, M., Mackay, J., \& Hoss, H. (2012). The Tobacco Atlas, fourth edition. New York: American Cancer Society, Atlanta, Georgia World Lung Foundation. Retrieved from www.TobaccoAtlas.org

Figueiredo, V. C., Szlo, A. S., Costa, L. C., Kuschnir, MC. C., Silva, T.L.N., Bloch, K. V., Szlo, M. (2016). ERICA: Prevalência de tabagismo em adolescentes brasileiros. Revista Saúde Pública.2016; 50 (supl1):12s.

Giovino, G. A., Mirza, S. A., Samet, J. M., Gupta, P. C., Jarvis, M. J., Bhala, N., Asma, S. (2012). Tobacco use in 3 billion individuals from 16 countries: An analysis of nationally representative cross-sectional household surveys. The Lancet, 380(9842), 668679.

Grana, R., Benowitz, N., Staton, A.G.,(2014). E-cigarettes A scientific review. Contemporary Reviews in Cardiovascular Medicine, 129:1972-1986.

Grassi, M.C., Chiamulera, C., Baraldo, M., Culasso, F., Ferketich, A. K., Raupach, T., Patrono, C., Nencini, P. (2012). Cigarette Smoking Knowledge and Perceptions Among Students in Four Italian Medical Schools. Nicotine \& Tobacco Research, Volume 14, Number 9 (September 2012) 1065-1072.

Hatsukami, D. K., Stead, L. F., Gupta, P. C., (2016). Tobacco Addiction: Diagnosis and Treatment. Lancet. 2008 June 14; 371(9629): 2027-2038. doi:10.1016/S01406736(08)60871-5.

Henrique, I. F. S., De Micheli, D., Lacerda, R. B. de, Lacerda, L. A. de, \& Formigoni, M. L. O. de S. (2004). Validação da versão brasileira do teste de triagem do envolvimento com álcool, cigarro e outras substâncias (ASSIST). Revista Da Associação Médica Brasileira, 50(2), 199-206.

Inoue-Choi, M., Hartge, P., Liao, L. M., Caporaso, N. and Freedman, N. D. (2018), Association between long-term low-intensity cigarette smoking and incidence of smoking-related cancer in the national institutes of health-AARP cohort. Int. J. Cancer, 142: 271-280. doi: 10.1002/ijc.31059 
INPAD - Instituto Nacional de Ciência e Tecnologia para Políticas Públicas do Álcool e Outras Drogas. (2014). Consumo de Tabaco no Brasil. Retrieved October 31, 2014, from http://inpad.org.br/wp-content/uploads/2013/12/Resultados_Preliminares_Tabaco1.pdf

Instituto Nacional de Câncer (2010). Global adult tobacco survey Brazil 2008 / Instituto Nacional de Câncer. - Rio de Janeiro: INCA, 2010.

Instituto Nacional de Câncer (Brasil). Organização Pan-Americana da Saúde. Pesquisa especial de tabagismo - PETab: relatório Brasil / Instituto Nacional de Câncer. Organização Pan-Americana da Saúde. - Rio de Janeiro: INCA, 2011.

Jarrett, T., Blosnich, J., Tworek, C., \& Horn, K. (2012). Hookah use among U.S. college students: results from the National College Health Assessment II. Nicotine \& Tobacco Research : Official Journal of the Society for Research on Nicotine and Tobacco, 14(10), $1145-53$.

Jirad, H., Al-Shehri, A. (2014). Knowledge about tobacco smoking among medical students in Saudi Arabia: Findings from three medical schools. Journal of Epidemiology and Global Health (2014) 4, 269- 276.

Kawakami, M., Nakamura, S., Fumimoto, H., Takizawa, J., \& Michiko, B. (1997). Relation between smoking status of physicians and their enthusiasm to offer smoking cessation advice. Internal Medicine, 36(3), 162-165.

Khubaib M U, Shahid Z Y, Lodhi S K, et al. (July 18, 2016) Prevalence and Associated Factors of Smoking Among Final Year Medical Students: A Multicentric Survey From Pakistan. Cureus 8(7): e701. DOI 10.7759/cureus.701

Kusma, B., Quarcoo, D., Vitzthum, K., Welte, T., Mache, S., Meyer-Falcke, A., Groneberg, D. A., Raupach, T.(2010). Berlins medical student's smoking habits, knowledge about smoking and attitudes toward smoking cessation counseling. Jounal of occupational medicine and toxicology. 5:9

Latimer, L.A, Batanova, M. A, Loukas, A. (2014). Prevalence and Harm Perceptions of Various Tobacco Products Among College Students Nicotine \& Tobacco Research, Volume 16, Issue 5, Pages 519-526.

La Torre, G., Kirch, W., Bes-Rastrollo, M., Ramos, R. M., Czaplicki, M., Gualano, M. R., Boccia, a. (2012). Tobacco use among medical students in Europe: results of a multicentre study using the Global Health Professions Student Survey. Public Health, 126(2), 159-64.

Leas, E. C., Ayers, J.W., Strong, D. R., Pierce, J. P. (2016) Which cigarettes do Americans think are safer? A population-based analysis with wave 1 of the PATH study. Tobacco Control. Published Online First: [14 de Outubro de 2017] doi:10.1136/tobaccocontrol-2016-05333

Lopez-Quintero, C., Pérez de los Cobos, J., Hasin, D. S., Okuda, M., Wang, S., Grant, B. F., Blanco, C. (2011). Probability and predictors of transition from first use to dependence on nicotine, alcohol, cannabis, and cocaine: results of the National 
Epidemiologic Survey on Alcohol and Related Conditions (NESARC). Drug and Alcohol Dependence, 115(1-2), 120-30.

Lopes, F., Cunha, S. M, Zibetti, M., Bizarro., L. (2014). Padrão de consumo e expectativas em relação ao cigarro entre universitários. PSICOLOGIA, SAÚDE \& DOENÇAS, 2014, 15(2), 439-453 EISSN - 2182-8407 Sociedade Portuguesa de Psicologia da Saúde - SPPS - $\quad$ www.sp-ps.com DOI: http://dx.doi.org/10.15309/14psd150209

Madruga, C. S., Laranjeira, R., Caetano, R., Pinsky, I., Zaleski, M., \& Ferri, C. P. (2012). Use of licit and illicit substances among adolescents in Brazil--a national survey. Addictive Behaviors, 37(10), 1171-5.

Malta, D._C., (2015), Andrade, S. C. A. A., Stopa, S. R., Pereira, C. A., Szwarcwald, C. L., Silva Junior, J. B., Resi, A. A. C. (2015). Estilos de vida da população brasileira: resultados da Pesquisa Nacional de Saúde, 2013. Epidemiol. Serv. Saúde [online], Brasília, vol.24, n.2, pp.217-226. ISSN 1679-4974. http://dx.doi.org/10.5123/S1679497420150002000004.

Martins, S. R., Paceli, R. B., Bussacos, M. A., Fernandes, F. L. A., Prado, G. F., Lombardi, E. M. S., Santos, U. P. (2014). Experimentation with and knowledge regarding water-pipe tobacco smoking among medical students at a major university in Brazil. Jornal Brasileiro de Pneumologia, 40(2), 102-110.

Martins, S. R, Paceli, R. B., Bussacos, M. A. Fernandes F. L. A., Prado, G. F., Lombardi, E. M. S., Terra-Filho, M., Santos, U. P. (2017). Medidas eficazes de controle do tabagismo:concordância entre estudantes de Medicina. Jornal Brasileiro de Pneumologia, 43(3):202-207

Mattos, M. H. de O., Silva, L. A. da, \& Franken, R. A. (2009). Tabagismo no currículo da Faculdade de Ciências Médicas da Santa Casa de São Paulo. Revista Brasileira de Educação Médica, 33(1), 33-39.

McMillen, R., Maduka, J., \& Winickoff, J. (2012). Use of emerging tobacco products in the United States. Journal of Environmental and Public Health, 2012, 989474.

Ministério da Saúde (2009). A situação do tabagismo no Brasil: dados dos inquéritos do Sistema Internacional de Vigilância, da Organização Mundial da Saúde, realizados no $\begin{array}{llllll}\text { Brasil, entre } 2002 & \text { e } & 2009 & \text { (p.76). Rio de }\end{array}$ Janeiro.http://bvsms.saude.gov/bvs/controle_cancer

Ministério da Saúde (2017) Secretaria de Vigilância em Saúde, Departamento de Vigilância de Doenças e Agravos não Transmissíveis e Promoção da Saúde). Vigitel Brasil 2016: vigilância de fatores de risco e proteção para doenças crônicas por inquérito telefônico: estimativas sobre frequência e distribuição sociodemográfica de fatores de risco e proteção para doenças crônicas nas capitais dos 26 estados brasileiros e no Distrito Federal em 2016 . Brasília: Ministério da Saúde, 2017. 160p.: il. 
Pepper, J.K, Brewer NT. Electronic nicotine delivery system (electronic cigarette) awareness, use, reactions and beliefs: a systematic review. Tobacco Control 2014;23:375-84

Pinto M, Bardach A, Palacios A, Biz AN, Alcaraz A, Rodríguez B, Augustovski F, Pichon-Riviere (2017). A carga de doença atribuível ao uso do tabaco no Brasil e potencial impacto do aumento de preços por meio de impostos. Documento técnico IECS $N^{\circ}$ 21. Instituto de Efectividad Clínica y Sanitaria, Buenos Aires, Argentina. Maio de 2017. Disponível em: www.iecs.org.ar/tabaco

Pinto, M. T., Pichon-Riviere, A., Bardach,A. (2015). Estimativa da carga do tabagismo no Brasil: mortalidade, morbidade e custos. Cad. Saúde Pública, Rio de Janeiro, 31(6):1283-1297.

Pinheiro, M. A., Torres, L. F., Bezerra, M. S., Cavalcante, R.C., Alencar, R. D., Donato, A, C, Campêlo, C. B. P., Gomes, I. P., Alencar, CH., Cavalcanti, L. P. G. (2017). Álcool e Tabaco entre Estudantes de Medicina no Nordeste Brasileiro. Revista Brasileira de Educação Médica, 41 (2): 231-250.

Ramis, T. R., Mielke, G. I., Habeyche, E. C., Oliz, M. M., Azevedo M. R., Hallal, P. C. (2012). Tabagismo e consumo de álcool em estudantes universitários: prevalência e fatores associados. Revista Brasileira de Epidemiologia 2012; 15(2): 376-85

Raupach, T., Shahab, L., Baetzing, S., Hoffmann, B., Hasenfuss, G., West, R., Andreas, Stefan. (2009). Medical students lack basic knowledge about smoking: Findings from two European medical schools. Nicotine \& Tobacco Research, 2008, 11(1),92-98.

Reichert, J, Araújo, A. J, Gonçalves, C. M. C., Godoy I, Chatkin, J. M., Sales M.P.U, Santos, S. R. P. A. (2008). Diretrizes para cessação do tabagismo - 2008. Jornal Brasileiro de Peneumologia;34(10):845-880

Regan, A. K., Dube, S. R., \& Arrazola, R. (2012). Smokeless and flavored tobacco products in the U.S.: 2009 Styles survey results. American Journal of Preventive Medicine, 42(1), 29-36.

Roncero, C., Egido, A., Rodríguez-Cintas, L., Péres-Pázos, J., Collazos, F., Casas, M., (2015). Substance use among Medical Students: A Literature Review 1988- 2013. Actas Esp Psiquiatria. 2015;43(3):109-21

Rosa, M. I., Caciatori, J. F. F., Panatto, A. R. R., Silva, B. R., Pandini,J. C., Luciana Freitas, B. S., Reis, M. E. F., Souza, S.L., Simões, P. W. T. A. (2014). Uso de tabaco e fatores associados entre alunos de uma universidade de Criciúma (SC). Cad. Saúde Colet., 2014, Rio de Janeiro, 22 (1): 25-31

Rosemberg, José (2003).Nicotina: Droga Universal. São Paulo: SES/Centro de Vigilância Epidemiológica "Prof. Alexandre Vranjac", 2003. 174 p.

Salgado, M. V., Mejía, R. M., Kaplan, C. P., Pérez-Stable, E. J. (2016). Smoking-Related Attitudes and Knowledge Among Medical Students and Recent Graduates in Argentina: A Cross-Sectional Study. Journal of General Internal Medicine, May 2017, Volume 32, Issue 5, pp 549-555 . First online 2016. DOI: 10.1007/s11606-016-3890-0 
Sheeran, P., Harris, P. R., \& Epton, T. (2013, June 3). Does Heightening Risk Appraisals Change People's Intentions and Behavior? A Meta-Analysis of Experimental Studies. Psychological Bulletin Advance online publication. doi: 10.1037/a0033065

Silva C. A. M, Sestelo M. R. (2007). Composição química da fumaça do cigarro. In C. A. de A. Viegas (Ed.), Tabagismo do Diagnóstico à Saúde Pública. São Paulo: Atheneu.

Siemińska, A., Jassem-Bobowicz, J. M., Uherek, M., Wilanowski,T., Nowak, R., Jassem, E. (2009). Medical students' attitudes towards tobacco smoking at the first and sixth year of their studies 2002-2008. Pneumonologia i Alergologia Polska 2009, vol. 77, no 4, pages $371-379$

Smith D R, Leggat P. A. (2007). An international review of tobacco smoking among medical students. Journal of Postgraduate Medicine, 53(1), 55-62.

Smith, D. R., Leggat, P. A. (2007). An international review of tobacco smoking in the medical profession: 1974-2004. BMC Public Health, 7, 115.

Springer, C. M., Tannert Niang, K. M., Matte, T. D., Miller, N., Bassett, M. T., Frieden, T. D. (2008). Do medical students know enough about smoking to help their future patients? Assessment of New York city fourth-year medical students' knowledge of tobacco cessation and treatment for nicotine addiction. Academic Medicine, Vol. 83, No. 10 / October 2008.

Stead, L. F., Buitrago, D., Preciado, N., Sanchez, G., Hartmann-Boyce, J., \& Lancaster, T. (2013). Physician advice for smoking cessation. The Cochrane Database of Systematic Reviews, 5(5), CD000165.

Sutfin, E. L., McCoy, T. P., Berg, C. J., Champion, H., Helme, D. W., O’Brien, M. C., Wolfson, M. (2012). Tobacco Use by College Students: A Comparison of Daily and Nondaily Smokers. Am J Health Behav. 2012 March ; 36(2): 218-229. doi:10.5993/AJHB.36.2.7.

Szklo, A. S., Sampaio, M. M. A., Fernandes, E. M., \& Almeida, L. M. de. (2011). Smoking of non-cigarette tobacco products by students in three Brazilian cities: should we be worried?. Cadernos de Saúde Pública, 27(11), 2271-5.

Tong, E. K., Ong, M. K., Vittinghoff, E., \& Pérez-Stable, E. J. (2006). Nondaily smokers should be asked and advised to quit. American Journal of Preventive Medicine, 30(1), $23-30$.

US Department of Health and Human Services. (2012). Preventing Tobacco Use Among Youth and Young Adults, a report from the Surgeon General (p. 890). Atlanta. Retrieved from http://www.surgeongeneral.gov/library/reports/preventing-youth-tobacco-use/fullreport.pdf

Vanderhoek, A, J, Hammal, F., Chappell, A., Wild, C. T., Raupach, T., Finegan, A. B. (2013). Future physicians and tobacco: an online survey of the habits, beliefs and 
knowledge base of medical students at a Canadian University. Tobacco Induced Diseases 2013, 11:9

Viegas, C. A. de A. (2007). Doenças Tabaco Relacionadas. In Tabagismo do Diagnóstico à Saúde Pública. São Paulo: Atheneu.

Viegas, C. A. de A. (2008). Formas não habituais de uso do tabaco. Jornal Brasileiro de Pneumologia, 34(12), 1069-1073. doi:10.1590/S1806-37132008001200013

WHO ASSIST Working Group. (2002). The Alcohol, Smoking and Substance Involvement Screening Test (ASSIST): development, reliability and feasibility. Addiction (Abingdon, $\quad$ England), 118394.www.who.int/substance_abuse/activities/assist_test/en/

World Health Organization. (2003). WHO FRAMEWORK CONVENTION ON TOBACCO CONTROL (p. 36). Geneva. Retrieved from www.who.int/ftct

World Health Organization. (2015). WHO global report on trends in prevalence of tobacco smoking 2015. ISBN 9789241564922 (NLM classification: WM 290)

WHO report on the global tobacco epidemic, 2017: monitoring tobacco use and prevention policies. Geneva: World Health Organization; (2017). Licence: CC BY-NCSA 3.0 IGO.

Zhou, S., Van Devanter, N., Fenstermaker,M., Cawkwell, P., Weitzman, M. (2016).

A Study of the Use, Knowledge, and Beliefs About Cigarettes and Alternative Tobacco Products Among Students at One U.S. Medical School. Acad Med. 2016 December; 90(12): 1713-1719. doi:10.1097 
ANEXOS 
ANEXO A 

(1) RIBEIRAOO PRETO DA UNIVERSIDADE DE SÃO PAULO

Ribeirão Preto, 03 de fevereiro de 2015

Oficio $n^{\circ} 386 / 2015$

$\mathrm{CEP} / \mathrm{MGV}$

Prezadas Senhoras,

O trabalho intitulado "CIGARRO E OUTRAS FORMAS DE TABACO: INVESTIGAÇÃO DE CONHECIMENTO, ATITUDES E PERCEPÇÃO DE RISCO EM ESTUDANTES DE MEDICINA", foi analisado "AD REFERENDUM" pelo Comitê de Ética em Pesquisa, e enquadrado na categoria: APROVADO, bem como o Termo de Consentimento Livre e Esclarecido, de acordo com o Processo HCRP ${ }^{0}$ $204 / 2015$.

De acordo com Carta Circular $n^{\circ}$ 003/2011/CONEP/CNS, datada de 21/03/2011, o sujeito de pesquisa ou seu representante, quando for o caso, deverá rubricar todas as folhas do Termo de Consentimento Livre e Esclarecido - TCLE - apondo sua assinatura na última do referido Termo; o pesquisador responsável deverá da mesma forma, rubricar todas as folhas do Termo de Consentimento Livre e Esclarecido - TCLE - apondo sua assinatura na última página do referido Termo.

Este Comitê segue integralmente a Conferência Internacional de Harmonização de Boas Práticas Clínicas (IGH-GCP), bem como a Resolução $n^{\circ}$ 196/96 CNS/MS.

Parcial e o Relatório Final da pesquisa.

Lembramos que devem ser apresentados a este CEP, o Relatório Atenciosamente.

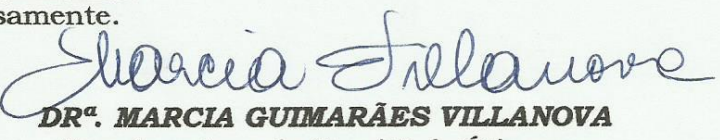

Coordenadora do Comitê de Ética em

Pesquisa do HCRP e da FMRP-USP

Ilustrissimas Senhoras

MARISTELA SCHAUFELBERGER SPANGHERO

TATIANA DE ABREU BRAGA SOARES

Depto. de Neurociências e Ciências do Comportamento

HOSPITAL DAS CLINICAS DA FACULDADE DE MEDICINA DE RIBEIRÃO PRETO DA UNIVERSIDADE DE SÃO PAULO Campus Universitário - Monte Alegre 14048-900 Ribeirão Preto SP Comitê de Ética em Pesquisa do HCRP e FMRP-USP
FWA- 00002733 ; IRB-00002186 e Registro PB/CONEP n० 5440 (16) $3602-2228$ cep@hcrp.usp.br 
APÊNDICE 


\section{PROJETO DE PESQUISA "CIGARRO E OUTRAS FORMAS DE TABACO: INVESTIGAÇÃO DE CONHECIMENTO, ATITUDES E PERCEPÇÃO DE RISCO EM ESTUDANTES DE MEDICINA}

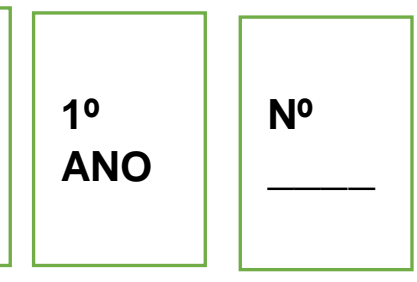

\section{BLOCO 1. DADOS DE IDENTIFICAÇÃO:}

1. Sexo:
a) Masculino ( )
b) Feminino ( )

2. Qual a sua idade?

3. Qual é o seu estado civil?
a) Solteiro ( )
b) Casado(a) ou morando junto ( )
c) Viúvo(a) ( )
d) Desquitado(a) ou divorciado(a) ( )
e) Separado(a) ( )

4. qual é aproximadamente a sua renda mensal familiar (em salários mínimos)
\# Anote o valor:
1 Até $\mathrm{R} \$ 880,00(1 \mathrm{SM})$
2 Mais de $\mathrm{R} \$ 880,01$ (1 SM) a $\mathrm{R} \$ 1.760,00$ (2 SM)
3 Mais de $R \$ 1.860,01$ (2 SM) a $R \$ 2.640,00$ (3 SM)
4 Mais de $R \$ 2.640,01$ (3 SM) a $R \$ 4.400,00$ (5 SM)
5 Mais de $R \$ 4.400,01$ (5 SM) a $R \$ 8.800,00$ (10 SM)
6 Mais de $R \$ 8.800,01$ (10 SM) a $R \$ 17.600$ (20 SM)
7 Mais de $R \$ 17.600,01$ (20 SM) a $R \$ 26.400,00$ (30 SM)
8 Mais de $R \$ 26.400,01$ (30SM)
9 Não sei

5. Qual a cidade e o estado onde você residia antes de ingressar na faculdade (SE ESTRANGEIRO ANOTAR O PAÍS E A CIDADE):

Cidade: Estado:

6. Há quanto tempo você vive na cidade em que estuda medicina?
a) Meses ( ) Quantos?
b) Anos ( ) Quantos ?
c) Não lembra/Não sei ( )
d) Não moro na cidade onde estudo ( ) 
7. Você diria que você é:
a) Branco ( )
b) Negro ( )
c) Pardo ( )
d) Amarelo ( )
e) Indígena ( )
f) Recuso a responder ( )

8. Atualmente, você mora com:
a) Pais/familiares
b) Cônjuge/companheiro (a)
c) Amigos/república
d) Pensionato
e) Sozinho(a)

9. Faculdade onde cursa Medicina

10. Antes de ingressar no curso de Medicina você cursou algum outro curso de graduação?
a) $\operatorname{Sim}($ ) Qual?

b) Não ( )

Por quanto tempo?

\section{BLOCO 2. USO DE TABACO -GERAL}

\section{A- Produtos de tabaco fumado}

11. Alguma vez o você já tentou ou experimentou fumar cigarros, mesmo uma ou duas tragadas?
a) $\operatorname{Sim}($ )
b) Não ( )

Se você nunca fumou:

12. Escolha o(s) motivo(s) pelo(s) qual(is) você decidiu não fumar. Se houver mais de um, coloque-os em ordem crescente de importância, sendo o número 1 o motivo mais importante:
a) Nunca senti vontade de fumar
b) Experimentei e não gostei ( )
c) Fumo é prejudicial à saúde ( )
d) Influência familiar ( )
e) Considero o ato de fumar vulgar ( )
f) Por estar cursando medicina ( )
g) Outro motivo. Qual:

\section{Caso tenha assinalado a resposta B no item 11, pule para a questão 25}

13. Quantos anos você tinha quando experimentou um cigarro pela primeira vez?
a) Anos ( ) Quantos?
b) Não sei/não me lembro ( )
c) Nunca experimentei ( ) 
14. Nos últimos 12 meses, você fumou cigarros?
a) $\operatorname{Sim}($ )
b) Não ( )

15. Quantos anos você tinha quando você começou a fumar pelo menos uma vez ao mês?
a) Anos ( ) Quantos?
b) Não sei/não me lembro ( )
c) Nunca fumei pelo menos uma vez ao mês ( )

16. Quantos anos você tinha quando começou a fumar regularmente, isto é, pelo menos 1 cigarro por semana?
a) Anos ( ) Quantos?
b) Não sei/não me lembro ( )
c) Nunca fumei pelo menos 1 cigarro por semana ( )

17. Quanto tempo depois de acordar você normalmente leva para fumar o primeiro cigarro?
a) Até 5 minutos ( )
b) De 6 a 30 minutos ( )
c) De 31 a 60 minutos ( )
d) Mais de 60 minutos ( )
e) Não fumo cigarros atualmente ( )

18. Somando todos os CIGARROS que você fumou na vida inteira, o total chega a 100 cigarros ou 5 maços?
a) $\operatorname{Sim}(\quad)$
b) Não ( )

19. Assinale o(s) motivo(s) pelo(s) qual(is) você começou a fumar?
a) Por curiosidade própria ( )
b) Para aliviar tensões ( )
c) Por influência dos pais/familiares ( )
d) Por influência dos colegas/amigos ( )
e) Para sentir-se adulto ( )
f) Por desconhecer os prejuízos do fumo à saúde ( )

20. Assinale o(s) motivo(s) pelo(s) qual (is) você fuma atualmente:
a) É um hábito relaxante ( )
b) Alivia o cansaço ( )
c) Dá sensação de prazer e de liberdade ( )
d) É um hábito comum entre colegas ( )
e) É um vício ( )
f) Ajuda a não engordar ( )
g) Aumenta o atrativo pessoal ( )
h) Outro motivo. ( ) Qual?

21. Assinale qual seu desejo atual em relação ao tabaco?
a) Quero parar de fumar
b) Não quero parar de fumar
c) Não sei 
22. Você acha que vai fumar um cigarro em qualquer dia nos próximos 12 meses?
a) Com certeza não ( )
b) Provavelmente não ( )
c) Provavelmente sim ( )
d) Com certeza sim ( )

23. Você acha que daqui a 05 anos estará fumando cigarros?
a) Com certeza não ( )
b) Provavelmente não( )
c) Provavelmente sim ( )
d) Com certeza sim ( )

24. É mais provável que você fume cigarro depois de ter ingerido bebidas alcoólicas ou usado outra droga (Maconha, Cocaína, Crack, ou outras drogas)?
a) Não fumo mais cigarros ( )
b) Eu fumo mas nunca bebo álcool ou uso outras drogas ( )
c) Não, fumo menos quando bebo álcool ou uso outras drogas ( )
d) Sim, fumo mais quando bebo álcool ou uso outras drogas ( )
e) Fumo a mesma quantidade quando bebo álcool ou uso outras drogas. ( )
f) Eu só fumo quando bebo álcool ou uso outras drogas ( )

25. Durante os 12 últimos meses, com que frequência você utilizou a(s) substância(s) abaixo. (Na sequencia é a presentado um quadro com os nomes populares e comerciais da substancias referidas

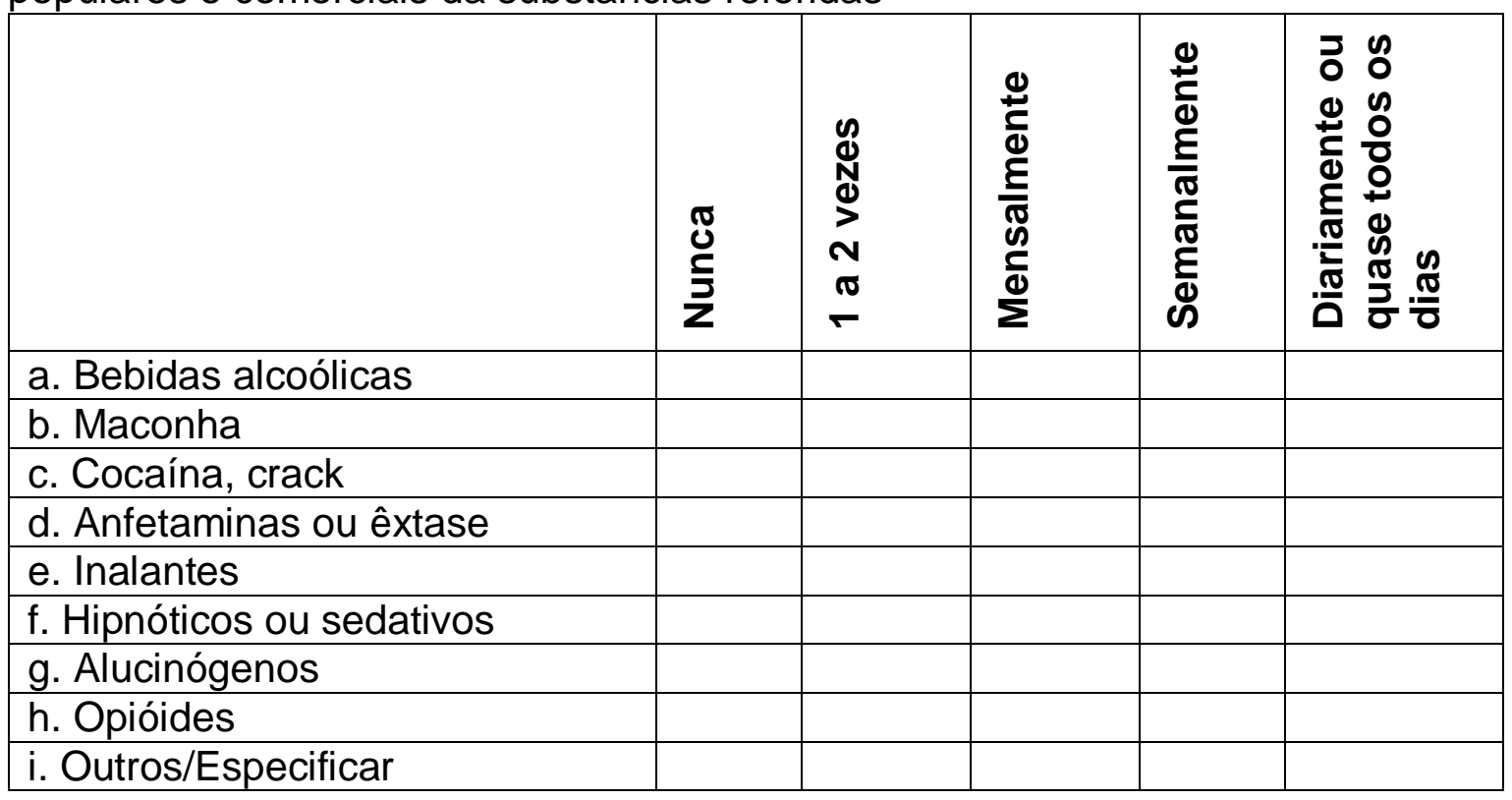

\section{NOMES POPULARES OU COMERCIAIS DAS DROGAS}

a. bebidas alcóolicas (cerveja, vinho, champagne, licor, pinga, uísque, vodca, vermutes, rum, caninha, gim, tequila)

b.maconha (baseado, erva, liamba, diamba, birra, fuminho, fumo, mato, bagulho, pango, manga-rosa, massa, haxixe, skank, etc)

c. cocaína, crack (coca, pó, branquinha, nuvem, farinha, neve, pedra, caximbo, brilho) 
d. estimulantes como anfetaminas (bolinhas, rebites, bifetamina, moderine, MDMA)

e. inalantes (solventes, cola de sapato, tinta, esmalte, corretivo, verniz, tinner, clorofórmio, tolueno, gasolina, éter, lança perfume, cheirinho de loló)

f. hipnóticos e sedativos (ansiolíticos, barbitúricos, tranquilizantes, fenobarbital, pentobarbital, benzodiazepínicos, diazepan)

g. alucinógenos (LSD, chá de lírio, ácido, passaporte, mescalina, peiote, cacto)

h. opiáceos (morfina, codeína, ópio, heroína, elixir, metadona

i. outros (especificar)

\section{BLOCO 3- USO ESPECÍFICO DE PRODUTOS DE TABACO}

26. Atualmente, você fuma algum dos produtos abaixo:

\begin{tabular}{|l|l|l|l|l|}
\hline & Diariamente & Semanalmente & Ocasionalmente & $\begin{array}{l}\text { Não } \\
\text { fumo }\end{array}$ \\
\hline a. Cigarros & & & & \\
\hline b. Charutos & & & & \\
\hline c. Cigarrilhas & & & & \\
\hline $\begin{array}{l}\text { d. Cigarros } \\
\text { de cravo ou } \\
\text { bali Cigarros }\end{array}$ & $\begin{array}{l}\text { e. Cu } \\
\text { indianos ou } \\
\text { bidis }\end{array}$ & & & \\
\hline $\begin{array}{l}\text { f. Narguilé ou } \\
\text { cachimbo } \\
\text { d'agua }\end{array}$ & & & & \\
\hline $\begin{array}{l}\text { g. Cigarro } \\
\text { eletrônico }\end{array}$ & & & & \\
\hline
\end{tabular}

27. No passado, você fumou algum desses produtos?

\begin{tabular}{|l|l|l|l|l|}
\hline & Diariamente & Semanalmente & Ocasionalmente & $\begin{array}{l}\text { Não } \\
\text { fumo }\end{array}$ \\
\hline a. Cigarros & & & & \\
\hline b. Charutos & & & & \\
\hline c. Cigarrilhas & & & & \\
\hline $\begin{array}{l}\text { d. Cigarros } \\
\text { de cravo ou } \\
\text { bali }\end{array}$ & & & & \\
\hline $\begin{array}{l}\text { e. Cigarros } \\
\text { indianos ou } \\
\text { bidis }\end{array}$ & & & & \\
\hline $\begin{array}{l}\text { f. Narguilé ou } \\
\text { cachimbo } \\
\text { d'agua }\end{array}$ & $\begin{array}{l}\text { g. Cigarro } \\
\text { eletrônico }\end{array}$ & & & \\
\hline
\end{tabular}


28. Caso tenha usado cigarro eletrônico, quantas vezes você usou:
a) Nunca usei ( )
b) 1 a 5 vezes ( )
c) 6 a 10 vezes ( )
d) 11 a 15 vezes ( )
e) Mais de 50 vezes ( )
f) Mais de 100 vezes ( )

Caso use diariamente uma das substancias listadas na questão 26 responda as questões abaixo do contrário vá para a questão 33

29. Quantos anos você tinha quando começou a fumar diariamente produtos derivados do tabaco?

a) Anos ( ) Quantos?

b) Não sabe ( )

30. Há quantos anos você começou a fumar diariamente produtos derivados do tabaco?
a) Anos ( ) Quantos?
b) Não sabe ( )

31. Na tabela abaixo, escreva a quantidade média dos seguintes produtos que você fuma por dia atualmente:

\begin{tabular}{|l|l|l|}
\hline & $\begin{array}{l}\text { Quantidade } \\
\text { média que } \\
\text { fumo por } \\
\text { dia }\end{array}$ & Não sei \\
\hline $\begin{array}{l}\text { a) Cigarros industrializados (não incluir cigarro } \\
\text { de cravo ou bali e cigarros indianos ou Bidi) }\end{array}$ & & \\
\hline $\begin{array}{l}\text { b) Cigarros de palha ou cigarros enrolados a } \\
\text { mão }\end{array}$ & & \\
\hline c) Cigarros de Cravo ou Bali & & \\
\hline d) Cigarros indianos ou Bidi & & \\
\hline e) Cachimbos (considere cachimbos cheios) & & \\
\hline f) Charutos ou cigarrilhas & & \\
\hline g) Narguilés (sessões) & & \\
\hline h) Cigarro eletrônico & & \\
\hline
\end{tabular}

32. Nos últimos 30 dias (um mês), em quantos dias você usou os produtos abaixo?

\begin{tabular}{|l|l|l|}
\hline & $\begin{array}{l}\text { Quantidade } \\
\text { de dias }\end{array}$ & Não sei \\
\hline $\begin{array}{l}\text { a) Cigarros industrializados (não incluir cigarro } \\
\text { de cravo ou bali e cigarros indianos ou Bidi) }\end{array}$ & & \\
\hline $\begin{array}{l}\text { b) Cigarros de palha ou cigarros enrolados a } \\
\text { mão }\end{array}$ & & \\
\hline c) Cigarros de Cravo ou Bali & & \\
\hline d) Cigarros indianos ou Bidi & & \\
\hline e) Cachimbos (considere cachimbos cheios) & & \\
\hline f) Charutos ou cigarrilhas & & \\
\hline
\end{tabular}


g) Narguilés (sessões)

h) Cigarro eletrônico

33. Na tabela abaixo, escreva a quantidade média dos seguintes produtos que você fuma por semana atualmente:

\begin{tabular}{|l|l|l|l|}
\hline & $\begin{array}{l}\text { Quantidade média que fumo } \\
\text { por semana }\end{array}$ & $\begin{array}{l}\text { Não } \\
\text { sei }\end{array}$ & $\begin{array}{l}\text { Não } \\
\text { fumo }\end{array}$ \\
\hline $\begin{array}{l}\text { Cigarros industrializados (não } \\
\text { incluir cigarro de cravo ou bali } \\
\text { e cigarros indianos ou Bidi) }\end{array}$ & & & \\
\hline $\begin{array}{l}\text { Cigarros de palha ou cigarros } \\
\text { enrolados a mão }\end{array}$ & & & \\
\hline Cigarros de Cravo ou Bali & & & \\
\hline Cigarros indianos ou Bidi & & & \\
\hline $\begin{array}{l}\text { Cachimbos (considere } \\
\text { cachimbos cheios) }\end{array}$ & & & \\
\hline Charutos ou cigarrilhas & & & \\
\hline Narguilés (sessões) & & & \\
\hline Cigarro eletrônico & & & \\
\hline
\end{tabular}

Caso tenha deixado de fumar algum dos produtos de tabaco fumado responda as questões abaixo, se não vá para a questão 36

34. Produto que deixou de fumar:

35. Há quanto tempo você parou de fumar este produto?

a) Anos ( ) Quantos?

b) Meses ( ) Quantos?

c) Semanas ( ) Quantos?

d) Dias ( ) Quantos?

\section{B- Produto de tabaco sem fumaça}

36. Atualmente qual seu padrão de consumo dos produtos abaixo, chamados de produtos de tabaco sem fumaça.

\begin{tabular}{|l|l|l|l|l|}
\hline & Diariamente & Semanalmente & Ocasionalmente & $\begin{array}{l}\text { Não } \\
\text { fumo }\end{array}$ \\
\hline Rapé & & & & \\
\hline Fumo de mascar & & & & \\
\hline $\begin{array}{l}\text { Snus ou snuffs (uso pela } \\
\text { boca) }\end{array}$ & & & & Especifique \\
\hline
\end{tabular}

Caso use alguns dos produtos listados na questão 36, responda as questões abaixo, do contrário vá para a questão 41 
37. Há quantos anos você começou a usar algum produto do tabaco que não faz fumaça, mesmo que de vez em quando?
a) $1+1 \mid$ anos
b) Não sei, não me lembro ( )

38. Há quantos anos você começou a usar algum produto do tabaco que não faz fumaça diariamente?
a) $|+1|$ _ anos
b) Não sei, não me lembro ( )
c) Nunca usei ( )

39. Quanto tempo depois de acordar você normalmente usa algum produto do tabaco que não faz fumaça?
a) Até 5 minutos
b) 6 a 30 minutos
c) 31 a 60 minutos
d) Mais que 60 minutos

40. Há quanto tempo você parou de usar algum outro produto do tabaco que não faz fumaça?
a) Anos ( ) Quantos?
b) Meses ( ) Quantos?
c) Semanas ( ) Quantos?
d) Dias ( ) Quantos?
e) Nunca usei ( )

\section{BLOCO 4. USO DO TABACO NO CURSO DE MEDICINA}

41. Em relação aos seguintes itens, seu primeiro uso ocorreu:

\begin{tabular}{|l|l|l|l|}
\hline & $\begin{array}{l}\text { Antes de ingressar } \\
\text { no curso de } \\
\text { Medicina }\end{array}$ & $\begin{array}{l}\text { Após o ingresso no } \\
\text { curso de Medicina }\end{array}$ & $\begin{array}{l}\text { Nunca } \\
\text { experimentei/nã } \\
\text { o conheço }\end{array}$ \\
\hline $\begin{array}{l}\text { a) Narguilé ou cachimbo } \\
\text { d'água }\end{array}$ & & & \\
\hline b) Cachimbo & & & \\
\hline c) Charuto & & & \\
\hline d) Cigarrilhas cravo, & & & \\
\hline $\begin{array}{l}\text { e) Cigarro de cigarros de Bali, cigarro } \\
\text { da India }\end{array}$ & & & \\
\hline f) Cigarros de palha & & & \\
\hline g) Rapé (tabaco em pó) & & & \\
\hline $\begin{array}{l}\text { h) Cigarro eletrônico/e- } \\
\text { cigarette }\end{array}$ & & & \\
\hline i) Fumo de mascar & & & \\
\hline
\end{tabular}




\section{BLOCO5. EXPOSIÇÃO AMBIENTAL À FUMAÇA DO TABACO}

42. Na sua família, alguém foi ou é fumante
a) Pai ( )
b) Mãe ( )
c) Irmãos ( )
d) Outros ( )

43. Algum de seus amigos mais próximos fuma cigarros?
a) Nenhum ( )
b) Alguns ( )
c) A maioria ( )
d) Todos ( )

44. Com que frequência alguém fuma dentro da sua casa?
a) Diariamente ( )
b) Semanalmente ( )
c) Mensalmente ( )
d) Menos que mensalmente ( )
e) Nunca ( )

45. Durante os últimos trinta dias, alguém fumou em algum ambiente fechado onde você estuda/trabalha?
a) $\operatorname{Sim}($ )
b) Não ( )
c) Não sabe ( )

Se sim, com que frequência:
a) Diariamente ( )
b) Semanalmente ( )
c) Mensalmente ( )
d) Menos que mensalmente ( )

\section{BLOCO 6. ATITUDES E PERCEPÇÃO}

46. Você acha difícil alguém largar os cigarros depois de começar a fumar?
a) Com certeza não ( )
b) Provavelmente não ( )
c) Provavelmente sim ( )
d) Com certeza sim ( )

47. Você acha que os rapazes que fumam cigarro tem:
a) Mais amigos ( )
b) Menos amigos ( )
c) Nenhuma diferença dos não fumantes ( )

48. Você acha que meninas que fumam cigarro tem:
a) Mais amigos ( )
b) Menos amigos ( )
c) Nenhuma diferença das não fumantes ( ) 
49. Você acredita que o cigarro faz com que as pessoas se sintam menos ou mais à vontade em festas ou outras reuniões sociais?
a) Mais a vontade ( )
b) Menos a vontade ( )
c) Nenhuma diferença dos não fumantes ( )

50. Você acha que fumar cigarros torna os rapazes:
a) Mais atraentes ( )
b) Menos atraentes ( )
c) Nenhuma diferença dos não fumantes ( )

51. Você acha que fumar cigarros torna as meninas:
a) Mais atraentes ( )
b) Menos atraentes ( )
c) Nenhuma diferença das não fumantes ( )

52. Você acha que fumar cigarros faz as pessoas:
a) Ganhar peso ( )
b) Perder peso ( )
c) Nenhuma diferença ( )

53.Com base no que você conhece ou acredita, fumar causa doenças graves?
a) $\operatorname{Sim}($ )
b) Não ( )
c) Não sei ( )

54. Com base no que você conhece ou acredita, fumar causa:

\begin{tabular}{|l|l|l|l|}
\hline & Sim & Não & Não sabe \\
\hline Derrame & & & \\
\hline Ataque cardíaco & & & \\
\hline $\begin{array}{l}\text { Câncer de } \\
\text { pulmão }\end{array}$ & & \\
\hline \multicolumn{2}{|l|}{ Outros (descreva): } & & \\
\hline
\end{tabular}

55. Com base no que você conhece ou acredita, usar tabaco sem fumaça (fumo para mascar, rapé ou outros produtos que não fazem fumaça) causa doenças graves?
a) $\operatorname{Sim}($ )
b) Não ( )
c) Não sei ( ) 
56. Em relação ao potencial de causar prejuízos para a saúde, você considera que, em comparação ao cigarro comum, os seguintes itens são:

\begin{tabular}{|l|l|l|l|l|}
\hline & $\begin{array}{l}\text { Mais } \\
\text { prejudiciais } \\
\text { que o } \\
\text { cigarro }\end{array}$ & $\begin{array}{l}\text { Menos } \\
\text { prejudiciais } \\
\text { que o } \\
\text { cigarro }\end{array}$ & $\begin{array}{l}\text { lgualmente } \\
\text { prejudiciais } \\
\text { ao cigarro }\end{array}$ & Não sei \\
\hline $\begin{array}{l}\text { a) Narguilé ou cachimbo } \\
\text { d'água }\end{array}$ & & & & \\
\hline b) Cachimbo & & & & \\
\hline c) Charuto & & & & \\
\hline d) Cigarrilhas & & & \\
\hline $\begin{array}{l}\text { e) Cigarro de cravo, } \\
\text { cigarros de Bali }\end{array}$ & & & & \\
\hline f) Cigarros de palha & & & & \\
\hline g) Rapé (tabaco em pó) & & & & \\
\hline $\begin{array}{l}\text { h) Cigarro eletrônico/e- } \\
\text { cigarette }\end{array}$ & & & & \\
\hline i) Tabaco mascado & & & & \\
\hline
\end{tabular}

57. Pessoas que fumam cigarros com baixo teor de Alcatrão e Nicotina (os chamados cigarros Light, suaves, leves) têm menos doenças causadas pelo cigarro do que aquelas que fumam com altos teores de Alcatrão e Nicotina?
a) Verdadeiro ( )
b) Falso ( )
c) Não sei ( )

58. Pessoas que nunca fumaram cigarro e que passam anos respirando a fumaça de cigarros de outras pessoas, têm risco aumentado de câncer?
a) Verdadeiro ( )
b) Falso ( )
c) Não sei ( )

59. Pessoas que nunca fumaram cigarro e que passam anos respirando a fumaça de cigarros de outras pessoas, têm risco aumentado de doenças cardiovasculares?
a) Verdadeiro ( )
b) Falso ( )
c) Não sei ( )

60. É muito difícil deixar de fumar cigarro, porque a Nicotina é uma droga com alto potencial para causar dependência?
a) Verdadeiro ( )
b) Falso ( )
c) Não sei ( ) 
61. Você acha que a fumaça do cigarro dos outros lhe é prejudicial?
a) Com certeza não ( )
b) Provavelmente não ( )
c) Provavelmente sim ( )
d) Com certeza sim ( )
e) Não sei ( )

62. Você acha que é seguro fumar cigarro durante 01 ou 02 anos desde que se abandone este comportamento após esse período?
a) Com certeza não ( )
b) Provavelmente não ( )
c) Provavelmente sim ( )
d) Com certeza sim ( )
e) Não sei ( )

63. Como você reage quando alguém fuma ao seu lado?
a) Não se importa ( )
b) Sente vontade de fumar ( )
c) Dá orientações sobre os malefícios do fumo ( )
d) Sente-se incomodado, mas não muda de lugar ( )
e) Sente-se incomodado e muda de lugar ( )

\section{BLOCO 7 - CONHECIMENTO MÉDICO}

64. Você acha que a nicotina é tão viciante quanto heroína ou cocaína?
a) $\operatorname{Sim}($ )
b) Não ( )
c) Não sei ( )

65. Na sua opinião, fumar durante a gravidez é seguro para o feto, desde que o fumo seja esporádico?
a) $\operatorname{Sim}($ )
b) Não ( )
c) Não sei ( )

66. Na sua opinião, os malefícios do cigarro para a saúde ocorrem apenas se a pessoa fumar diariamente?
a) $\operatorname{Sim}($ )
b) Não ( )
c) Não sei ( )

67. Na sua opinião, os malefícios do cigarro para a saúde ocorrem apenas se a pessoa fumar por vários anos?
a) $\operatorname{Sim}($ )
b) Não ( )
c) Não sei ( ) 
68. Você se considera fumante?
a) $\operatorname{Sim}($ )
b) Não ( )
c) Não sei ( )

69. Na sua opinião, só podem ser considerados fumantes aqueles que fumam cigarros diariamente?
a) $\operatorname{Sim}($ )
b) Não ( )
c) Não sei ( )

70. Na sua opinião, somente as pessoas que fumam diariamente são dependentes do cigarro?
a) $\operatorname{Sim}($ )
b) Não ( )
c) Não sei ( )

71. Em relação ao seu uso de cigarros, você se considera "dependente" ou "viciado"?
a) $\operatorname{Sim}($ )
b) Não ( )
c) Não sei ( )

72. Mesmo quem não fuma cigarros diariamente pode sofrer com síndrome de abstinência (fissura, tontura, peso na cabeça, dor de cabeça, dificuldade de concentração e confusão) ao parar de fumar?
a) $\operatorname{Sim}($ )
b) Não ( )
c) Não sei ( )

73. Qual a eficácia dos seguintes métodos na cessação do tabagismo:

\begin{tabular}{|l|l|l|l|l|l|}
\hline & $\begin{array}{l}\text { Nada } \\
\text { efetivo }\end{array}$ & $\begin{array}{l}\text { Pouco } \\
\text { efetivo }\end{array}$ & Efetivo & $\begin{array}{l}\text { Muito } \\
\text { efetivo }\end{array}$ & Não sei \\
\hline a) Força de vontade & & & & & \\
\hline b) Acupuntura & & & & & \\
\hline c) Aconselhamento médico & & & & & \\
\hline d) Material de Auto ajuda & & & & & \\
\hline $\begin{array}{l}\text { e) Terapia de reposição de } \\
\text { nicotina(TRN) Bupropiona }\end{array}$ & & & & & \\
\hline $\begin{array}{l}\text { f) } \\
\text { (antidepressivo inibidor de } \\
\text { seretonina, nome comercial: } \\
\text { Wellbutrin, Bup, Zetron, } \\
\text { Zyban) }\end{array}$ & & & & & \\
\hline $\begin{array}{l}\text { g) Vareniclina (Agonista } \\
\text { parcial de acetilcolina; nome } \\
\text { comercial: Champix) }\end{array}$ & & & & & \\
\hline
\end{tabular}


74. Na sua opinião qual o componente do cigarro que é o principal responsável pelo aumento do risco de doenças coronárias entre os fumantes?
a) Nicotina ( )
b) Alcatrão ( )
c) Aditivos de sabor ( )
d) Não sei ( )

75. Você conhece a porcentagem de fumantes no Brasil atualmente?
a) Menos de $10 \%$ da população ( )
b) $10-20 \%$ da população ( )
c) $20-40 \%$ da população ( )
d) Mais de $40 \%$ da população ( )
e) Não sei ( )

76. Você acha que profissionais de saúde deveriam aconselhar rotineiramente seus pacientes fumantes a parar de fumar?
a) $\operatorname{Sim}($ )
b) Não ( )
c) Não sei ( )

77. Você acha que a probabilidade de um fumante parar de fumar aumenta se um profissional de saúde o aconselha a parar?
a) $\operatorname{Sim}($ )
b) Não ( )
c) Não sei ( )

78. Você acha que os profissionais de saúde que fumam são menos propensos a aconselhar seus pacientes a parar de fumar?
a) $\operatorname{Sim}($ )
b) Não ( )
c) Não sei ( )

79. Você acha que os profissionais de saúde deveriam aconselhar rotineiramente seus pacientes a evitar outras formas de uso de tabaco ( por exemplo: produtos de tabaco não fumados, cigarro eletrônico)
a) $\operatorname{Sim}($ )
b) Não ( )
c) Não sei ( )

80. Você acha que os profissionais de saúde são modelos de conduta para seus pacientes e o público?
a) $\operatorname{Sim}($ )
b) Não ( )
c) Não sei ( ) 
81.Em relação aos seguintes itens, responda de acordo com sua opinião/conhecimento:

\begin{tabular}{|c|c|c|c|c|c|c|c|c|c|}
\hline & \multicolumn{3}{|c|}{$\begin{array}{l}\text { São seguros } \\
\text { para uso na } \\
\text { gestação }\end{array}$} & \multicolumn{3}{|c|}{$\begin{array}{l}\text { Aumentam o } \\
\text { risco de alguns } \\
\text { tipos de câncer }\end{array}$} & \multicolumn{3}{|c|}{$\begin{array}{l}\text { Aumentam } \\
\text { risco } \\
\text { doenças } \\
\text { cardiovasculare } \\
\text { s }\end{array}$} \\
\hline & Sim & Não & $\begin{array}{l}\text { Não } \\
\text { sei }\end{array}$ & Sim & Não & $\begin{array}{l}\text { Não } \\
\text { sei }\end{array}$ & Sim & Não & $\begin{array}{l}\text { Não } \\
\text { sei }\end{array}$ \\
\hline $\begin{array}{l}\text { a) Narguilé ou cachimbo } \\
\text { d'água }\end{array}$ & & & & & & & & & \\
\hline b) Cachimbo & & & & & & & & & \\
\hline c) Charuto & & & & & & & & & \\
\hline d) Cigarrilhas & & & & & & & & & \\
\hline $\begin{array}{l}\text { e) Cigarro de cravo, } \\
\text { cigarros de Bali, cigarro da } \\
\text { India }\end{array}$ & & & & & & & & & \\
\hline f) Cigarros de palha & & & & & & & & & \\
\hline g) Rapé (tabaco em pó) & & & & & & & & & \\
\hline $\begin{array}{l}\text { h) Cigarro eletrônico/e- } \\
\text { cigarette }\end{array}$ & & & & & & & & & \\
\hline i) Fumo de mascar & & & & & & & & & \\
\hline
\end{tabular}

82. Em relação aos seguintes itens, assinale de acordo com sua opinião/ conhecimento, se o mesmo contem Nicotina:

\begin{tabular}{|l|l|l|l|}
\hline & Sim & Não & Não sei \\
\hline a) Narguilé ou cachimbo d'água & & & \\
\hline b) Cachimbo & & & \\
\hline c) Charuto & & & \\
\hline d) Cigarrilhas & & & \\
\hline e) Cigarro de cravo, cigarros de Bali, cigarro da India & & & \\
\hline f) Cigarros de palha & & & \\
\hline g) Rapé (tabaco em pó) & & & \\
\hline h) Cigarro eletrônico/e-cigarette & & & \\
\hline i) Fumo de mascar & & & \\
\hline
\end{tabular}

83. Em relação ao seguintes itens, assinale de acordo com sua opinião/conhecimento se os mesmos podem causar dependência:

\begin{tabular}{|l|l|l|l|}
\hline \multicolumn{2}{|l|}{ Sim } & Não & Não sei \\
\hline b) Cachimbo & & & \\
\hline c) Charuto & & & \\
\hline d) Cigarrilhas & & & \\
\hline e) Cigarro de cravo, cigarros de Bali, cigarro da India & & & \\
\hline f) Cigarros de palha & & & \\
\hline g) Rapé (tabaco em pó) & & & \\
\hline h) Cigarro eletrônico & & & \\
\hline i) Fumo de mascar & & & \\
\hline
\end{tabular}




\section{BLOCO 1. DADOS DE IDENTIFICAÇÃO:}

1. Sexo:

a) Masculino ( )

b) Feminino ( )

2. Qual a sua idade?

3. Qual é o seu estado civil?
a) Solteiro ( )
b) Casado(a) ou morando junto ( )
c) Viúvo(a) ( )
d) Desquitado(a) ou divorciado(a) ( )
e) Separado(a) ( )

4. qual é aproximadamente a sua renda mensal familiar (em salários mínimos)

\begin{tabular}{|l|l|}
\hline$\#$ & Anote o valor: \\
\hline 1 & Até $R \$ 880,00(1 \mathrm{SM})$ \\
\hline 2 & Mais de $\mathrm{R} \$ 880,01(1 \mathrm{SM})$ a $\mathrm{R} \$ 1.760,00(2 \mathrm{SM})$ \\
\hline 3 & Mais de $\mathrm{R} \$ 1.860,01(2 \mathrm{SM})$ a $\mathrm{R} \$ 2.640,00(3 \mathrm{SM})$ \\
\hline 4 & Mais de $\mathrm{R} \$ 2.640,01(3 \mathrm{SM})$ a $\mathrm{R} \$ 4.400,00(5 \mathrm{SM})$ \\
\hline 5 & Mais de $\mathrm{R} \$ 4.400,01(5 \mathrm{SM})$ a $\mathrm{R} \$ 8.800,00(10 \mathrm{SM})$ \\
\hline 6 & Mais de $\mathrm{R} \$ 8.800,01(10 \mathrm{SM})$ a $\mathrm{R} \$ 17.600(20 \mathrm{SM})$ \\
\hline 7 & Mais de $\mathrm{R} \$ 17.600,01(20 \mathrm{SM})$ a $\mathrm{R} \$ 26.400,00(30 \mathrm{SM})$ \\
\hline 8 & Mais de $\mathrm{R} \$ 26.400,01(30 \mathrm{SM})$ \\
\hline 9 & Não sei \\
\hline
\end{tabular}

5. Qual a cidade e o estado onde você residia antes de ingressar na faculdade (SE ESTRANGEIRO ANOTAR O PAÍS E A CIDADE):

Cidade:

Estado:

6. Há quanto tempo você vive na cidade em que estuda medicina?
a) Meses ( ) Quantos?
b) Anos ( ) Quantos?
c) Não lembra/Não sei ( )
d) Não moro na cidade onde estudo ( )

7. Você diria que você é:
a) Branco ( )
b) Negro ( )
c) Pardo ( )
d) Amarelo ( )
e) Indígena ( )
f) Recuso a responder ( ) 
8. Atualmente, você mora com:

a) Pais/familiares

b) Cônjuge/companheiro (a)

c) Amigos/república

d) Pensionato

e) Sozinho(a)

9. Faculdade onde cursa Medicina

10. Antes de ingressar no curso de Medicina você cursou algum outro curso de graduação?

a) $\operatorname{Sim}($ ) Qual?

b) Não ( )

Por quanto tempo?

\section{BLOCO 2. USO DE TABACO -GERAL}

\section{A- Produtos de tabaco fumado}

11. Alguma vez o você já tentou ou experimentou fumar cigarros, mesmo uma ou duas tragadas?
a) $\operatorname{Sim}($ )
b) Não ( )

Se você nunca fumou:

12. Escolha o(s) motivo(s) pelo(s) qual(is) você decidiu não fumar. Se houver mais de um, coloque-os em ordem crescente de importância, sendo o número 1 o motivo mais importante:

a) Nunca senti vontade de fumar ( )

b) Experimentei e não gostei ( )

c) Fumo é prejudicial à saúde ( )

d) Influência familiar ( )

e) Considero o ato de fumar vulgar ( )

f) Por estar cursando medicina ( )

g) Outro motivo. Qual:

Caso tenha assinalado a resposta B no item 11, pule para a questão 25

13. Quantos anos você tinha quando experimentou um cigarro pela primeira vez?
a) Anos ( ) Quantos?
b) Não sei/não me lembro ( )
c) Nunca experimentei ( )

14. Nos últimos 12 meses, você fumou cigarros?
a) $\operatorname{Sim}($ )
b) Não ( ) 
15. Quantos anos você tinha quando você começou a fumar pelo menos uma vez ao mês?

a) Anos ( ) Quantos?

b) Não sei/não me lembro ( )

c) Nunca fumei pelo menos uma vez ao mês ( )

16. Quantos anos você tinha quando começou a fumar regularmente, isto é, pelo menos 1 cigarro por semana?

a) Anos ( ) Quantos?

b) Não sei/não me lembro ( )

c) Nunca fumei pelo menos 1 cigarro por semana ( )

17. Quanto tempo depois de acordar você normalmente leva para fumar o primeiro cigarro?
a) Até 5 minutos ( )
b) De 6 a 30 minutos ( )
c) De 31 a 60 minutos ( )
d) Mais de 60 minutos ( )
e) Não fumo cigarros atualmente ( )

18. Somando todos os CIGARROS que você fumou na vida inteira, o total chega a 100 cigarros ou 5 maços?
a) $\operatorname{Sim}(\quad)$
b) Não ( )

19. Assinale o(s) motivo(s) pelo(s) qual(is) você começou a fumar?
a) Por curiosidade própria ( )
b) Para aliviar tensões ( )
c) Por influência dos pais/familiares ( )
d) Por influência dos colegas/amigos ( )
e) Para sentir-se adulto ( )
f) Por desconhecer os prejuízos do fumo à saúde ( )

20. Assinale o(s) motivo(s) pelo(s) qual (is) você fuma atualmente:
a) É um hábito relaxante ( )
b) Alivia o cansaço ( )
c) Dá sensação de prazer e de liberdade ( )
d) É um hábito comum entre colegas ( )
e) É um vício ( )
f) Ajuda a não engordar ( )
g) Aumenta o atrativo pessoal ( )
h) Outro motivo. ( ) Qual?

21. Assinale qual seu desejo atual em relação ao tabaco?
a) Quero parar de fumar
b) Não quero parar de fumar
c) Não sei 
22. Você acha que vai fumar um cigarro em qualquer dia nos próximos 12 meses?
a) Com certeza não ( )
b) Provavelmente não ( )
c) Provavelmente sim ( )
d) Com certeza sim ( )

23. Você acha que daqui a 05 anos estará fumando cigarros?
a) Com certeza não ( )
b) Provavelmente não( )
c) Provavelmente sim ( )
d) Com certeza sim ( )

24. É mais provável que você fume cigarro depois de ter ingerido bebidas alcoólicas ou usado outra droga (Maconha, Cocaína, Crack, ou outras drogas)?
a) Não fumo mais cigarros ( )
b) Eu fumo mas nunca bebo álcool ou uso outras drogas ( )
c) Não, fumo menos quando bebo álcool ou uso outras drogas ( )
d) Sim, fumo mais quando bebo álcool ou uso outras drogas ( )
e) Fumo a mesma quantidade quando bebo álcool ou uso outras drogas. ( )
f) Eu só fumo quando bebo álcool ou uso outras drogas ( )

25. Durante os 12 últimos meses, com que frequência você utilizou a(s) substância(s) abaixo. (Na sequencia é a presentado um quadro com os nomes populares e comerciais da substancias referidas

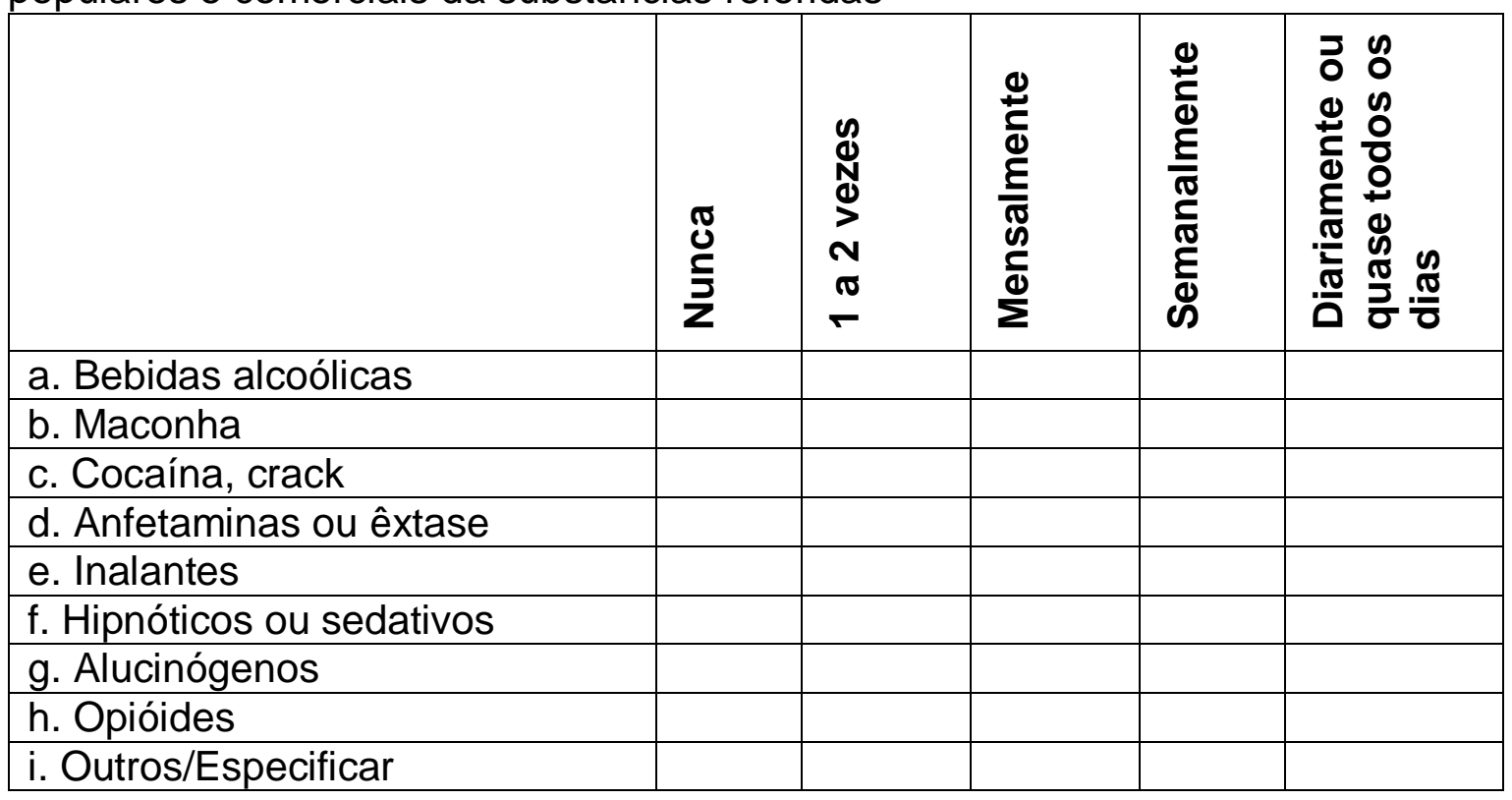

\section{NOMES POPULARES OU COMERCIAIS DAS DROGAS}

a. bebidas alcóolicas (cerveja, vinho, champagne, licor, pinga, uísque, vodca, vermutes, rum, caninha, gim, tequila)

b.maconha (baseado, erva, liamba, diamba, birra, fuminho, fumo, mato, bagulho, pango, manga-rosa, massa, haxixe, skank, etc)

c. cocaína, crack (coca, pó, branquinha, nuvem, farinha, neve, pedra, caximbo, brilho) 
d. estimulantes como anfetaminas (bolinhas, rebites, bifetamina, moderine, MDMA)

e. inalantes (solventes, cola de sapato, tinta, esmalte, corretivo, verniz, tinner, clorofórmio, tolueno, gasolina, éter, lança perfume, cheirinho de loló)

f. hipnóticos e sedativos (ansiolíticos, barbitúricos, tranquilizantes, fenobarbital, pentobarbital, benzodiazepínicos, diazepan)

g. alucinógenos (LSD, chá de lírio, ácido, passaporte, mescalina, peiote, cacto)

h. opiáceos (morfina, codeína, ópio, heroína, elixir, metadona

i. outros (especificar)

\section{BLOCO 3- USO ESPECÍFICO DE PRODUTOS DE TABACO}

26. Atualmente, você fuma algum dos produtos abaixo:

\begin{tabular}{|l|l|l|l|l|}
\hline & Diariamente & Semanalmente & Ocasionalmente & $\begin{array}{l}\text { Não } \\
\text { fumo }\end{array}$ \\
\hline a. Cigarros & & & & \\
\hline b. Charutos & & & & \\
\hline c. Cigarrilhas & & & & \\
\hline $\begin{array}{l}\text { d. Cigarros } \\
\text { de cravo ou } \\
\text { bali Cigarros }\end{array}$ & $\begin{array}{l}\text { e. Cu } \\
\text { indianos ou } \\
\text { bidis }\end{array}$ & & & \\
\hline $\begin{array}{l}\text { f. Narguilé ou } \\
\text { cachimbo } \\
\text { d'agua }\end{array}$ & & & & \\
\hline $\begin{array}{l}\text { g. Cigarro } \\
\text { eletrônico }\end{array}$ & & & & \\
\hline
\end{tabular}

27. No passado, você fumou algum desses produtos?

\begin{tabular}{|l|l|l|l|l|}
\hline & Diariamente & Semanalmente & Ocasionalmente & $\begin{array}{l}\text { Não } \\
\text { fumo }\end{array}$ \\
\hline a. Cigarros & & & & \\
\hline b. Charutos & & & & \\
\hline c. Cigarrilhas & & & & \\
\hline $\begin{array}{l}\text { d. Cigarros } \\
\text { de cravo ou } \\
\text { bali }\end{array}$ & & & & \\
\hline $\begin{array}{l}\text { e. Cigarros } \\
\text { indianos ou } \\
\text { bidis }\end{array}$ & & & & \\
\hline $\begin{array}{l}\text { f. Narguilé ou } \\
\text { cachimbo } \\
\text { d'agua }\end{array}$ & $\begin{array}{l}\text { g. Cigarro } \\
\text { eletrônico }\end{array}$ & & & \\
\hline
\end{tabular}


28. Caso tenha usado cigarro eletrônico, quantas vezes você usou:
a) Nunca usei ( )
b) 1 a 5 vezes ( )
c) 6 a 10 vezes ( )
d) 11 a 15 vezes ( )
e) Mais de 50 vezes ( )
f) Mais de 100 vezes ( )

Caso use diariamente uma das substancias listadas na questão 26 responda as questões abaixo do contrário vá para a questão 33

29. Quantos anos você tinha quando começou a fumar diariamente produtos derivados do tabaco?

a) Anos ( ) Quantos?

b) Não sabe ( )

30. Há quantos anos você começou a fumar diariamente produtos derivados do tabaco?
a) Anos ( ) Quantos?
b) Não sabe ( )

31. Na tabela abaixo, escreva a quantidade média dos seguintes produtos que você fuma por dia atualmente:

\begin{tabular}{|l|l|l|}
\hline & $\begin{array}{l}\text { Quantidade } \\
\text { média que } \\
\text { fumo por } \\
\text { dia }\end{array}$ & Não \\
\hline $\begin{array}{l}\text { a) Cigarros industrializados (não incluir cigarro } \\
\text { de cravo ou bali e cigarros indianos ou Bidi) }\end{array}$ & & \\
\hline $\begin{array}{l}\text { b) Cigarros de palha ou cigarros enrolados a } \\
\text { mão }\end{array}$ & & \\
\hline c) Cigarros de Cravo ou Bali & & \\
\hline d) Cigarros indianos ou Bidi & & \\
\hline e) Cachimbos (considere cachimbos cheios) & & \\
\hline f) Charutos ou cigarrilhas & & \\
\hline g) Narguilés (sessões) & & \\
\hline h) Cigarro eletrônico & & \\
\hline
\end{tabular}

32. Nos últimos 30 dias (um mês), em quantos dias você usou os produtos abaixo?

\begin{tabular}{|l|l|l|}
\hline $\begin{array}{l}\text { a) Cigarros industrializados (não incluir cigarro } \\
\text { de cravo ou bali e cigarros indianos ou Bidi) }\end{array}$ & $\begin{array}{l}\text { Quantidade } \\
\text { de dias }\end{array}$ & Não sei \\
\hline $\begin{array}{l}\text { b) Cigarros de palha ou cigarros enrolados a } \\
\text { mão }\end{array}$ & & \\
\hline c) Cigarros de Cravo ou Bali & & \\
\hline d) Cigarros indianos ou Bidi & & \\
\hline e) Cachimbos (considere cachimbos cheios) & & \\
\hline
\end{tabular}


f) Charutos ou cigarrilhas

g) Narguilés (sessões)

h) Cigarro eletrônico

33. Na tabela abaixo, escreva a quantidade média dos seguintes produtos que você fuma por semana atualmente:

\begin{tabular}{|l|l|l|l|}
\hline & $\begin{array}{l}\text { Quantidade média que fumo } \\
\text { por semana }\end{array}$ & $\begin{array}{l}\text { Não } \\
\text { sei }\end{array}$ & $\begin{array}{l}\text { Não } \\
\text { fumo }\end{array}$ \\
\hline $\begin{array}{l}\text { Cigarros industrializados (não } \\
\text { incluir cigarro de cravo ou bali } \\
\text { e cigarros indianos ou Bidi) }\end{array}$ & & & \\
\hline $\begin{array}{l}\text { Cigarros de palha ou cigarros } \\
\text { enrolados a mão }\end{array}$ & & & \\
\hline Cigarros de Cravo ou Bali & & & \\
\hline Cigarros indianos ou Bidi & & & \\
\hline $\begin{array}{l}\text { Cachimbos considere } \\
\text { cachimbos cheios) }\end{array}$ & & & \\
\hline Charutos ou cigarrilhas & & & \\
\hline Narguilés (sessões) & & & \\
\hline Cigarro eletrônico & & \\
\hline
\end{tabular}

Caso tenha deixado de fumar algum dos produtos de tabaco fumado responda as questões abaixo, se não vá para a questão 36

34. Produto que deixou de fumar:

35. Há quanto tempo você parou de fumar este produto?
a) Anos ( ) Quantos?
b) Meses ( ) Quantos?
c) Semanas ( ) Quantos?
d) Dias ( ) Quantos?

\section{B- Produto de tabaco sem fumaça}

36. Atualmente qual seu padrão de consumo dos produtos abaixo, chamados de produtos de tabaco sem fumaça.

\begin{tabular}{|l|l|l|l|l|}
\hline & Diariamente & Semanalmente & Ocasionalmente & $\begin{array}{l}\text { Não } \\
\text { fumo }\end{array}$ \\
\hline Rapé & & & & \\
\hline Fumo de mascar & & & & \\
\hline $\begin{array}{l}\text { Snus ou snuffs (uso pela } \\
\text { boca) }\end{array}$ & & & & \multicolumn{2}{|c|}{ Especifique } \\
\hline
\end{tabular}


Caso use alguns dos produtos listados na questão 36, responda as questões abaixo, do contrário vá para a questão 41

37. Há quantos anos você começou a usar algum produto do tabaco que não faz fumaça, mesmo que de vez em quando?

a) $|+1|$ _ anos

b) Não sei, não me lembro ( )

38. Há quantos anos você começou a usar algum produto do tabaco que não faz fumaça diariamente?
a) $|+1|$ anos
b) Não sei, não me lembro ( )
c) Nunca usei ( )

39. Quanto tempo depois de acordar você normalmente usa algum produto do tabaco que não faz fumaça?
a) Até 5 minutos
b) 6 a 30 minutos
c) 31 a 60 minutos
d) Mais que 60 minutos

40. Há quanto tempo você parou de usar algum outro produto do tabaco que não faz fumaça?
a) Anos ( ) Quantos?
b) Meses ( ) Quantos?
c) Semanas ( ) Quantos?
d) Dias ( ) Quantos?
e) Nunca usei ( )

\section{BLOCO 4. USO DO TABACO NO CURSO DE MEDICINA}

41. Em relação aos seguintes itens, seu primeiro uso ocorreu:

\begin{tabular}{|l|l|l|l|}
\hline & $\begin{array}{l}\text { Antes de ingressar } \\
\text { no curso de } \\
\text { Medicina }\end{array}$ & $\begin{array}{l}\text { Após o ingresso no } \\
\text { curso de Medicina }\end{array}$ & $\begin{array}{l}\text { Nunca } \\
\text { experimentei/nã } \\
\text { o conheço }\end{array}$ \\
\hline $\begin{array}{l}\text { a) Narguilé ou cachimbo } \\
\text { d'água }\end{array}$ & & & \\
\hline b) Cachimbo & & & \\
\hline c) Charuto & & & \\
\hline d) Cigarrilhas de cravo, & & \\
\hline $\begin{array}{l}\text { e) Cigarro de cigarros de Bali, cigarro } \\
\text { da India }\end{array}$ & & & \\
\hline f) Cigarros de palha & & & \\
\hline g) Rapé (tabaco em pó) & & & \\
\hline $\begin{array}{l}\text { h) Cigarro eletrônico/e- } \\
\text { cigarette }\end{array}$ & & & \\
\hline i) Fumo de mascar & & & \\
\hline
\end{tabular}




\section{BLOCO5. EXPOSIÇÃO AMBIENTAL À FUMAÇA DO TABACO}

42. Na sua família, alguém foi ou é fumante
a) Pai ( )
b) Mãe ( )
c) Irmãos ( )
d) Outros ( )

43. Algum de seus amigos mais próximos fuma cigarros?
a) Nenhum ( )
b) Alguns ( )
c) A maioria ( )
d) Todos ( )

44. Com que frequência alguém fuma dentro da sua casa?
a) Diariamente ( )
b) Semanalmente ( )
c) Mensalmente ( )
d) Menos que mensalmente ( )
e) Nunca ( )

45. Durante os últimos trinta dias, alguém fumou em algum ambiente fechado onde você estuda/trabalha?
a) $\operatorname{Sim}($ )
b) Não ( )
c) Não sabe ( )

Se sim, com que frequência:
a) Diariamente ( )
b) Semanalmente ( )
c) Mensalmente ( )
d) Menos que mensalmente ( )

\section{BLOCO 5. ATITUDES E PERCEPÇÃO}

46. Você acha difícil alguém largar os cigarros depois de começar a fumar?
a) Com certeza não ( )
b) Provavelmente não ( )
c) Provavelmente sim ( )
d) Com certeza sim ( )

47. Você acha que os rapazes que fumam cigarro tem:
a) Mais amigos ( )
b) Menos amigos ( )
c) Nenhuma diferença dos não fumantes ( ) 
48. Você acha que meninas que fumam cigarro tem:
a) Mais amigos ( )
b) Menos amigos ( )
c) Nenhuma diferença das não fumantes ( )

49. Você acredita que o cigarro faz com que as pessoas se sintam menos ou mais à vontade em festas ou outras reuniões sociais?
a) Mais a vontade ( )
b) Menos a vontade ( )
c) Nenhuma diferença dos não fumantes ( )

50. Você acha que fumar cigarros torna os rapazes:
a) Mais atraentes ( )
b) Menos atraentes ( )
c) Nenhuma diferença dos não fumantes ( )

51. Você acha que fumar cigarros torna as meninas:
a) Mais atraentes ( )
b) Menos atraentes ( )
c) Nenhuma diferença das não fumantes ( )

52. Você acha que fumar cigarros faz as pessoas:
a) Ganhar peso ( )
b) Perder peso ( )
c) Nenhuma diferença ( )

53.Com base no que você conhece ou acredita, fumar causa doenças graves?
a) $\operatorname{Sim}($ )
b) Não ( )
c) Não sei ( )

54. Com base no que você conhece ou acredita, fumar causa:

\begin{tabular}{|l|l|l|l|}
\hline & Sim & Não & Não sabe \\
\hline Derrame & & & \\
\hline Ataque cardíaco & & & \\
\hline $\begin{array}{l}\text { Câncer de } \\
\text { pulmão }\end{array}$ & & \\
\hline \multicolumn{2}{|l}{ Outros (descreva): } \\
\hline
\end{tabular}

55. Com base no que você conhece ou acredita, usar tabaco sem fumaça (fumo para mascar, rapé ou outros produtos que não fazem fumaça) causa doenças graves?
a) $\operatorname{Sim}($ )
b) Não ( )
c) Não sei ( ) 
56. Em relação ao potencial de causar prejuízos para a saúde, você considera que, em comparação ao cigarro comum, os seguintes itens são:

\begin{tabular}{|l|l|l|l|l|}
\hline & $\begin{array}{l}\text { Mais } \\
\text { prejudiciais } \\
\text { que o } \\
\text { cigarro }\end{array}$ & $\begin{array}{l}\text { Menos } \\
\text { prejudiciais } \\
\text { que o } \\
\text { cigarro }\end{array}$ & $\begin{array}{l}\text { lgualmente } \\
\text { prejudiciais } \\
\text { ao cigarro }\end{array}$ & Não sei \\
\hline $\begin{array}{l}\text { a) Narguilé ou cachimbo } \\
\text { d'água }\end{array}$ & & & & \\
\hline b) Cachimbo & & & & \\
\hline c) Charuto & & & & \\
\hline d) Cigarrilhas & & & \\
\hline $\begin{array}{l}\text { e) Cigarro de cravo, } \\
\text { cigarros de Bali }\end{array}$ & & & & \\
\hline f) Cigarros de palha & & & & \\
\hline g) Rapé (tabaco em pó) & & & & \\
\hline $\begin{array}{l}\text { h) Cigarro eletrônico/e- } \\
\text { cigarette }\end{array}$ & & & & \\
\hline i) Tabaco mascado & & & & \\
\hline
\end{tabular}

57. Pessoas que fumam cigarros com baixo teor de Alcatrão e Nicotina (os chamados cigarros Light, suaves, leves) têm menos doenças causadas pelo cigarro do que aquelas que fumam com altos teores de Alcatrão e Nicotina?
a) Verdadeiro ( )
b) Falso ( )
c) Não sei ( )

58. Pessoas que nunca fumaram cigarro e que passam anos respirando a fumaça de cigarros de outras pessoas, têm risco aumentado de câncer?
a) Verdadeiro ( )
b) Falso ( )
c) Não sei ( )

59. Pessoas que nunca fumaram cigarro e que passam anos respirando a fumaça de cigarros de outras pessoas, têm risco aumentado de doenças cardiovasculares?
a) Verdadeiro ( )
b) Falso ( )
c) Não sei ( )

60. É muito difícil deixar de fumar cigarro, porque a Nicotina é uma droga com alto potencial para causar dependência?
a) Verdadeiro ( )
b) Falso ( )
c) Não sei ( ) 
61. Você acha que a fumaça do cigarro dos outros lhe é prejudicial?
a) Com certeza não ( )
b) Provavelmente não ( )
c) Provavelmente sim ( )
d) Com certeza sim ( )
e) Não sei ( )

62. Você acha que é seguro fumar cigarro durante 01 ou 02 anos desde que se abandone este comportamento após esse período?
a) Com certeza não ( )
b) Provavelmente não ( )
c) Provavelmente sim ( )
d) Com certeza sim ( )
e) Não sei ( )

63. Como você reage quando alguém fuma ao seu lado?
a) Não se importa ( )
b) Sente vontade de fumar ( )
c) Dá orientações sobre os malefícios do fumo ( )
d) Sente-se incomodado, mas não muda de lugar ( )
e) Sente-se incomodado e muda de lugar ( )

\section{BLOCO 7 - CONHECIMENTO MÉDICO}

64. Você acha que a nicotina é tão viciante quanto heroína ou cocaína?
a) $\operatorname{Sim}($ )
b) Não ( )
c) Não sei ( )

65. Na sua opinião, fumar durante a gravidez é seguro para o feto, desde que o fumo seja esporádico?
a) $\operatorname{Sim}($ )
b) Não ( )
c) Não sei ( )

66. Na sua opinião, os malefícios do cigarro para a saúde ocorrem apenas se a pessoa fumar diariamente?
a) $\operatorname{Sim}($ )
b) Não ( )
c) Não sei ( )

67. Na sua opinião, os malefícios do cigarro para a saúde ocorrem apenas se a pessoa fumar por vários anos?
a) $\operatorname{Sim}($ )
b) Não ( )
c) Não sei ( ) 
68. Você se considera fumante?
a) $\operatorname{Sim}($ )
b) Não ( )
c) Não sei ( )

69. Na sua opinião, só podem ser considerados fumantes aqueles que fumam cigarros diariamente?
a) $\operatorname{Sim}($ )
b) Não ( )
c) Não sei ( )

70. Na sua opinião, somente as pessoas que fumam diariamente são dependentes do cigarro?
a) $\operatorname{Sim}($ )
b) Não ( )
c) Não sei ( )

71. Em relação ao seu uso de cigarros, você se considera "dependente" ou "viciado"?
a) $\operatorname{Sim}($ )
b) Não ( )
c) Não sei ( )

72. Mesmo quem não fuma cigarros diariamente pode sofrer com síndrome de abstinência (fissura, tontura, peso na cabeça, dor de cabeça, dificuldade de concentração e confusão) ao parar de fumar?
a) $\operatorname{Sim}($ )
b) Não ( )
c) Não sei ( )

73. Qual a eficácia dos seguintes métodos na cessação do tabagismo:

\begin{tabular}{|l|l|l|l|l|l|}
\hline & $\begin{array}{l}\text { Nada } \\
\text { efetivo }\end{array}$ & $\begin{array}{l}\text { Pouco } \\
\text { efetivo }\end{array}$ & Efetivo & $\begin{array}{l}\text { Muito } \\
\text { efetivo }\end{array}$ & Não sei \\
\hline a) Força de vontade & & & & & \\
\hline b) Acupuntura & & & & & \\
\hline c) Aconselhamento médico & & & & & \\
\hline d) Material de Auto ajuda & & & & & \\
\hline $\begin{array}{l}\text { e) Terapia de reposição de } \\
\text { nicotina(TRN) }\end{array}$ & & & & & \\
\hline $\begin{array}{l}\text { f) Bupropiona } \\
\text { (antidepressivo inibidor de } \\
\text { seretonina, nome comercial: } \\
\text { Wellbutrin, Bup, Zetron, } \\
\text { Zyban) }\end{array}$ & & & & & \\
\hline
\end{tabular}




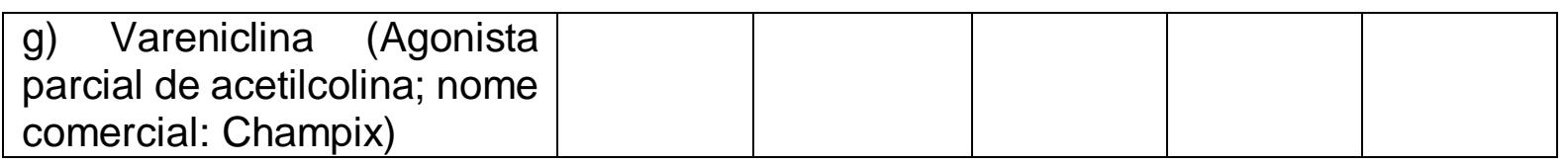

74. Na sua opinião qual o componente do cigarro que é o principal responsável pelo aumento do risco de doenças coronárias entre os fumantes?
a) Nicotina ( )
b) Alcatrão ( )
c) Aditivos de sabor ( )
d) Não sei ( )

75. Você conhece a porcentagem de fumantes no Brasil atualmente?
a) Menos de $10 \%$ da população ( )
b) $10-20 \%$ da população ( )
c) $20-40 \%$ da população ( )
d) Mais de $40 \%$ da população ( )
e) Não sei ( )

76. Você acha que profissionais de saúde deveriam aconselhar rotineiramente seus pacientes fumantes a parar de fumar?
a) $\operatorname{Sim}($ )
b) Não ( )
c) Não sei ( )

77. Você acha que a probabilidade de um fumante parar de fumar aumenta se um profissional de saúde o aconselha a parar?
a) $\operatorname{Sim}($ )
b) Não ( )
c) Não sei ( )

78. Você acha que os profissionais de saúde que fumam são menos propensos a aconselhar seus pacientes a parar de fumar?
a) $\operatorname{Sim}($ )
b) Não ( )
c) Não sei ( )

79. Você acha que os profissionais de saúde deveriam aconselhar rotineiramente seus pacientes a evitar outras formas de uso de tabaco ( por exemplo: produtos de tabaco não fumados, cigarro eletrônico)
a) $\operatorname{Sim}($ )
b) Não ( )
c) Não sei ( )

80. Você acha que os profissionais de saúde são modelos de conduta para seus pacientes e o público?
a) $\operatorname{Sim}($ )
b) Não ( )
c) Não sei ( ) 
81.Em relação aos seguintes itens, responda de acordo com sua opinião/conhecimento:

\begin{tabular}{|c|c|c|c|c|c|c|c|c|c|}
\hline & \multicolumn{3}{|c|}{$\begin{array}{l}\text { São seguros } \\
\text { para uso na } \\
\text { gestação }\end{array}$} & \multicolumn{3}{|c|}{$\begin{array}{l}\text { Aumentam o } \\
\text { risco de alguns } \\
\text { tipos de câncer }\end{array}$} & \multicolumn{3}{|c|}{$\begin{array}{l}\text { Aumentam } \\
\text { risco } \\
\text { doenças } \\
\text { cardiovasculare } \\
\text { s }\end{array}$} \\
\hline & Sim & Não & $\begin{array}{l}\text { Não } \\
\text { sei }\end{array}$ & Sim & Não & $\begin{array}{l}\text { Não } \\
\text { sei }\end{array}$ & Sim & Não & $\begin{array}{l}\text { Não } \\
\text { sei }\end{array}$ \\
\hline $\begin{array}{l}\text { a) Narguilé ou cachimbo } \\
\text { d'água }\end{array}$ & & & & & & & & & \\
\hline b) Cachimbo & & & & & & & & & \\
\hline c) Charuto & & & & & & & & & \\
\hline d) Cigarrilhas & & & & & & & & & \\
\hline $\begin{array}{l}\text { e) Cigarro de cravo, } \\
\text { cigarros de Bali, cigarro da } \\
\text { India }\end{array}$ & & & & & & & & & \\
\hline f) Cigarros de palha & & & & & & & & & \\
\hline g) Rapé (tabaco em pó) & & & & & & & & & \\
\hline $\begin{array}{l}\text { h) Cigarro eletrônico/e- } \\
\text { cigarette }\end{array}$ & & & & & & & & & \\
\hline i) Fumo de mascar & & & & & & & & & \\
\hline
\end{tabular}

82. Em relação aos seguintes itens, assinale de acordo com sua opinião/ conhecimento, se o mesmo contem Nicotina:

\begin{tabular}{|l|l|l|l|}
\hline & Sim & Não & Não sei \\
\hline a) Narguilé ou cachimbo d'água & & & \\
\hline b) Cachimbo & & & \\
\hline c) Charuto & & & \\
\hline d) Cigarrilhas & & & \\
\hline e) Cigarro de cravo, cigarros de Bali, cigarro da India & & & \\
\hline f) Cigarros de palha & & & \\
\hline g) Rapé (tabaco em pó) & & & \\
\hline h) Cigarro eletrônico/e-cigarette & & & \\
\hline i) Fumo de mascar & & & \\
\hline
\end{tabular}

83. Em relação ao seguintes itens, assinale de acordo com sua opinião/conhecimento se os mesmos podem causar dependência:

\begin{tabular}{|l|l|l|l|}
\hline & Sim & Não & Não sei \\
\hline a) Narguilé ou cachimbo d'água & & & \\
\hline b) Cachimbo & & & \\
\hline c) Charuto & & & \\
\hline d) Cigarrilhas & & & \\
\hline e) Cigarro de cravo, cigarros de Bali, cigarro da India & & & \\
\hline f) Cigarros de palha & & & \\
\hline
\end{tabular}




\begin{tabular}{|l|l|l|l|}
\hline g) Rapé (tabaco em pó) & & & \\
\hline h) Cigarro eletrônico/e-cigarette & & & \\
\hline i) Fumo de mascar & & & \\
\hline
\end{tabular}

84. Durante o curso de Medicina, você teve alguma aula sobre os perigos do cigarro para a saúde?
a) $\operatorname{Sim}($ )
b) Não ( )
c) Não tenho certeza/não me lembro ( )

85. Durante o curso de Medicina, você recebeu algum treinamento para avaliar e tratar o tabagismo?
a) $\operatorname{Sim}($ )
b) Não ( )
c) Não tenho certeza/não me lembro ( )

86. Você pergunta para o paciente sobre tabagismo?
a) Sim, sempre ( )
b) Sim, mas apenas para alguns casos específicos ( )
c) Não ( )

87. Se o paciente é fumante, você discute o assunto com ele e o orienta em relação ao abandono?
a) Sim, sempre ( )
b) Sim, mas apenas para alguns casos específicos ( )
c) Não ( )

88. Você se sente confiante para aconselhar um paciente que deseja parar de fumar?
a) $\operatorname{Sim}($ )
b) Não ( )

89. Você se considera capacitado para prescrever tratamento farmacológico para cessação de tabagismo?
a) $\operatorname{Sim}($ )
b) Não ( ) 
APÊNDICE B

Projeto de pesquisa

\title{
CIGARRO E OUTRAS FORMAS DE TABACO: INVESTIGAÇÃO DE CONHECIMENTO, ATITUDES E PERCEPÇÃO DE RISCO EM ESTUDANTES DE MEDICINA
}

\author{
TERMO DE CONSENTIMENTO LIVRE E ESCLARECIDO
}

Você está sendo convidado(a) a participar de um estudo chamado "Cigarro e outras formas de tabaco: investigação de conhecimento, atitudes e percepção de risco em estudantes de Medicina". Antes de você decidir sobre a sua participação é importante que você entenda porque esta pesquisa está sendo realizada e do que ela trata. Por favor, leia as seguintes informações com cuidado e fique à vontade para fazer perguntas, caso haja algo que não esteja claro para você ou se você precisar de mais detalhes.

Obrigada pelo seu interesse em nosso projeto.

\section{Qual o objetivo deste estudo?}

O uso de tabaco, tanto na forma de cigarros quanto na forma de cachimbos e charutos é um problema de Saúde Pública mundial. Os profissionais de saúde lidam com pacientes portadores de diversas doenças causadas pelo uso do tabaco e com pessoas que desejam parar de fumar.

Este estudo tem como objetivos avaliar as atitudes, comportamentos, crenças e conhecimento a respeito do tabaco entre os alunos ingressantes e formandos do curso de graduação em Medicina em relação ao uso do tabaco (tanto do cigarro quanto das outras formas de tabaco como charutos, cachimbos, fumo mascado, bem como de formas recentes de equipamentos eletrônicos que liberam nicotina por vaporização, os chamados cigarros eletrônicos).

\section{Por que eu fui foi convidado?}

Você foi convidado para participar do estudo porque você é aluno de graduação de curso de Medicina, e está regularmente matriculado no primeiro ou último ano do curso, na cidade de Ribeirão Preto - SP, onde nós estamos conduzindo o estudo. Todos os alunos de sua turma serão convidados a participar.

Você deve ter idade mínima de 18 anos para participar.

\section{Eu sou obrigado a participar?}

Esta é uma escolha sua. Antes que você concorde em participar, nós descreveremos o estudo ao longo desse termo de informação. Nós então pediremos que você assine um termo de consentimento para demonstrar que você concordou em participar. Você é livre para se retirar do estudo a qualquer momento, sem dar explicações. Essa escolha não irá afetar suas notas ou avaliações no seu curso, nem quaisquer cuidados de saúde que poderá a vir receber no Hospital das Clínicas FMRP-USP.

\section{O que me pedirão para fazer?}

Nós pediremos que você responda, por escrito, a alguns questionários que incluem perguntas sobre seus dados sociodemográficos, sobre seu uso passado e atual de tabaco, álcool e outras substâncias como drogas ilícitas, sobre o que você pensa e conhece a respeito do uso do tabaco e do tratamento do tabagismo. Também há questões sobre suas atitudes em relação às doenças em geral e como você se sente em relação 
a estados de ansiedade. sobre suas atitudes em relação a doenças em geral. Se você for aluno do último ano de graduação, você também receberá questões sobre a formação em tabagismo que você recebeu durante o curso médico.

\section{Quanto tempo irá durar a coleta de dados?}

Nós estimamos que o preenchimento de todos os questionários leve cerca de 2 horas. Você é livre para fazer pausas em qualquer momento que desejar e pode escolher o melhor horário e local para respondêlos. Apenas solicitamos que você os responda individualmente, em local com privacidade, para que possa dedicar atenção à atividade. Solicitamos também que você devolva os questionários preenchidos para a pesquisadora, em momento a ser agendado, que não deve ultrapassar 2 semanas desde que você os recebeu.

\section{Eu receberei algum pagamento?}

Não haverá nenhum tipo de pagamento por sua participação neste estudo. Não está previsto nenhum tipo de gasto financeiro por parte dos participantes. Se houver despesa pelos participantes por conta da pesquisa ou em decorrência dela, os participantes serão ressarcidos.

\section{Onde o estudo será realizado?}

Você receberá os questionários em mãos, nas dependências da sua faculdade ou local de estágio, em horários pré-determinados com os professores responsáveis pelo seu período atual do curso. Não haverá necessidade de seu deslocamento até a equipe de pesquisa.

\section{O que acontecerá se eu optar por sair do estudo?}

A participação no estudo é absolutamente voluntária. Você é livre para mudar de ideia a qualquer momento. Todas as informações pessoais serão destruídas. Esta situação também se aplica no caso de você se sentir indisposto para continuar participando do estudo.

\section{Quais são os possíveis riscos e benefícios da participação?}

Nós faremos perguntas sobre circunstâncias pessoais, o que algumas pessoas podem considerar angustiante. As pesquisadoras responsáveis pela coleta de dados são psicólogas treinadas e experientes e oferecerão suporte se você precisar. Você também poderá achar o preenchimento dos questionários cansativo e então você poderá fazer uma pausa ou retomar em outra ocasião para completá-lo. Você não tem obrigação de responder nenhuma questão e você pode sair do estudo a qualquer momento.

Ao participar do estudo você irá nos ajudar a entender mais sobre os hábitos de saúde dos estudantes de Medicina e sobre as informações que os mesmos têm a respeito do tabagismo.

Essas informações são importantes para que os currículos dos cursos de Medicina sejam constantemente aprimorados e para que ações de prevenção e tratamento do tabagismo possam ser melhor desenvolvidas. Todos os participantes receberão, no momento em que devolverem os questionários à pesquisadora, informações por escrito sobre como proceder no caso de interesse em busca de orientação ou tratamento para uso ou abuso de substâncias (tabaco, álcool ou outras drogas)

\section{O que acontecerá com as minhas informações?}

Sua confidencialidade será mantida em todos os momentos e o manuseio e arquivamento dos questionários seguirão as práticas éticas e legais. Todas as informações sobre você serão manejadas com estrita confidencialidade. Os questionários serão identificados apenas por um número, que será utilizado no lugar dos seus dados pessoais. Isso significa que toda informação que você nos der será efetivamente anônima. Informações identificáveis (como o seu nome) serão registradas em uma base de dados separada e protegida por senha, sendo acessível somente pela coordenadora do projeto. Suas respostas serão digitadas em planilhas eletrônicas, mas seu nome não será incluído nestas, apenas seu número. Você 
poderá ter acesso ao seu questionário e tirar dúvidas sobre qualquer questão após a entrega do mesmo, se assim o desejar, desde que autorize a pesquisadora a identificá-lo.

No final do estudo suas informações serão mantidas seguras por no mínimo 20 anos de acordo com as boas práticas de pesquisa e não serão utilizados com nenhum outro propósito além dos descritos no estudo. Se você decidir se retirar do estudo nós iremos destruir toda informação pessoal que nós temos de você, mas nós poderemos manter seus dados anonimamente para nossa pesquisa. Os resultados deste estudo serão publicados em jornais científicos em um nível grupal e não individual. Nós não iremos nunca revelar informações pessoais sobre você, nem nas publicações científicas, nem em aulas ou palestras ou meios de comunicação.

O que acontecerá se eu tiver algum dano em função do estudo?

Como a participação neste estudo restringe-se ao preenchimento de questionários, não há risco de danos físicos ou materiais decorrentes do mesmo, além dos descritos anteriormente (desconforto emocional ou cansaço durante o preenchimento). No entanto, caso você tenha algum dano em relação a sua saúde em função da realização do estudo, Ihe será oferecido acompanhamento clínico no Hospital das Clínicas com direito à assistência integral e a indenização, se for o caso.

\section{Onde eu posso conseguir mais informação sobre o estudo?}

Você pode entrar em contato com os responsáveis pelo estudo sobre qualquer dúvida que você tiver. Os contatos estão detalhados abaixo.

\section{Onde eu posso fazer reclamações e/ou esclarecimentos sobre o estudo?}

Se você está descontente ou precisar de esclarecimentos sobre como este estudo está sendo realizado você pode fazer contato, a qualquer momento, com os responsáveis pelo estudo e com o Comitê de Ética em Pesquisa que garante as boas práticas de pesquisa além de zelar pelo cumprimento do que é descrito neste termo de consentimento livre e esclarecido.

Você estará recebendo uma cópia integral deste documento, no qual constam os contatos abaixo:

\section{Coordenadora}

Prof. Dra. Maristela

Schaufelberger Spanghero

\section{CREMESP 94146}

Departamento de Neurociências e Ciências do Comportamento, Faculdade de Medicina de Ribeirão Preto, USP.

Avenida dos Bandeirantes, 3900, CEP 14049-900

Email: maristela-ss@usp.br

\section{Pesquisadora responsável}

Tatiana Braga Soares

CRP 10/01743

Departamento de

Neurociências e Ciências do Comportame Faculdade de Medicina de Ribeirão Preto, USP.

Avenida dos Bandeirantes, 3900,

CEP 14049-900, Ribeirão Preto, SP

Fone 16-30215490

Email: projetotabagismomed@gmail.com

\section{Comitê de Ética em Pesquisa - HCFMRP}

Avenida dos Bandeirantes, 3900 CEP: $14049-900$

Fone: 16 3602-2228

E-mail: cep@hcrp.usp.br Horário de funcionamento: Segunda à sexta das $8 \mathrm{~h}$ às $17 \mathrm{~h}$. 


\title{
CIGARRO E OUTRAS FORMAS DE TABACO: INVESTIGAÇÃO DE CONHECIMENTO, ATITUDES E PERCEPÇÃO DE RISCO EM ESTUDANTES DE MEDICINA
}

\author{
Coordenadora: Maristela Schaufelberger Spanghero (CREMESP: 94146) \\ Pesquisadora responsável: Tatiana Braga Soares (CRP: 10/01743)
}

TERMO DE CONSENTIMENTO LIVRE E ESCLARECIDO

Antes de você concordar em participar deste estudo, é importante que você tenha lido e entendido o Termo de Consentimento Livre e Esclarecido, que é elaborado em duas vias sendo uma de propriedade do pesquisador e outra do participante. Todas as páginas, das duas vias do termo de consentimento deverão ser rubricadas pelo participante e pelo pesquisador do estudo e estes deverão assiná-lo ao seu término. $O$ termo de consentimento contém informações importantes sobre a pesquisa e sobre o que será pedido para você fazer. Se você se sentir inseguro sobre o projeto ou tiver alguma dúvida, você pode fazer perguntas para qualquer membro da equipe de pesquisa. As declarações abaixo contêm informações importantes sobre a sua participação no estudo. Por favor, leia estas declarações e coloque as iniciais do seu nome no espaço apropriado

\begin{tabular}{|l|l|}
\hline & INICIAIS \\
\hline $\begin{array}{l}\text { Eu li e entendi o termo de consentimento livre e esclarecido e todas as minhas } \\
\text { dúvidas foram respondidas satisfatoriamente. }\end{array}$ & \\
\hline $\begin{array}{l}\text { Eu entendo que a minha participação no estudo é voluntária e que eu posso mudar } \\
\text { de ideia a qualquer momento, sem motivo ou qualquer prejuízo, e que isso não irá } \\
\text { afetar o andamento do meu curso atual ou meus direitos legais. }\end{array}$ & \\
\hline $\begin{array}{l}\text { Eu entendo que as minhas informações serão armazenadas confidencialmente e } \\
\text { anonimamente e que não serão repassadas a terceiros ou usadas de outra forma a } \\
\text { não ser para responder questões relevantes para os objetivos do estudo, exceto } \\
\text { quando os pesquisadores tiverem obrigação de informar aos meus cuidadores se eu } \\
\text { estiver em risco de causar danos a mim ou a outras pessoas. }\end{array}$ & \\
\hline $\begin{array}{l}\text { Eu entendo que as minhas informações podem ser utilizadas anonimamente, } \\
\text { contribuindo para apresentações e artigos científicos. }\end{array}$ & \\
\hline
\end{tabular}

Por meio desta, concordo em participar do estudo e entendo que a minha participação é totalmente voluntária e que eu posso retirar o meu consentimento em qualquer momento, sem necessidade de expor minhas razões e sem sofrer penalidades. 


\title{
Cigarro e outras formas de tabaco: investigação de conhecimento, atitudes e percepção de risco em estudantes de Medicina
}

\author{
Tatiana de Abreu Braga Soares ${ }^{1}$, Flávia de Lima Osório ${ }^{2}$ \\ ${ }^{1}$ Aluna de mestrado do Programa de Pós-graduação em Saúde Mental, Departamento de \\ Neurociências e Ciências do Comportamento da Faculdade de Medicina de Ribeirão Preto \\ - USP \\ 2 Profa ${ }^{a}$. Dra . Orientadora do Programa de Pós-graduação em Saúde Mental, Departamento \\ de Neurociências e Ciências do Comportamento da Faculdade de Medicina de Ribeirão \\ Preto - USP
}

Objetivo: caracterizar o perfil de consumo, percepção de risco, atitudes e conhecimentos a respeito de tabagismo em estudantes de Medicina do $1^{\circ}$ e $6^{\circ}$ anos. Método: Foram entrevistados alunos do curso de Medicina de 4 faculdades de Ribeirão Preto-SP, em 2016 e 2017. O questionário incluiu dados sociodemográficos, de exposição ao tabaco, substâncias psicoativas, motivação para cessação, avaliação de conhecimento médico sobre tabagismo, atitudes perante o tabaco e percepção de risco. Resultados: Dos 859 alunos convidados, 420 responderam o questionário. Os resultados estão de acordo com o que vem sendo descrito na literatura. Prevalência de tabagismo: semelhante à encontrada no Brasil; idade média de experimentação: 17,5 anos. Maioria não se via como dependente de tabaco, fazia uso ocasional e utilizava principalmente o Narguilé $(15,2 \%)$, considerado mais prejudicial quando comparado ao cigarro comum ( $>0,001)$. Consumo de álcool elevado e descrito como facilitador para o uso de tabaco; nicotina considerada como viciante ( $p>0,001)$; fumo ocasional prejudicial $(88,3 \%)$. Os alunos acreditam que: $93,1 \%$ deveriam aconselhar seus pacientes a parar de fumar; $63,7 \%$ profissionais fumantes seriam menos propensos a aconselhar; $81,3 \%$ deveriam aconselhar a evitar outras formas de tabaco e $78,2 \%$ profissionais são modelo. Há falta de conhecimento e percepção de risco distorcida relacionada ao potencial de dependência dos produtos alternativos de tabaco e riscos do tabagismo. Conclusões: ações que trabalhem especialmente as crenças, percepções de risco e atitudes a respeito dos diferentes tipos de tabaco, são necessárias para maior conscientização quanto ao uso e prejuízos à saúde causados pelo tabagismo. 
Palavras chaves: Tabagismo, estudantes de medicina, conhecimento médico, percepção de risco.

\section{Introdução}

Atualmente cerca de $21 \%$ da população mundial é usuária de tabaco, o que o torna uma das substâncias aditivas mais utilizada no mundo. Além disso, uma em cada 10 mortes são causadas pelo tabaco(1). Além da dependência à nicotina, a exposição às diversas substâncias que constituem o tabaco relacionase a cerca de 50 doenças, em especial a doenças cardiovasculares e respiratórias, doença pulmonar obstrutiva crônica e, de maneira relevante, a diversos tipos de câncer (2). O tabagismo é a principal causa global evitável de morbidade e mortalidade, e tem relevante impacto econômico, respondendo por prejuízos econômicos devido à perda de produtividade, adoecimento e mortes prematuras ${ }^{\cdot(3)}$ No Brasil, apesar da adesão às propostas da Convenção-Quadro, da OMS (WHO Framework Convention on Tobacco Control), a prevalência de fumantes ainda é relevante ${ }^{(4)}$ e, mesmo havendo queda recente do número de fumantes, espera-se que nas próximas décadas o impacto das doenças associadas ao fumo sobre o Sistema de Saúde ainda seja extremamente relevante. ${ }^{(5)}$

Cerca de $80 \%$ dos tabagistas começam a usar tabaco antes dos 18 anos de idade.(6) Um estudo com jovens com idade média de 16 anos na cidade de Ribeirão Preto, mostrou que jovens experimentadores de tabaco têm maior risco de se tornar tabagista através do consumo de álcool, uso de drogas ilícitas e amigos fumantes. ${ }^{(7)}$ Apesar do conhecimento crescente acerca dos riscos à saúde associados ao fumo, a queda no consumo em jovens e adultos que vinha ocorrendo nos últimos anos, vem estagnando.

Enquanto o uso de cigarros vem diminuindo mais lentamente, o uso de formas não combustíveis de tabaco mantém-se estável, e observa-se, atualmente, o uso concomitante de mais de uma forma de tabaco entre os jovens. A tendência que se observa é a de popularização e uso crescente dos chamados produtos de tabaco alternativos ou formas alternativas de tabaco. E, entre os jovens brasileiros, inclusive entre os universitários, vem se disseminando, o uso do 
tabaco através do narguilé, sendo considerado como o tabaco da moda do século XXI, assim como o cigarro o foi no século XX. ${ }^{(8)}$

É sabido que os profissionais de saúde têm um papel fundamental na redução do uso de tabaco e que mesmo intervenções breves podem aumentar a chance de cessação dos fumantes. ${ }^{(9)}$ Sendo o tabagismo uma pandemia relacionada a altas taxas de morbimortalidade, o treinamento de profissionais de saúde em relação à prevenção e ao tratamento e cessação do uso de tabaco é fundamental. Do mesmo modo que, como o início do uso se dá geralmente na adolescência, deve-se lembrar da importância de se avaliar os futuros profissionais de saúde ainda enquanto estudantes, na faixa de maior risco para transição de uso para dependência. Além disso, é durante o curso de formação que os profissionais vão adquirir treinamento adequado para abordagem do tabagismo.

Estudo realizado pelo Ministério da Saúde em 2009 com alunos no terceiro ano de graduação, mostra que, apesar da maioria dos alunos reconhecerem que os profissionais de saúde devem receber treinamento em cessação de tabagismo e que eles devem rotineiramente aconselhar seus pacientes a parar de fumar, 22 a 50\% deles não acreditam que profissionais de saúde têm papel como modelo de comportamento. ${ }^{(10)}$ Como no curso de Medicina o contato com o paciente e o treinamento clínico ocorre principalmente durante o internato (dois últimos anos), seria recomendável que se avaliasse os alunos no final do curso, não no terceiro ano.

Outro ponto importante é a avaliação sobre percepção de risco relacionada ao uso ocasional de tabaco e do risco de transição desse uso para dependência e quais os fatores associados ao uso ocasional e ao uso regular.

O presente estudo objetivou caracterizar o perfil de consumo, crenças, atitudes e conhecimentos a respeito de tabagismo em estudantes de Medicina que ainda não tiveram qualquer treinamento médico formal ou prática clínica, e em estudantes de Medicina que já passaram por todo o período de treinamento formal (teórico e prático) do curso de graduação, do 1․ e 6ํ․ anos.

\section{MÉTODOS}


Nos anos de 2016 e 2017, estudantes de Medicina do $1^{\circ}$ e $6^{\circ}$ anos da FMRP-USP, UniSEB, UNAERP e Universidade Barão de Mauá da cidade de Ribeirão Preto foram convidados a preencher um questionário autoaplicável desenvolvido para o estudo, que investigava: perfil de uso de tabaco e percepção de risco, uso de outras substâncias, conhecimento médico, atitudes e práticas. A participação foi voluntária e o preenchimento aconteceu nos períodos de aula. Os alunos participantes assinaram um termo de consentimento livre e esclarecido. O estudo foi aprovado pelo comitê de ética do Hospital das Clínicas da FMRP-USP (Processo HCRP n204/2015).

Foram considerados fumantes alunos que fumaram mais de 100 cigarros na vida e que continuavam fumando no momento da coleta de dados.

Os dados foram analisados com o programa Statistical Package for the Social Sciences (SPSS) versão 20 (IBM Corporate); foram realizadas análises descritivas e para comparação dos grupos (alunos $1^{\circ}$ e $6^{\circ}$ anos), utilizou-se de testes como: Qui-quadrado ou teste Exato de Fisher, teste T de Student e o teste para duas proporções com correção de Bonferroni. Adotou-se como nível de significância para todas as análises $p \leq 0,05$.

\section{RESULTADOS}

De um total de 859 alunos, 420 (48,9\%) responderam o questionário. As médias de idade dos alunos do primeiro ano e do sexto ano foram $20 \pm 3,2$ anos e $25 \pm 2,2$ anos, respectivamente. A maioria era do sexo feminino (63,3\%). A prevalência de tabagismo foi de $6,2 \%$ para o $1^{\circ}$ ano e $16,9 \%$ para o $6^{\circ}$ ano.

Para os fumantes atuais, o principal motivo para continuar a fumar era $o$ fato de considerarem esta prática um hábito relaxante (Figura1). Houve diferença significativa entre os grupos apenas para os motivos "ingestão de álcool", sextanistas o faziam mais frequentemente $(p<0,001)$ e "não fumo com frequência" $(p<0,001)$. O consumo de álcool foi elevado, $45,5 \%$ dos alunos do $1^{\circ}$ ano e $38,6 \%$ dos alunos do 6을 ano, faziam uso semanal. $O$ álcool foi apontado como um facilitador para o uso de tabaco. 


\section{Motivos para fumar atualmente}

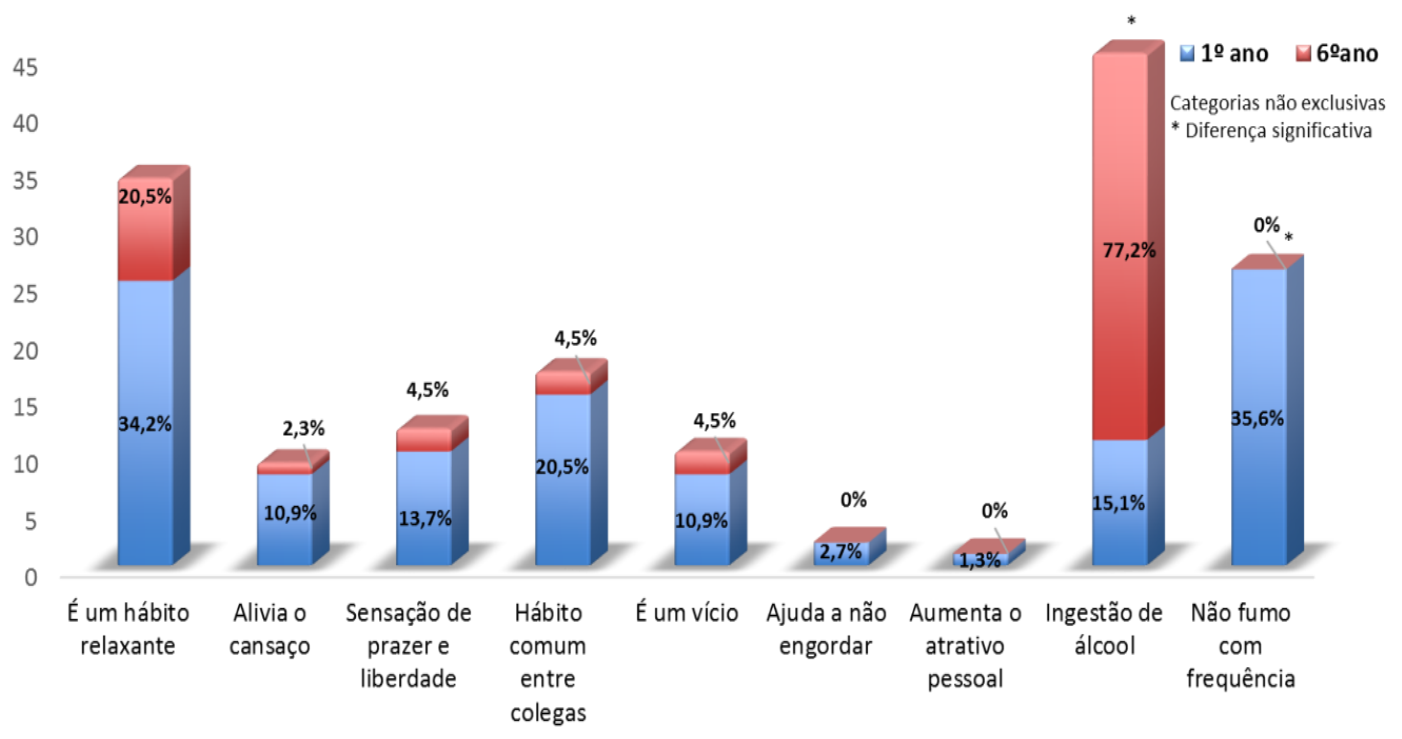

Figura 1- Caracterização dos estudantes do $1^{\circ}(\mathrm{N}=73)$ e $6^{\circ}$ ano $(\mathrm{N}=44)$ de Medicina quanto as motivos para fumar atualmente

A forma de uso de tabaco com maior prevalência foi o Narguilé, sendo o produto mais utilizado ocasionalmente pelos estudantes da amostra $(14,2 \%)$ do $1^{\circ}$ ano e $(19,3 \%)$ do $6^{\circ}$ ano, sem diferença significativa (Tabela 1), e foi o segundo produto mais utilizado de forma geral. Este produto foi experimentado mais frequentemente pelos alunos do $6^{\circ}$ ano após o ingresso à faculdade de Medicina $\left(1,8 \%\right.$ do $1^{\circ}$ ano e $16,9 \%$ do $6^{\circ}$ ano, $\left.p<0,001\right)$. 
Tabela 1- Frequência de uso atual de produtos do tabaco pelos estudantes do $1^{\circ}(\mathrm{N}=337)$ e $6^{\circ}$ ano $(\mathrm{N}=83)$ de Medicina

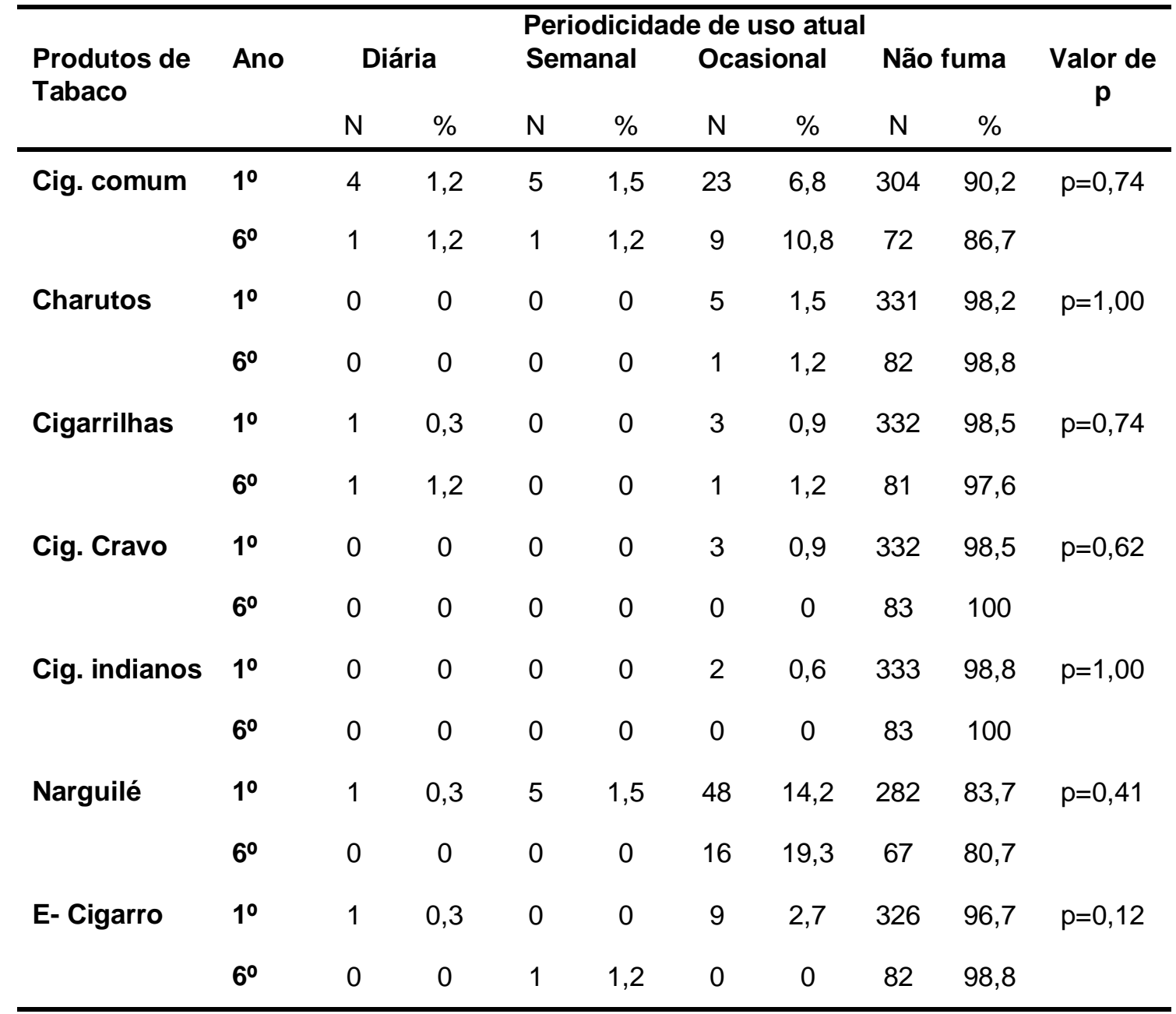

Cig= cigarro, E= eletrônico, $\mathrm{NI}=$ não informado, $\mathrm{N}$ = frequência, \%= percentual, $\mathrm{X}^{2}$ = Qui-quadrado, $\mathrm{p}=$ nível de significância

No que se refere a nicotina ser tão viciante quanto a cocaína, alunos do $1^{\circ}$ ano $(23,0 \%)$ não sabiam responder e alunos do 6ํano $(75,9 \%)$ afirmaram que $\operatorname{sim}(p<0,001)$.

Não houve diferença significativa em relação às seguintes percepções: 94,7\% respondeu que a nicotina causa dependência e 52,5\% deles referiu não ser seguro fumar por apenas um período de tempo, mesmo que um ou dois anos; O grupo de alunos do $1^{\circ}$ ano (15,8\%) considerou fumantes as pessoas que faziam uso do tabaco diariamente; demonstrou ter dúvidas quanto aos malefícios dos produtos de tabaco em relação ao aumento da probabilidade de causar algum tipo de câncer. Já os alunos do 6ㅇa ano (91,6\%) não relacionaram o status de fumante ao fumo diário $(p=0,016)$. Os alunos estavam conscientes quanto aos prejuízos do tabagismo na gestação, demonstraram ter 
maior conhecimento em relação aos malefícios dos produtos alternativos de tabaco os considerando produtos com potencial para aumentar o risco de alguns tipos de câncer.

Os alunos acreditam que: profissionais de saúde deveriam aconselhar seus pacientes a parar de fumar $(93,1 \%)$, a evitar outras formas de tabaco (81,3\%); são modelos para seus pacientes e público em geral $(78,2 \%)$; profissionais de saúde fumantes são menos propensos a aconselhar seus pacientes $(63,7 \%)$, sem diferença significativa entre os grupos.

Os grupos se diferenciaram no que diz respeito à crença de que 0 aconselhamento médico aumentaria a probabilidade da cessação: alunos do $1^{\circ}$ ano tinham dúvida (12,2\%) e não acreditavam no aumento da probabilidade de cessação com aconselhamento médico $(27,8 \%)$ com maior frequência, já o grupo do 60 ano $(86,7 \%)$ acreditava que $\operatorname{sim}(p<0,001)$.

Em relação ao conhecimento sobre o potencial de dependência dos produtos alternativos de tabaco (Tabela2), o narguilé $(p=0,007)$ foi considerado pelos alunos do $1^{\circ}$ ano um produto que não causa dependência, o charuto $(\mathrm{p}=0,05)$ considerado pelos estudantes do 60 ano um produto que causa dependência. $O$ cigarro de palha $(p=0,02)$ gerou mais dúvida nos alunos do $1^{\circ}$ ano e foi considerado pelos alunos do $6^{\circ}$ ano um produto que pode causar dependência. 
Tabela 2- Conhecimento quanto ao potencial de dependência dos produtos de tabaco pelos estudantes do $1^{\circ}(\mathrm{N}=337)$ e $6^{\circ}(\mathrm{N}=83)$ ano de Medicina

\begin{tabular}{|c|c|c|c|c|c|c|c|c|}
\hline \multirow{3}{*}{ Produtos de Tabaco } & \multicolumn{7}{|c|}{ Causa dependência } & \multirow{3}{*}{ Valor de $\mathrm{p}$} \\
\hline & \multirow[t]{2}{*}{ Ano } & \multicolumn{2}{|c|}{ Sim } & \multicolumn{2}{|c|}{ Não } & \multicolumn{2}{|c|}{ Não sei } & \\
\hline & & $\mathrm{N}$ & $\%$ & $\mathrm{~N}$ & $\%$ & $\mathrm{~N}$ & $\%$ & \\
\hline \multirow[t]{2}{*}{ Narguilé } & 10 & 220 & 65,3 & 56 & 16,6 & 59 & 17,5 & $p=0,007^{*}$ \\
\hline & 60 & 68 & 81,9 & 4 & 4,8 & 11 & 13,3 & \\
\hline \multirow[t]{2}{*}{ Cachimbo } & 10 & 271 & 80,4 & 12 & 3,6 & 52 & 15,4 & $p=0,07$ \\
\hline & 60 & 76 & 91,6 & 1 & 1,2 & 6 & 7,2 & \\
\hline \multirow[t]{2}{*}{ Charuto } & $1^{0}$ & 269 & 79,8 & 15 & 4,5 & 51 & 15,1 & $\mathrm{p}=0,05^{\star}$ \\
\hline & $6^{\circ}$ & 76 & 91,6 & 1 & 1,2 & 6 & 7,2 & \\
\hline \multirow[t]{2}{*}{ Cigarrilhas } & $1^{0}$ & 257 & 76,3 & 5 & 1,5 & 73 & 21,7 & $p=0,11$ \\
\hline & 60 & 72 & 86,1 & 0 & 0 & 11 & 13,3 & \\
\hline \multirow[t]{2}{*}{ Cigarros de bali/cravo } & 10 & 251 & 74,4 & 4 & 1,2 & 80 & 23,7 & $p=0,13$ \\
\hline & 60 & 69 & 83,1 & 2 & 2,4 & 12 & 14,5 & \\
\hline \multirow[t]{2}{*}{ Cigarros de palha } & 10 & 276 & 81,9 & 5 & 1,5 & 53 & 15,7 & $\mathrm{p}=0,02^{*}$ \\
\hline & 60 & 79 & 95,2 & 0 & 0 & 4 & 4,8 & \\
\hline \multirow[t]{2}{*}{ Rapé } & 10 & 256 & 75,9 & 4 & 1,2 & 75 & 22,3 & $p=0,23$ \\
\hline & 60 & 65 & 78,3 & 3 & 3,6 & 15 & 18,1 & \\
\hline \multirow[t]{2}{*}{ Cigarro eletrônico } & 10 & 207 & 61,4 & 36 & 10,7 & 92 & 27,3 & $p=0,17$ \\
\hline & 60 & 60 & 72,3 & 5 & 6,0 & 18 & 21,7 & \\
\hline \multirow[t]{2}{*}{ Fumo de mascar } & 10 & 249 & 73,4 & 12 & 3,6 & 74 & 21,9 & $\mathrm{p}=0,28$ \\
\hline & 60 & 67 & 80,7 & 4 & 4,8 & 12 & 14,5 & \\
\hline
\end{tabular}

\section{DISCUSSÃO}

Futuros médicos tem um importante papel na prevenção, controle e cessação do tabagismo. sendo assim, é necessário que se tenha conhecimento quanto aos produtos alternativos de tabaco e seus malefícios, bem como o impacto de sua conduta.

A amostra era composta principalmente por mulheres com idade entre 20 e 25 anos. Dados semelhantes foram encontrados em outros estudos brasileiros $^{(11,12,13)}$ e em estudos internacionais. ${ }^{(14,15,16)}$ Em dois estudos na Arábia saudita obteve-se uma prevalência do sexo masculino. ${ }^{(17,18)}$ 
A prevalência de tabagismo encontrada foi semelhante à prevalência de tabagismo no Brasil e menor que a prevalência mundial $21,0 \%,{ }^{(1)}$ mostrando-se elevada para futuros de profissionais da saúde.

O uso de álcool era elevado e foi considerado, pela amostra, um facilitador para o consumo de tabaco, $(7,12,19,20,21,22)$ sendo a ingestão de álcool um dos motivos apontados para fumar atualmente, principalmente pelos alunos sextanistas, em conformidade com estudos anteriores. ${ }^{(22,23)}$ Outro motivo apontado, foi considerar fumar um hábito relaxante. Não obstante, alunos sextanistas já tiveram treinamento referente aos prejuízos do uso de tabaco e acabam por desconsidera-los em seu uso ocasional. Desconsideram, também, o potencial de dependência da nicotina, mesmo acreditando que essa substância é tão aditiva quanto a cocaína e que não é seguro fumar, mesmo que por um curto período de tempo. Dessa forma, é fundamental que campanhas de prevenção e conscientização abordem o uso de álcool e tabaco em conjunto, na tentativa de reduzir a morbidade futura decorrente do uso dessas substâncias. Há um alto índice de alunos do $1^{\circ}$ ano que consideram não fazer uso do cigarro com frequência, ou seja, por não reconhecerem que têm o hábito do fumo, continuam fumando.

No presente estudo verificou-se que o cigarro comum não era o principal produto usado pelos estudantes de Medicina. O Narguilé foi o produto com maior prevalência de consumo no presente estudo, dado que está em concordância com os resultados obtidos no levantamento do Vigescola ${ }^{(24)}$ e PETab ${ }^{(25)}$. Atualmente, o Narguilé têm ganhado preferência entre os universitários ${ }^{(14)}$. A propagação do uso de outras formas de tabaco pode estar relacionada ao sucesso de programas de prevenção e cessação ao tabagismo, com foco principalmente no cigarro comum, fazendo com que os indivíduos suscetíveis ao uso de tabaco migrem para outras formas de tabaco (26).

Alunos do $1^{\circ}$ ano mostraram ter menor conhecimento dos malefícios causados pelo uso produtos de alternativos de tabaco, esse dado é esperado, já que não obtiveram treinamento formal quanto ao tabagismo. Sabe-se que a percepção de risco tem grande impacto no comportamento humano e favorece a formação de base para intervenções na saúde pública ${ }^{(27)}$.

Em conformidade com a literatura, os alunos participantes da pesquisa acreditavam que os profissionais de saúde deveriam aconselhar seus pacientes 
a parar de fumar, $(13,17,18,26,28,29,30,31)$ o que é bastante positivo, pois aqueles que atribuem pouca importância ao aconselhamento médico, podem tender a não fazê-lo quando estiverem atendendo um paciente tabagista.

O papel do médico é fundamental para o controle do tabaco. Verificou-se que os estudantes consideraram os profissionais de saúde como modelo para pacientes e público em geral. $(13,14,18,29,30,16,17,31,32) \bigcirc$ aconselhamento médico pode aumentar a taxa de cessação de 3 a 5 vezes $^{(33)}$. Os estudantes de Medicina do presente estudo, principalmente do $6^{\circ}$ ano, relataram acreditar que o aconselhamento médico facilita a cessação. ${ }^{(13,16,26,30,31,34)}$

A maioria dos participantes da pesquisa respondeu que os profissionais de saúde deveriam aconselhar seus pacientes a evitar outras formas de tabaco, em conformidade com o encontrado na literatura. $(13,30,31)$ Esses dados confirmam a importância da inserção do treinamento para a cessação do tabagismo no currículo das faculdades de Medicina.

Profissionais de saúde fumantes foram considerados menos propensos a aconselhar seus pacientes, dado que está de acordo com o que diz a literatura. ${ }^{(16,17,31,35)}$

Os estudantes do $1^{\circ}$ ano apresentaram dúvidas com mais frequência em relação a todos os produtos sobre os quais foram questionados. A crença de que alguns produtos não ameaçam a vida ou não são nocivos à saúde pode prejudicar a promoção à cessação do tabagismo(28). É de grande valia que futuros médicos tenham conhecimento quanto ao tabagismo e doenças relacionadas para que possam promover a prevenção e cessação.

\section{CONCLUSÕES}

Sabe-se que os médicos têm um papel relevante por serem modelo de saúde para seus pacientes e para a população em geral, o que demanda uma maior responsabilidade social e acadêmica por parte dos estudantes de Medicina, futuros profissionais de saúde. $O$ investimento em ações que trabalhem especialmente as crenças, percepções de risco e atitudes a respeito do cigarro comum e de formas alternativas de tabaco, são necessários para que ocorra uma maior conscientização quanto uso e prejuízos à saúde causados por esses produtos. 


\section{REFERENCIAS}

1. WHO report on the global tobacco epidemic, 2017: monitoring tobacco use and prevention policies. Geneva: World Health Organization; (2017). Licence: CC BY-NC-SA 3.0 IGO.

2. Viegas, C. A. de A. (2007). Doenças Tabaco Relacionadas. In Tabagismo do Diagnóstico à Saúde Pública. São Paulo: Atheneu.

3. Eriksen, M., Mackay, J., \& Hoss, H. (2012). The Tobacco Atlas, fourth edition. New York: American Cancer Society, Atlanta, Georgia World Lung Foundation. Retrieved from www.TobaccoAtlas.org

4. Giovino, G. A., Mirza, S. A., Samet, J. M., Gupta, P. C., Jarvis, M. J., Bhala, N., Asma, S. (2012). Tobacco use in 3 billion individuals from 16 countries: An analysis of nationally representative cross-sectional household surveys. The Lancet, 380(9842), 668-679.

5. Pinto, M. T., Pichon-Riviere, A., Bardach,A. (2015). Estimativa da carga do tabagismo no Brasil: mortalidade, morbidade e custos. Cad. Saúde Pública, Rio de Janeiro, 31(6):1283-1297.

6. US Department of Health and Human Services. (2012). Preventing Tobacco Use Among Youth and Young Adults, a report from the Surgeon General (p. 890). Atlanta. Retrieved from http://www.surgeongeneral.gov/library/reports/preventing-youth-tobaccouse/full-report.pdf

7. Bonilha, A. G., Ruffino-Netto, A., Sicchieri, M. P., Achcar, J.A., RodriguesJunior, A. L., Baddini- Martinez, J. (2014). Correlatos de experimentação e consumo atual de cigarros entre adolescentes. Jornal Brasileiro de Pneumologia. 2014 Nov-Dec; 40(6):634-42.

8. Akl, E. A., Gaddam, S., Gunukula, S. K., Honeine, R., Jaoude, P. A., \& Irani, J. (2010). The effects of waterpipe tobacco smoking on health outcomes: a systematic review. International Journal of Epidemiology, 39(3), 834-57.

9. Stead, L. F., Buitrago, D., Preciado, N., Sanchez, G., Hartmann-Boyce, J., \& Lancaster, T. (2013). Physician advice for smoking cessation. The Cochrane Database of Systematic Reviews, 5(5), CD000165.

10. Ministério da Saúde (2009). A situação do tabagismo no Brasil: dados dos inquéritos do Sistema Internacional de Vigilância, da Organização Mundial da Saúde, realizados no Brasil, entre 2002 e 2009 (p.76). Rio de Janeiro.http://bvsms.saude.gov/bvs/controle_cancer

11. Botelho, C., Da Silva., AM. P., Melo, C.D., (2011). Tabagismo em universitários de ciências da saúde: prevalência e conhecimento. Jornal Brasileiro de Pneumologia. 2011; 37(3):360-366.

12. Pinheiro, M. A., Torres, L. F., Bezerra, M. S., Cavalcante, R.C., Alencar, R. D., Donato, A, C, Campêlo, C. B. P., Gomes, I. P., Alencar, CH., Cavalcanti, L. P. G. (2017). Álcool e Tabaco entre Estudantes de Medicina no Nordeste Brasileiro. Revista Brasileira de Educação Médica, 41 (2): 231-250. 
13. Da Silva, A.C., Teixeira, E. R., Gonçalvez S.J.C., de Souza M.C.A.(2017). Tabagismo entre estudantes de profissões de saúde: prevalência,conhecimento, atitudes e opiniões. Revista de Saúde. 2017 Jan./Jun.; 08(1): 23-27.

14. Vanderhoek, A, J, Hammal, F., Chappell, A., Wild, C. T., Raupach, T., Finegan, A. B. (2013). Future physicians and tobacco: an online survey of the habits, beliefs and knowledge base of medical students at a Canadian University. Tobacco Induced Diseases 2013, 11:9

15. Chidiac, A., Tamim, H., Kanso, M., Tfalyli, A., (2016) Smoking among Lebanese medical students: Prevalence and attitudes. Ann Thoracic Medicine, 2016;11:183-90.

16. Boopathirajan, R., Muthunarayanan, L. (2017). Awareness, Attitude and Use of Tobacco among Medical Students in Chennai. Journal of Lifestyle Medicine Vol. 7, No. 1, January 2017.

17. Almutairi, K. M. (2014). Prevalence of Tobacco Use and Exposure to Environmental Tobacco Smoke Among Saudi Medical Students in Riyadh, Saudi Arabia. Jounal Community Health, 39:668-673.

18. Jirad, H., Al-Shehri, A. (2014). Knowledge about tobacco smoking among medical students in Saudi Arabia: Findings from three medical schools. Journal of Epidemiology and Global Health (2014) 4, 269- 276.

19. Ramis, T. R., Mielke, G. I., Habeyche, E. C., Oliz, M. M., Azevedo M. R., Hallal, P. C. (2012). Tabagismo e consumo de álcool em estudantes universitários: prevalência e fatores associados. Revista Brasileira de Epidemiologia 2012; 15(2): 376-85

20.Sutfin, E. L., McCoy, T. P., Berg, C. J., Champion, H., Helme, D. W., O'Brien, M. C., Wolfson, M. (2012). Tobacco Use by College Students: A Comparison of Daily and Nondaily Smokers. Am J Health Behav. 2012 March ; 36(2): 218-229. doi:10.5993/AJHB.36.2.7.

21. Rosa, M. I., Caciatori, J. F. F., Panatto, A. R. R., Silva, B. R., Pandini,J. C., Luciana Freitas, B. S., Reis, M. E. F., Souza, S.L., Simões, P. W. T. A. (2014). Uso de tabaco e fatores associados entre alunos de uma universidade de Criciúma (SC). Cad. Saúde Colet., 2014, Rio de Janeiro, $22(1): 25-31$

22. Lopes, F., Cunha, S. M, Zibetti, M., Bizarro., L. (2014). Padrão de consumo e expectativas em relação ao cigarro entre universitários. PSICOLOGIA, SAÚDE \& DOENÇAS, 2014, 15(2), 439-453 EISSN - 21828407 Sociedade Portuguesa de Psicologia da Saúde - SPPS - www.spps.com DOI: http://dx.doi.org/10.15309/14psd150209

23. Roncero, C., Egido, A., Rodríguez-Cintas, L., Péres-Pázos, J., Collazos, F., Casas, M., (2015). Substance use among Medical Students: A Literature Review 1988- 2013. Actas Esp Psiquiatria. 2015;43(3):109-21

24. Szklo, A. S., Sampaio, M. M. A., Fernandes, E. M., \& Almeida, L. M. de. (2011). Smoking of non-cigarette tobacco products by students in three Brazilian cities: should we be worried?. Cadernos de Saúde Pública, 27(11), 2271-5.

25. Instituto Nacional de Câncer (Brasil). Organização Pan-Americana da Saúde. Pesquisa especial de tabagismo - PETab: relatório Brasil / 
Instituto Nacional de Câncer. Organização Pan-Americana da Saúde. Rio de Janeiro: INCA, 2011.

26. Martins, S. R., Paceli, R. B., Bussacos, M. A., Fernandes, F. L. A., Prado, G. F., Lombardi, E. M. S., Santos, U. P. (2014). Experimentation with and knowledge regarding water-pipe tobacco smoking among medical students at a major university in Brazil. Jornal Brasileiro de Pneumologia, 40(2), 102-110.

27. Adkison S.E, O'Connor R.J, Bansal-Travers M, Hyland A, Borland R, Yong H.H, Cummings KM, McNeill A, Thrasher JF, Hammond D, Fong GT. (2013).Electronic nicotine delivery systems: international tobacco control four- country survey. American Journal of Preventive Medicine.;44:207215.

28. Kusma, B., Quarcoo, D., Vitzthum, K., Welte, T., Mache, S., Meyer-Falcke, A., Groneberg, D. A., Raupach, T.(2010). Berlins medical student's smoking habits, knowledge about smoking and attitudes toward smoking cessation counseling. Jounal of occupational medicine and toxicology. 5:9

29. Awopeju, O. F., Erhabor, G. E., Awosusi, B., Awopeju, O. A, Adewole, O. O., Irabor, I. (2013). Smoking prevalence among health professional students. Annals of Medical and Health Sciences Research, Jul-Sep 2013, Vol 3, Issue 3

30. La Torre, G., Kirch, W., Bes-Rastrollo, M., Ramos, R. M., Czaplicki, M., Gualano, M. R., Boccia, a. (2012). Tobacco use among medical students in Europe: results of a multicentre study using the Global Health Professions Student Survey. Public Health, 126(2), 159-64.

31. Martins, S. R, Paceli, R. B., Bussacos, M. A. Fernandes F. L. A., Prado, G. F., Lombardi, E. M. S., Terra-Filho, M., Santos, U. P. (2017). Medidas eficazes de controle do tabagismo:concordância entre estudantes de Medicina. Jornal Brasileiro de Pneumologia, 43(3):202-207

32. Salgado, M. V., Mejía, R. M., Kaplan, C. P., Pérez-Stable, E. J. (2016). Smoking-Related Attitudes and Knowledge Among Medical Students and Recent Graduates in Argentina: A Cross-Sectional Study. Journal of General Internal Medicine, May 2017, Volume 32, Issue 5, pp 549-555 . First online 2016. DOI: 10.1007/s11606-016-3890-0

33. Hatsukami, D. K., Stead, L. F., Gupta, P. C., (2016). Tobacco Addiction: Diagnosis and Treatment. Lancet. 371(9629): 2027-2038. doi:10.1016/S0140-6736(08)60871-5.

34.Zhou, S., Van Devanter, N., Fenstermaker,M., Cawkwell, P., Weitzman, M. (2016). A Study of the Use, Knowledge, and Beliefs About Cigarettes and Alternative Tobacco Products Among Students at One U.S. Medical School. Acad Med. 2016 December; 90(12): 1713-1719. doi:10.1097

35. Armstrong, G.W., George, P. F., Veronese,G., Montroni, I., UgoliniG., (2017). Assessment of Tobacco Habits, Attitudes, and Education Among Medical Students in the United States and Italy: A Cross-sectional Survey. Journal of Preventive Medicine e Public Health, 50:177-187. 